\title{
Pour une géoarchéologie du patrimoine : pierres, carrières et constructions en Bretagne
}

Onzième et dernière partie : autres granites, microgranites, quartz ;

épilogue

For a Geo-Archaeology of Heritage: Stones, Quarries and Buildings in Brittany.

Eleventh and last part: other granites, microgranites, quartz; epilogue

Für eine Geoarchäologie des kulturellen Erbes: Gesteine, Steinbrüche und

Gebäude in der Bretagne. Elfter und letzter Teil: Andere Granite, Mikrogranite, Quarz; Epilog

Por una geoarqueología del patrimonio: piedras, canteras y construcciones en Bretaña. Undécima y última parte: otros granitos, microgranitos, cuarzo; epílogo

Louis Chauris

\section{CpenEdition}

\section{Journals}

Édition électronique

URL : https://journals.openedition.org/rao/6699

DOI : $10.4000 /$ rao.6699

ISSN : $1775-3732$

Éditeur

Presses universitaires de Rennes

Édition imprimée

Date de publication : 21 décembre 2021

Pagination : 323-361

ISBN : 978-2-7535-8668-0

ISSN : 0767-709X

Référence électronique

Louis Chauris, «Pour une géoarchéologie du patrimoine : pierres, carrières et constructions en Bretagne », Revue archéologique de l'Ouest [En ligne], 37 | 2021, mis en ligne le 21 décembre 2021, consulté le 10 octobre 2022. URL : http://journals.openedition.org/rao/6699 ; DOI : https://doi.org/ $10.4000 /$ rao.6699 


\title{
Pour une géoarchéologie du patrimoine : pierres, carrières et constructions en Bretagne* \\ Onzième et dernière partie : autres granites, microgranites, quartz; épilogue
}

\author{
For a Geo-Archaeology of Heritage: Stones, Quarries and Buildings in Brittany
}

Eleventh and last part: other granites, microgranites, quartz; epilogue

Louis Chauris

Directeur de Recherche au CNRS (e. r.), 3 rue Goethe, 29200 Brest (France)

Résumé: Avec cette onzième livraison s'achève notre "saga "; celle-ci regroupe :

- La présentation de quelques massifs granitiques hercyniens qui n’ont pas trouvé place dans les chapitres antérieurs (fig. 1).

- Une vue d'ensemble sur les microgranites, fort nombreux en Bretagne mais qui, à part quelques exceptions, sont encore peu connus sous l'angle de nos propos.

- Un panorama sur le quartz de la péninsule, matériau qui n’a jamais été l'objet d'un regard synthétique.

Nous terminerons en évoquant l'éblouissante parure lithologique bretonne, envisagée pour la première fois sous sa triple appartenance : les pierres des géologues - ici on compte le plus souvent par centaines de millions d'années...; les pierres des carriers et des tailleurs, à la vie éphémère entre leur arrachement aux entrailles de la terre et leur façonnement...; les pierres des constructions enfin, à l'épreuve des temps historiques, présentant une vie et des formes toujours renouvelées, des mégalithes aux cathédrales et à l'urbanisme moderne...

Abstract: With this eleventh article ends our "saga"; bringing together:

- The presentation of some hercynian granite massifs not yet presented in the previous chapters (fig. 1).

- A panorama on Quartz in the peninsula, a material, which has not yet been considered from a synthetic point of view.

- We will end with the dazzling lithological adornments from Brittany, considered for the first time in its threefold capacity. The stones of geologists - here we usually count in hundreds of millions of years...; the stones of quarrymen and cutters, with an ephemeral life between their uprooting from the bowels of the earth and their shaping...; building stones, which have stood the test of time, presenting an ever-renewed life and forms, from megaliths to cathedrals and modern urbanism...

Mots clés: granites, microgranites, quartz, Bretagne.

Keywords: granites, microgranites, quartz, Brittany.

\section{GRANITES HERCYNIENS}

\section{Rostrenen}

Le massif granitique de Rostrenen s'est mis en place lors de l'orogenèse hercynienne, au cours du Carbonifere; son intrusion a interrompu la continuité entre les Montagnes noires, à l'ouest, et les monts de Quénécan, à l'est. Ce pluton présente différentes variétés; la mieux caractérisée - qui correspond au granite de Rostrenen au sens strict (le seul dont il sera question ici) s'étend d'ouest en est sur une douzaine de kilomètres entre Glomel, Rostrenen et Plouguernével. De bons affleurements sont observables à proximité du canal de Nantes à Brest, entre Kerguiniou et la Ville Blanche (ouest et sud-ouest de Rostrenen), ainsi qu'à Kerroc'h - toponyme signifiant le village des rochers et où apparaissent des chaos de blocs décamétriques. En divers points toutefois, l'arénisation, très intense, peut dépasser $15 \mathrm{~m}$ de profondeur.

De teinte blanc-gris clair, ce granite est essentiellement caractérisé par des cristaux de feldspaths potassiques maclés le plus souvent "Carlsbad ", présentant 


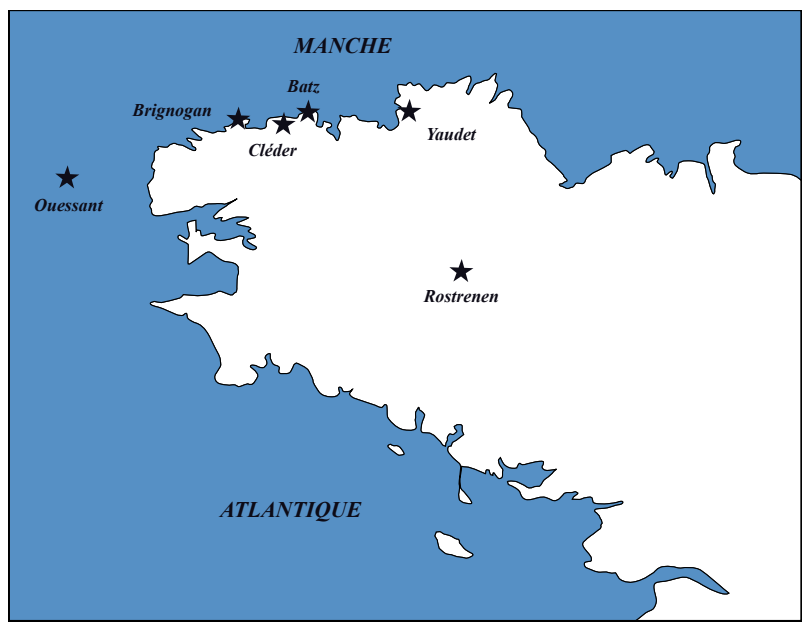

Figure 1 : Localisation des granites examinés.

Figure 1: Location of considered granites.

des dimensions exceptionnelles : jusqu'à 10 et parfois même 12 à $15 \mathrm{~cm}$ de long, de nuance gris nacré. Entre ces feldspaths géants, les minéraux sont représentés par le mica noir, un plagioclase blanc-verdâtre, le quartz en grains irréguliers blancs ou gris, sans contour cristallin... Localement, les mégafeldspaths se rassemblent en cumulats. En certains points, leur orientation peut entraîner une texture fluidale. Les enclaves sont relativement rares et de faibles dimensions. La pierre de Rostrenen correspond typiquement à la "granitite " des géologues du $\mathrm{XIX}^{\mathrm{e}}$ s., s'opposant à la "granulite " (ou granite à mica blanc) des mêmes auteurs (Barrois, 1884; Jérémine et Pruvost, 1955; Cotten, 1975; Chauris, 2000a).

Le site d'extraction du menhir colossal qui se dresse un peu à l'est de Glomel n'est pas connu, mais la présence toute proche d'un affleurement identique, suggère une origine locale qu'appuient les $9 \mathrm{~m}$ de haut et la centaine de tonnes du monument. Même si, après plusieurs millénaires d'exposition à l'air, on note quelques surfaces desquamées, un arrachement basal, une fissure sommitale... mais ces altérations restent somme toute minimes (Langouët et al., 2006, p. 24-27). Ainsi, l'un des plus anciens monuments connus en granite de Rostrenen témoigne-t-il - de tout son poids, pourrions-nous dire - de la singulière résistance de cette roche aux vicissitudes d'un climat particulièrement humide... C'est à l'époque gauloise qu'est rapportée la stèle de Kerléo en Plouguernével. Ce monolithe à huit pans est surmonté d'une croix en schiste, témoignage de sa christianisation tardive.

La construction de l'église paroissiale de Rostrenen (Notre-Dame du Roncier) s'est échelonnée du XIv au $\mathrm{XIX}^{e}$ s. Si la puissante tour a fait une large utilisation du granite porphyroïde local, des leucogranites à grain fin, plus distaux (massif de Pontivy), ont été également mais altéré. Comme de juste, le dallage a privilégié le granite de Rostrenen, très résistant à l'usure. Les piliers montrent la même dualité pétrographique. À Glomel, la tour de l'église a largement recherché le granite porphyroïde local, mais le porche occidental est en leucogranite. L'église de Perret (1758), déjà à quelque distance du pluton, en a utilisé la pierre mais aussi différents leucogranites et des schistes. L'association granite de Rostrenen-leucogranite est également notée dans la chapelle Saint-Michel en Glomel (début du XVI ${ }^{\mathrm{e}}$ s.), de même pour celle de Saint-Conogan (fin $\mathrm{XV}^{\mathrm{e}}$-début XVIII ${ }^{\mathrm{e}}$ s.). Dans la chapelle de Rosquelfen (fin $\mathrm{XV}^{\mathrm{e}}$ s.-début $\mathrm{XVI}^{\mathrm{e}}$ ), à l'est de Gouarec et hors des limites du massif granitique, la touche du terroir est soulignée par l'emploi du schiste local. Dans l'élévation méridionale de Sainte-Christine en Glomel (fin $\mathrm{XV}^{\mathrm{e}}$ s.-début $\mathrm{XvI}$ ), granite et schiste, en grand appareil, sont juxtaposées de façon tout à fait aléatoire.

Beaucoup plus surprenant à première vue est l'emploi du granite de Rostrenen (en association avec la diorite de Plélauff) dans le soubassement de l'église Saint-Idunet, édifiée à Châteaulin, à une soixantaine de kilomètres à vol d'oiseau des sites d'extraction, à la fin des années 1860. L'utilisation de ces deux roches distales, dans une région où des granitoïdes nettement plus proximaux ne manquent pas, est une confirmation éclatante de l'engouement manifesté alors envers ces pierres lointaines, leur emploi étant facilité par le canal de Nantes à Brest.

L'un des plus remarquables exemples de l'utilisation de la pierre de Rostrenen en grand appareil pour l'habitat est fourni par la tour de Saint-Péran en Glomel, seul vestige de l'ancien manoir (début du Xvi ${ }^{\mathrm{e}} \mathrm{s}$.) ; les pierres de taille en sont remarquablement ajustées, avec un minimum de liant. À Rostrenen, le sévère manoir de Campostal (fin Xvi ${ }^{\mathrm{e}-}$ $\mathrm{XVII}^{\mathrm{e}}$ s.) a surtout fait appel au granite local; en ville, plusieurs demeures anciennes laissent voir d'austères façades en pierre locale. Dans le bourg de Glomel, un bel ensemble en granite de Rostrenen a été aménagé en bâtiment communal. Un peu partout, tant dans les bourgs qu'à la campagne, dans la zone d'affleurement ou à proximité, de vieux bâtiments présentent de belles portes en granite porphyroïde (en plein cintre comme près du menhir de Glomel ou à Gouarec; en anse de panier, comme encore à Gouarec ou à Kergornou Izellan en Plouguernével...). L'aptitude du granite de Rostrenen au façonnement est également attestée par des auges monolithes : château de Coat-Couraval en Glomel, Kerléo en Plouguernével, Gouarec...

La construction du canal de Nantes à Brest (essentiellement entre 1822 et 1842) a exigé l'établissement de 238 écluses. Pour la pierre de taille, 51 ouvrages ont fait appel au granite porphyroïde de Rostrenen, soit majoritairement (dans 44 cas semble-t-il : les conditions d'observation sont parfois difficiles!), soit en association avec 


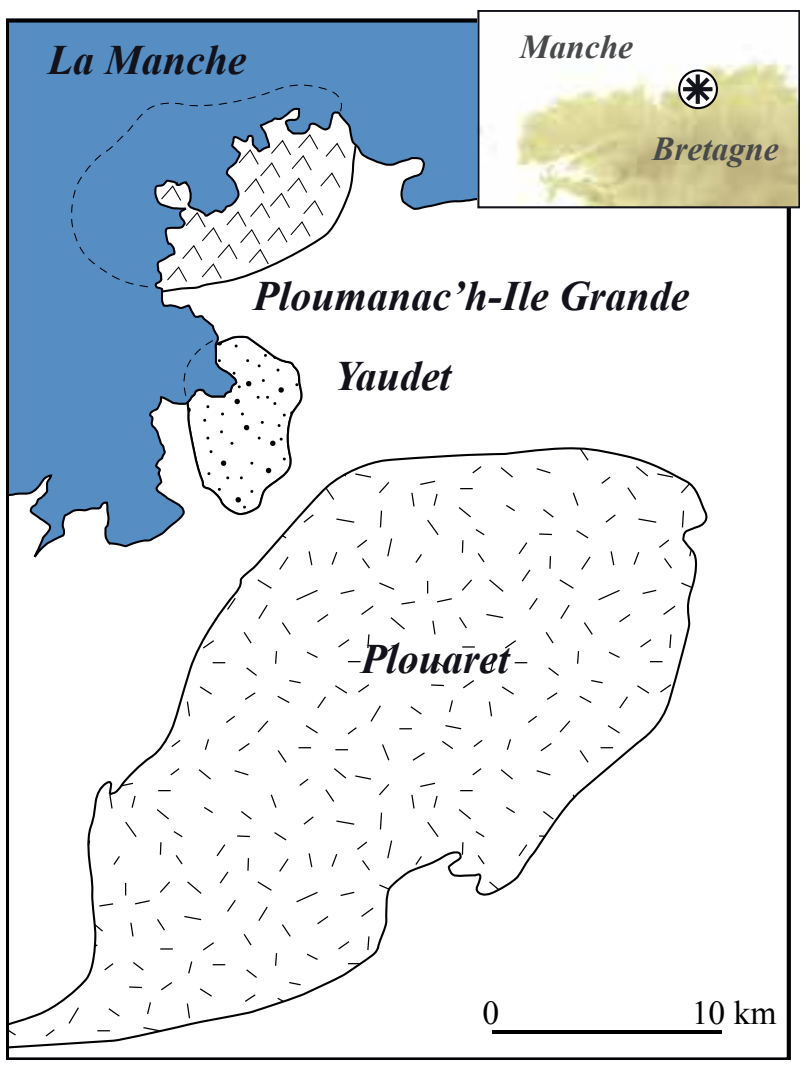

Figure 2 : Le granite du Yaudet, entre les massifs de Plouaret et de Ploumanac'h-île Grande.

Figure 2: Yaudet granite, between Plouaret and Ploumanac'h-île Grande massifs.

un faciès moins porphyroïde du même complexe (3 cas), avec le granite du Huelgoat (1), avec la granodiorite de Plélauff (2), et avec un leucogranite (1). À l'est de l'écluse de Bellevue (en Saint-Gelven), où le granite de Rostrenen est déjà très rare, le canal est aujourd'hui submergé sous le lac de barrage de Guerlédan; plusieurs écluses sont ainsi inaccessibles à l'observation mais il est probable que le granite de Rostrenen ait été encore employé - au moins pour partie - dans quelques-unes d'entre elles. Une telle proportion s'explique au moins en partie par le fait que ses affleurements coïncident approximativement avec le secteur le plus élevé du canal $(184 \mathrm{~m})$, ce qui a entraîné la multiplication des écluses - et permis un transport en avalage. Ces ouvrages ont nécessité des volumes énormes de granite, admirablement façonné dans les parements vus. Ainsi, la tablette des musoirs ( $3 \mathrm{~m}$ de large) est souvent constituée uniquement par trois éléments en grand appareil : $1,10 \mathrm{~m}$ sur les côtés et $0,80 \mathrm{~m}$ dans la partie médiane pour les longueurs, $0,90 \mathrm{~m}$ pour les largeurs et $0,40 \mathrm{~m}$ en épaisseur; les plus grands éléments présentent un volume d'environ $0,40 \mathrm{~m}^{3}$, soit approximativement 1 t. Par ailleurs, l'alimentation en eau de la "Grande Tranchée » de Glomel a nécessité l'édification d'un bar- rage, dit du Coronq. La digue mesure une centaine de mètres de long, sur $12 \mathrm{~m}$ de hauteur, sans compter les fondations dans le rocher qui descendent jusqu'à $4 \mathrm{~m}$ de profondeur. La base de l'ouvrage offre 7,40 m d'épaisseur tandis que parapet et dallage supérieur totalisent $4,20 \mathrm{~m}$ de large. Les pierres de taille des parements vus, en assises réglées, sont admirablement façonnées, certains éléments atteignant $2 \mathrm{~m}$ de long. La masse totale du barrage est estimée à 15000 t (Guyomard, 1994). Au total, les différents ouvrages du canal de Nantes à Brest, qui représentent l'utilisation majeure du granite de Rostrenen, soulignent encore aujourd'hui les remarquables aptitudes de cette roche pour les Travaux publics.

\section{Le Yaudet}

Situé entre le vaste massif granitique polyphasé de Plouaret au sud et le célèbre pluton à venues emboîtées de Ploumanac'h-île Grande au nord (fig. 2), le petit pointement du Yaudet n'a guère attiré l'attention - depuis sa première cartographie par Barrois (1909) - avant ces dernières années (fig. 3; Chauris, 1987, 2004a; Chauris et Garreau, 1999). Il offre localement d'excellents affleurements, voire même des amas rocheux assez spectaculaires. Mieux, il a fait l'objet, dans le passé, de multiples extractions dont les mises en œuvre témoignent d'un intérêt prolongé, aujourd'hui oublié. Bien qu'affleurant seulement à $1,5 \mathrm{~km}$ au nord-ouest du massif de Plouaret, il ne présente toutefois avec ce dernier aucune relation : il en differe par sa composition, son âge et ses conditions de mise en place. La masse principale du pluton, à contour subovoïde (8 km du nord au sud, moins de $5 \mathrm{~km}$ d'ouest en est), est formée par un faciès porphyroïde de nuance blanc-gris, dont les mégacristaux de feldspath potassique, atteignant jusqu'à 5-6 cm de long, offrent assez souvent un alignement qui souligne la fluidalité magmatique. La monotonie pétrographique du massif est interrompue localement par quelques intrusions tardives à grain fin au sud et au sud-est du pluton, et sous forme de quelques rares filons.

L'aptitude du granite du Yaudet à fournir de grands monolithes a été tôt mise à profit, ainsi que l'attestent quelques menhirs encore conservés : au sud de Toul al Lan, à proximité de la D 786, ou près de Lianver (avec détachement d'une épaisse plaque dans la partie haute). On l'observe aussi sur le site protohistorique et antique du Coz-Yaudet (Cunliffe et Galliou, 2004). À noter également une stèle de l'âge du Fer actuellement placée sur le côté nord de l'église de Servel et une probable borne milliaire gallo-romaine, ultérieurement christianisée, insérée dans le mur de l'enclos paroissial de Ploulec'h. Beaucoup plus tardivement, les emplois se sont diversifiés : près de 


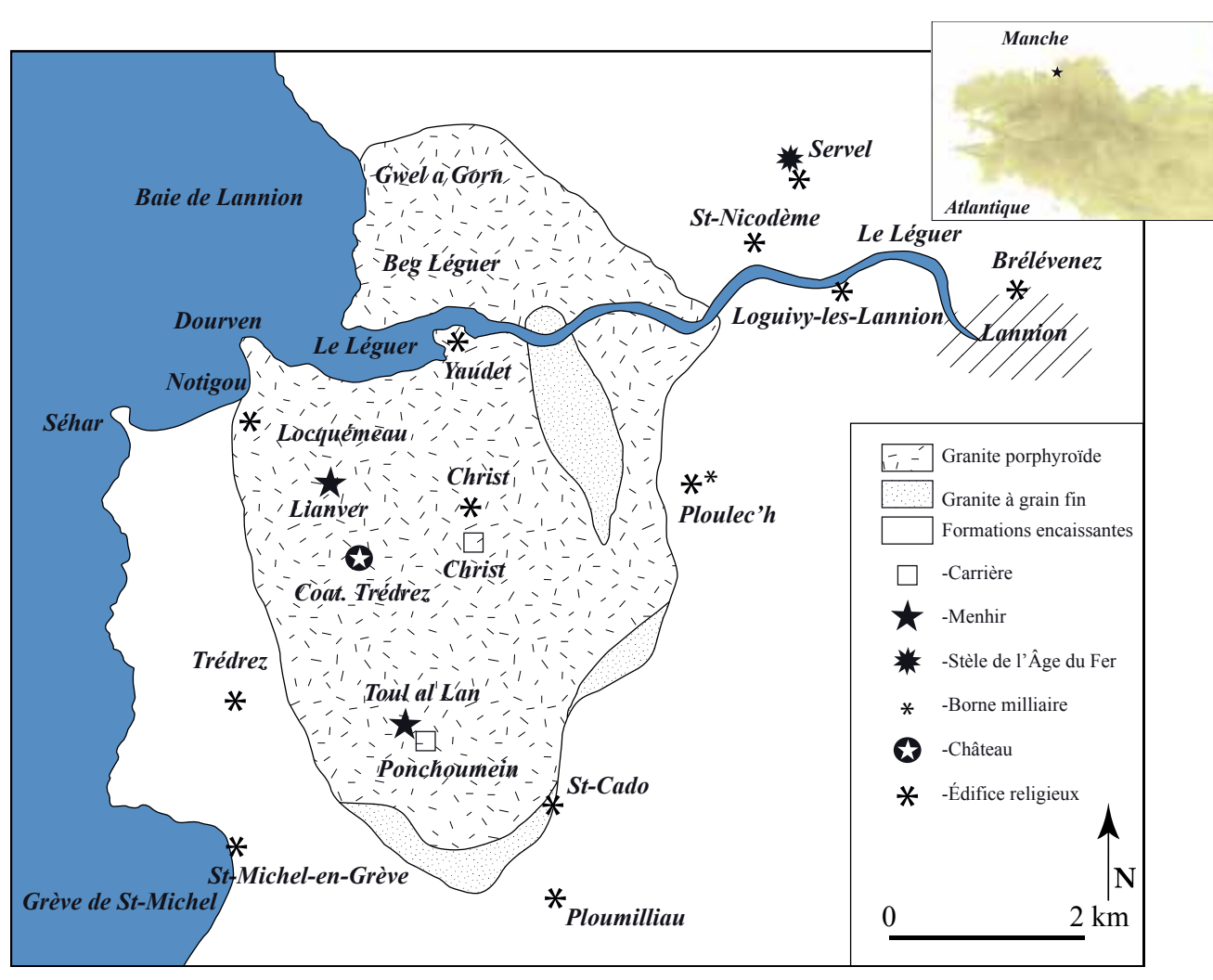

Figure 3 : Le massif granitique du Yaudet. Esquisse géologique simplifiée (d'après Chauris, 1999) et impacts sur les constructions; à Lannion même (zone hachurée), les principales constructions concernées sont détaillées dans le texte).

Figure 3: Yaudet granitic massif. Geological sketch map (after Chauris, 1999) and impacts on buildings; in Lannion town (hatched area), the main constructions are detailed in text. la chapelle du Yaudet, une croix basse monolithe; le corps de garde à la pointe du Yaudet et le château de CoatTrédrez ( $\mathrm{XV}^{\mathrm{e}}-\mathrm{XVI}^{\mathrm{e}}$ s.) montrent de superbes éléments de grand appareil (Chauris et Minor, 2011). Dans le couvent des Augustines à Lannion, qui remonte à la seconde partie du XVII ${ }^{\mathrm{e}}$ s., ce granite a été largement utilisé tant en pierre de taille qu'en moellons pour les élévations, associé aux schistes tuffacés locaux ainsi qu'aux granites de l'île Grande, ces derniers étant recherchés préférentiellement pour les encadrements des ouvertures. Ponctuellement, les élévations se font remarquer par l'emploi, en assises alternées, des schistes tuffacés gris-vert et du granite du Yaudet, devenu ocre par altération, ce qui confère au bâti une réelle élégance (Chauris, 2007). Toujours à Lannion, le mur du quai érigé au XviII ${ }^{\mathrm{e}}$ s., sur la rive droite du Léguer (aujourd'hui quai d'Aiguillon) a utilisé, pour partie, le granite du Yaudet.

De nombreux édifices religieux ont mis en œuvre ce même granite. L'église de Brélévenez, édifiée pro parte à l'époque romane, offre pour notre propos un double intérêt : elle représente, à notre connaissance, le premier édifice religieux, encore conservé aujourd'hui, ayant fait appel au granite porphyroïde du Yaudet et, qui plus est, à une certaine distance des sites d'extraction; le handicap de la distance était néanmoins diminué par le recours à la ria navigable du Léguer qui permettait d'acheminer les pierres jusqu'au pied des hauteurs où s'élevait le monument. Son étude permet, en outre, de préciser l'impact d'un matériau local - en l'occurrence des tufs volcaniques, d'âge briovérien - extraits à proximité immédiate et en compétition avec le granite, nettement plus distal. Parmi les autres églises ayant mis en œuvre le granite du Yaudet en association avec d'autres roches, citons Loguivy-lèsLannion, Ploulec'h, Locquémeau, Saint-Michel-enGrève, Servel; il en est de même pour plusieurs chapelles (le Yaudet, Saint-Nicodème au sud-ouest de Servel, SaintCado au nord de Ploumilliau).

Au total, malgré ses qualités indéniables, le granite du Yaudet n'a eu qu'une diffusion locale, pour partie liée à la proximité des granites du district de l'île Grande dont le rayonnement et l'impact ont été considérables pendant des siècles. Non seulement ces derniers offrent de meilleures aptitudes à la taille, mais bénéficient en outre de facilités d'extraction assez exceptionnelles en bordure même des rivages et d'acheminement par mer. Ces circonstances permettent de comprendre que les granites de l'île Grande ont été utilisés jusque sur le domaine du granite du Yaudet et, a fortiori, inhibant son expansion au loin. Par ailleurs, les différents granitoïdes du massif de Plouaret, tout proche, ont contrarié son impact vers le sud. Le granite du Yaudet fournit ainsi un cas exemplaire d'une bonne pierre dont l'emploi n'a guère diffusé par suite de l'existence de voisins constituant de redoutables concurrents. Seuls les édifices locaux - et le plus souvent anciens - ont mis en œuvre le matériau du terroir. Ces remarques ont pour corollaire le développement du poly- 
lithisme dans le bâti, largement lié à l'impact des granites de l'île Grande. S'y adjoint aussi l'appel aux moellons de tufs locaux, beaucoup plus faciles à extraire et à façonner.

\section{Ouessant}

La morphologie de cette île reflète remarquablement sa structure géologique (fig. 4; Chauris et Hallegouët, 1994; Jérémine et Sandrea, 1957) : au centre, en retrait, une dépression de micaschistes recoupés par de petites intrusions de granite sodique à affinité trondhjémitique (Lost Logod); au sud, un granite à biotite, dit de Porz Gwenn, enclavant de vastes panneaux micaschisteux; au nord, des leucogranites (Béninou et Locqueltas), localement en contact avec des migmatites. Un étroit feuillet de granite porphyroïde rose, dit de Lampaul, jalonne le contact entre leucogranite de Locqueltas et micaschistes. Des filons de leucogranites tardifs et des tourmalinites recoupent le granite de Porz Gwen; le leucogranite de Locqueltas est traversé par des filons de microsyénite (Chauris, 1966, 1991a, 1992). Seules les formations granitiques et apparentées sont ici présentées.

Dans le granite de Porz Gwenn, plus ou moins orienté et de teinte grisâtre, le quartz se dispose en traînées légèrement onduleuses, formant des microlentilles parallèles à l'alignement de la biotite; sur ce fond se détachent des cristaux de feldspath à section presque carrée, pouvant atteindre 1 à $2 \mathrm{~cm}$. Localement, le granite est légèrement

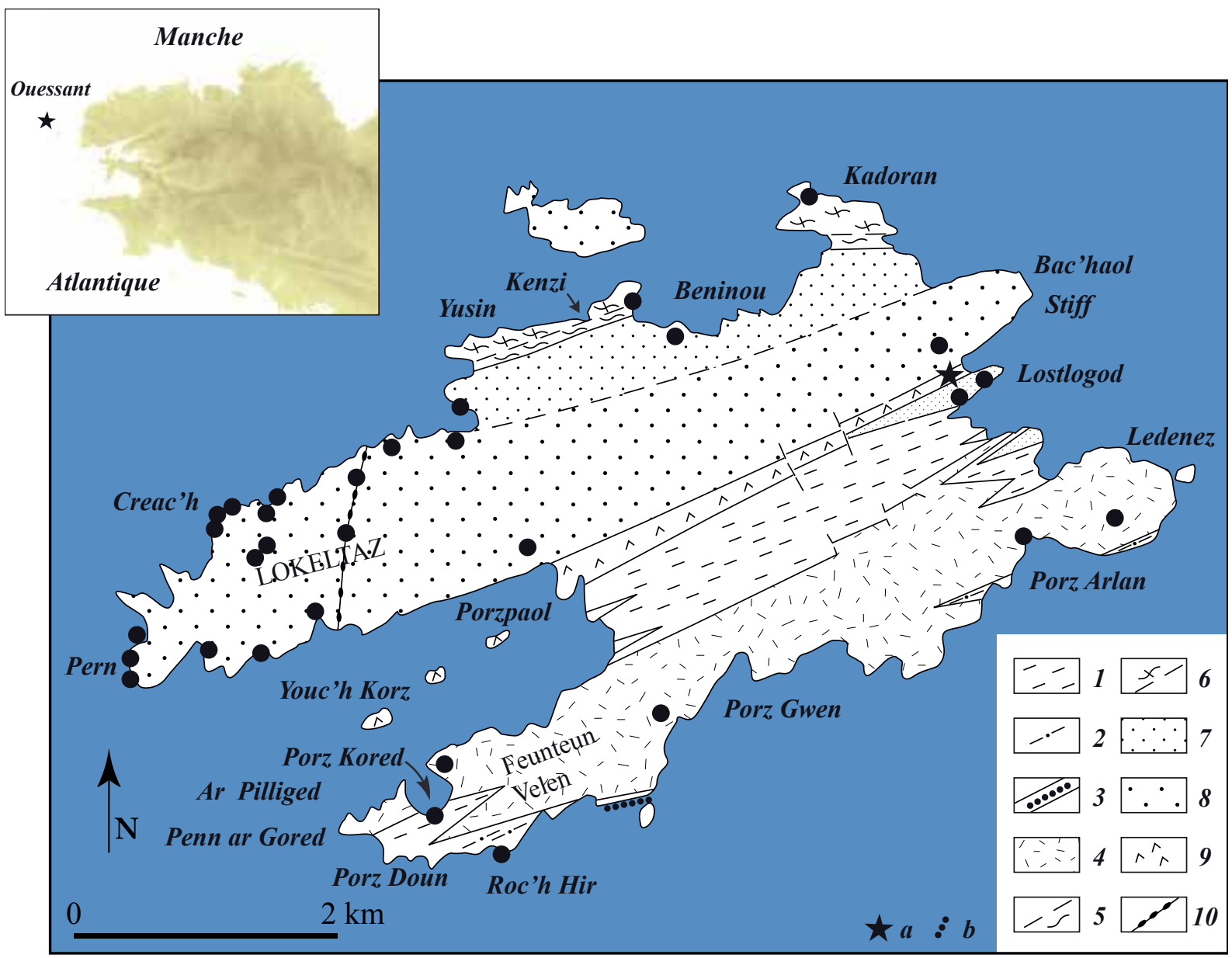

Figure 4 : Esquisse géologique de l'île d'Ouessant.

\section{Figure 4: Geological sketchmap of Ushant Island.}

1 : Micaschistes séricito-chloritiques ; 2 : Micaschistes muscovitiques ; 3 : Intrusions sodiques à affinités trondhjémitiques ; 4 : Granite de Porz Gwen ; 5 : Gneiss migmatitiques de Kenzi ; 6 : Granites anatectiques de Yusin et de Kadoran ; 7 : Leucogranite de Berninou ; 8 : Leucogranite de Lokeltas ; 9 : Granite porphyroïde rose cataclastique de Porz Paol ; 10 : Microsyénite (les filons leucogranitiques n'ont pas été représentés). Les points marquent les principaux sites d'extraction recensés (dont : a) granite kaolinisé et b) graphite).

1: sericito-chloritic micaschists; 2: muscovitic micaschists; 3: sodic intrusions with trondjemitic affinities; 4: Porz Gwen granite; 5: Kenzi migmatitic gneiss; 6: Yusin and Kadoran anatectic granites; 7: Berninou leucogranite; 8: Lokeltas leucogranite; 9: PorzPaol cataclastic pink porphyroïd granite; 10: microsyenite (leucogranitic veins not reported). Dots mark the main checked extraction sites (including a-kaolinized granite and b-graphite). 
écrasé selon la direction WSW-ENE. Le leucogranite de Béninou offre un grain fin à moyen; il est parfois orienté et même écrasé; dans l'ensemble, il apparaît en creux topographique par rapport au leucogranite de Locqueltas qui le limite au sud. Ce dernier, grossier, à deux micas, constitue l'ossature septentrionale de l'île sur plus de $8 \mathrm{~km}$, de la pointe de Pern à la pointe de Bac'haol, en s'élargissant progressivement d'est en ouest; sa bordure sud, rectiligne, est fortement laminée et mylonitisée. Il présente assez fréquemment (presqu'île de Locqueltas) des amas pluricentimétriques de tourmaline qui lui conferent un aspect caractéristique. L'étroit feuillet de granite porphyroïde rose de Lampaul montre des degrés variables dans la cataclase; l'écrasement n'est jamais fluidal, mais toujours bréchique.

Le granite de Porz Gwenn fournit une pierre de taille de qualité secondaire et surtout des moellons. Des extractions ont eu lieu près de Porz Arlan, au nord-est de Porz Kored, près de la croix de Saint-Pol... Au sud de Toul al Lan, le granite arénisé était recherché comme sable pour les mortiers. Cette pierre constitue le matériau de prédilection dans la partie méridionale de l'île : encadrement

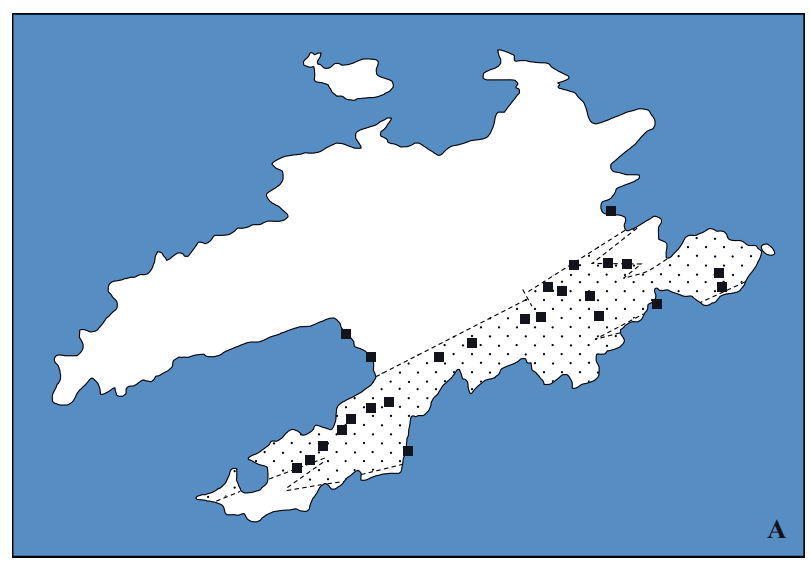

Figure 5 : A : Constructions en granite de Porz Gwen ; B : Constructions en leucogranites de la zone septentrionale d'Ouessant (Lokeltas et Beninou).

Figure 5: A: Buildings of Porz Gwen granite; B: Buildings of leucogranites fron the northern part of Ushant. des ouvertures, chaînages d'angle; sa linéation, parfois assez accusée, a permis la confection de linteaux. Plus généralement, il apparaît ici dans toutes les constructions rurales (murs, murets, puits...). Il a même pu être taillé pour la croix de Saint-Pol. Il a trouvé sa principale utilisation dans la jetée de Porz Arlan. La répartition des différentes constructions dans sa zone de provenance est frappante et les exceptions sont rares (fig. 5a).

Les leucogranites de la zone nord (Locqueltas, et dans une nette moindre mesure, Béninou) constituent la principale pierre de construction de l'île. C'est la seule qui permette une taille de bonne qualité, aussi la trouvet-on dans de nombreux édifices (forts du Kernic et de Trebechou, église paroissiale, écoles, maisons des gardiens du phare du Stiff, hangar du canot de sauvetage de Porz Paol...) et dans d'innombrables habitations, tant du bourg que des villages, sans oublier les murets. C'était en outre une pierre recherchée pour la confection des meules des petits moulins à vent si caractéristiques d'Ouessant, ainsi que des auges; elle a fourni aussi des bornes limitant les terrains militaires... Les leucogranites ont été préférentiellement utilisés dans la zone septentrionale de l'île; la localisation des principales carrières, en presqu'île de Locqueltas, implique toutefois le transport du matériau en direction des parties centrale et orientale. Par contre, les constructions de la zone méridionale de l'île restent, en règle générale, pauvres en leucogranites qui étaient ici, à l'évidence, concurrencés par le granite de Porz Gwenn. Par ailleurs, les galets couronnant les murettes sont généralement en leucogranite de Locqueltas (fig. 5b).

Les autres matériaux ouessantins ne représentent généralement que des utilisations locales. L'un des meilleurs exemples est fourni par le granite porphyrö̈de rose cataclastique de Porz Paol, qui a joué un rôle essentiel dans l'édification du môle barrant la crique. Le granite sodique de Lost Logod, très fissuré, ne peut guère fournir de pierres de taille. Son emploi est resté principalement limité à sa zone de provenance, où il a livré un matériau de qualité secondaire pour les enrochements portuaires (jetée de Porz Ligoudou pro parte et terre-plein du nouveau port du Stiff). Il a été également utilisé comme granulat dans les escaliers de l'ancienne cale du Stiff et pour l'empierrement des routes; parfois aussi dans les constructions (ancien bâtiment de la gare maritime pro parte). Quant à la microsyénite, la répartition des constructions (essentiellement murettes) concernées est étroitement concentrée à proximité du champ filonien. (voir infra).

Précisons, en terminant, que plusieurs granites « continentaux " ont été également utilisés dans l'île et tout particulièrement celui de l'Aber Ildut, bien caractérisé par ses gros feldspaths roses et ses enclaves oblongues gris-noirâtres. 


\section{Brignogan}

L'appellation « granite de Brignogan » est généralement réservée à la partie occidentale du vaste pluton qui s'étend de Kerlouan à Sibiril, en bordure de la Manche, à l'ouest de la baie de Goulven (fig. 6). Comme à l'est de ladite baie - à Plouescat ou Cléder - ce massif présente de sensibles variations dans sa granulométrie, passant d'un faciès très porphyroïde au nord, à des faciès nettement moins grossiers sur sa périphérie méridionale (sa partie septentrionale est masquée sous la Manche). Seul ici sera examiné le faciès porphyroïde, de loin le plus original. Ce granite forme fréquemment des amas spectaculaires de blocs énormes tant sur le littoral qu'à travers la couverture limoneuse ou dunaire; il est caractérisé par l'abondance des mégacristaux de feldspath potassique blanchâtre (5 à $6 \mathrm{~cm}$, parfois 8$)$, fréquemment orientés (Chauris et Marcoux, 1998).

Les gigantesques chaos granitiques du massif de Brignogan appelaient, naturellement, l'érection de puissants mégalithes. Le menhir de Pontusval en Brignogan (environ 8,5 m) est riche en cumulats de feldspaths blanchâtres, mis en relief par l'érosion. Son façonnement est quasi-inexistant; sa face nord présente des figures d'altération météorique qui n'apparaissent que sur des surfaces subhorizontales; le rocher dont le "dos » a livré le menhir a disparu. Le menhir de Menoignon en Plounéour-Trez montre une face plane correspondant à une diaclase qui a facilité son extraction. Le menhir du Théven à Kerlouan est en granite porphyroïde bien caractérisé. Dans le dolmen du Diévet en Plounéour-Trez, l'énorme table est en "faciès Cléder ", variété du massif de Brignogan où le grain est nettement moins accusé, tandis que les orthostates sont en "faciès Brignogan " sensu stricto; cette dualité est d'autant plus remarquable que le monument est situé juste à la limite des deux roches (Chauris, 2009b; Sparfel et Chauris, 2009a).

Le granite de Brignogan a été également recherché à l'époque gauloise pour façonner des stèles (Chauris, 2004b). Au Kroazou en Kerlouan, l'une d'elles forme l'angle de la chapelle. Celle de Rann Hir, en Guissény, est aussi en granite de Brignogan, mais on est ici bien loin du lieu d'extraction. La même roche a été façonnée pour la stèle à quatre pans chanfreinés, aujourd'hui placée derrière la mairie de Plounéour-Trez, ainsi que pour celle à présent érigée devant la mairie de Kerlouan.

Plusieurs édifices religieux ont fait un large appel au granite de Brignogan (Chauris, 2001b). Tel est, entre autres, le cas de l'église de Kerlouan (1863-1865), due à l'architecte Tritschler (qui, curieusement, avait proposé d'associer la brique au granite - ce que refusa l'architecte diocésain Bigot en faisant remarquer que " le mélange de la brique dans un pays granitique sur le bord de la mer parait devoir être supprimé, autant pour l'aspect peu sévère que pour celui du peu de garantie de durée ". Tel est aussi le cas de l'église de Plounéour-Trez (1889-1890),
Figure 6 : Zones d'affleurement du granite de Cléder (d'après Chauris et Marcoux, 1998), et anciens sites d'extraction.

Figure 6: Outcrop areas of Cleder granite (after Chauris and Marcoux, 1998), and ancient quarrying sites.

1 : Dans le granite de Cléder ; 2 : Dans le granite de Brignogan ; 3 : Dans le granite de Moguériec (les points d'extraction dans les autres roches n'ont pas été figurés).

1: In Cléder granite; 2: in Brignogan granite; 3: in Moguériec granite (quarrying spots not reported for other rocks).

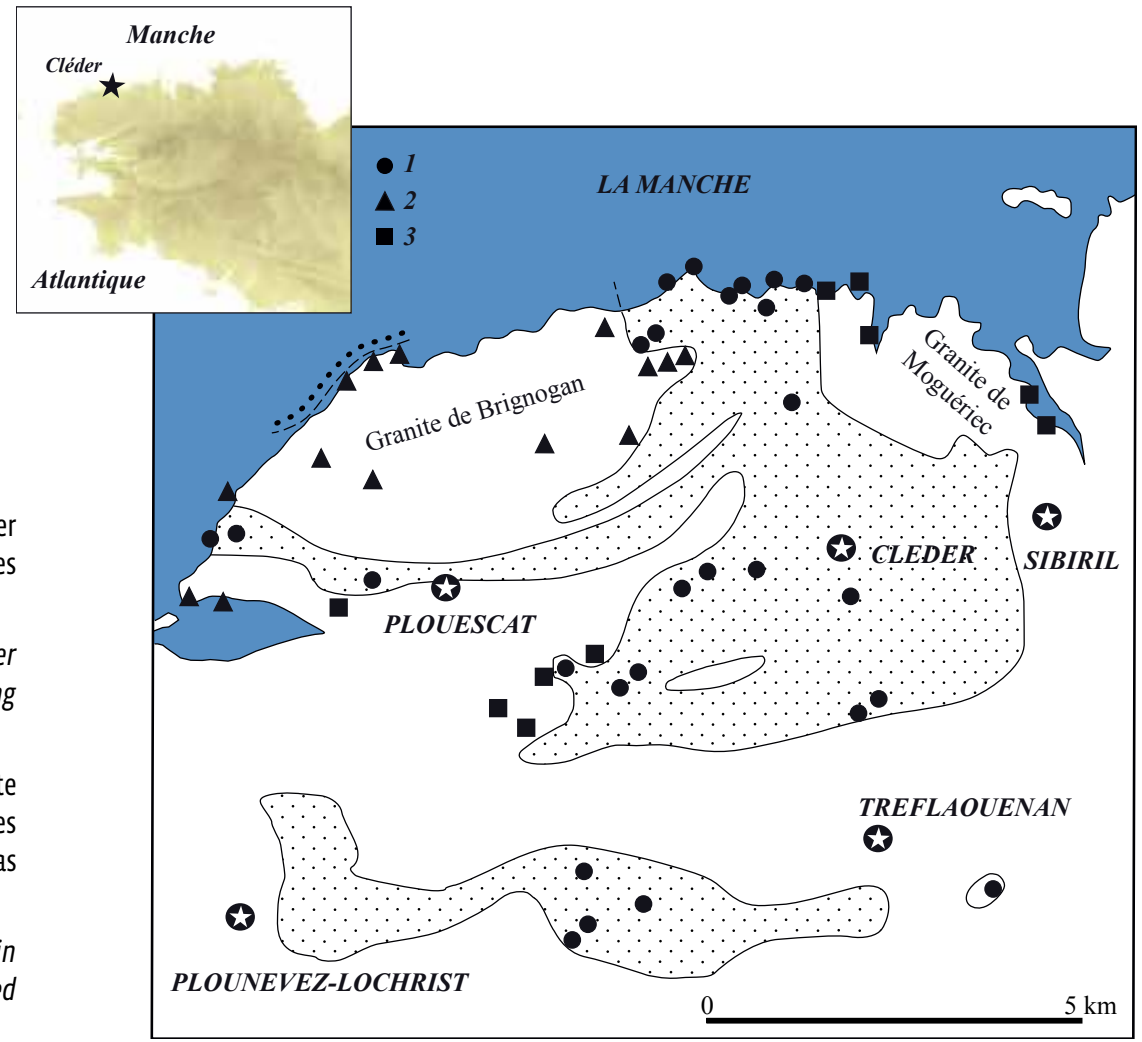


due à l'architecte Le Guerrannic (avec toutefois conservation de l'ancien clocher)...

Le même granite a été aussi utilisé pour façonner des croix dont plusieurs remontent au Moyen Âge (Le Croazou en Kerlouan, christianisant une stèle à dix pans, de même nature pétrographique). Le puissant soubassement et le fût monolithe du calvaire de SaintSauveur, vers l'extrémité méridionale de la commune de Kerlouan, est érigé bien loin au sud des derniers affleurements de cette roche; il atteste l'intérêt naguère porté à ce matériau, même dans un secteur où d'autres pierres ne manquent pas. Les hauts fûts, à section cylindrique, des deux calvaires (respectivement du Xve et du XvI ${ }^{\mathrm{e}}$ s.) du cimetière de Guissény témoignent des aptitudes de ce granite au façonnement, malgré les fortes dimensions de ses feldspaths (Chauris, 2004c).

Le phare de Pontusval, allumé en 1869 , fournit un excellent exemple de mise en œuvre du granite de Brignogan dans les travaux publics : on admirera en particulier le soubassement, les marches de l'escalier et la plateforme sommitale où les quatre pierres d'angle présentent chacune une surface de l'ordre du mètre carré (Chauris, 1995b). Cet ouvrage démontre à son tour que le granite de Brignogan - en fait nettement moins exploité que son voisin oriental de Cléder (voir infra) - est également susceptible de livrer des éléments de grand appareil.

\section{Cléder}

La commune de Cléder est située un peu à l'ouest de Saint-Pol-de-Léon dans la " ceinture dorée " du HautLéon. Çà et là, au milieu des champs soigneusement cultivés, surgissent d'énormes masses granitiques arrondies qui dominent un paysage à peine ondulé. Sur le rivage, ces mêmes roches aux formes pittoresques crèvent le manteau dunaire et se prolongent en mer par une barrière de récifs. Tel est le premier contact que prend le visiteur avec le granite de Cléder. La cité a fait naguère figure de " petite capitale du granite " comme nous l'a assuré avec force un vieux cultivateur et comme l'ont pleinement confirmé nos enquêtes. Vers la fin du XIx ${ }^{e}$ s., la pierre y occupait plus de 200 personnes (Chauris, 1993e).

Le granite de Cléder constitue l'un des faciès du grand massif, connu sous l'appellation générale de "Brignogan " (voir supra et fig. 6; Chauris et Marcoux, 1998). C'est sur le faciès Cléder s.s., aux feldspaths nettement plus petits que dans le Brignogan s.s. que se concentre le maximum des extractions : sur la côte, les anciens chantiers s'y succèdent presque sans interruption (les seules lacunes sont dues à la présence de dunes) tandis que la partie concernée par le Brignogan s.s. présente de longues zones sans extractions, celles-ci n'apparaissant qu'à proximité du faciès Cléder (côte au nord de Plouescat). Plus à l'est, le granite de Moguériec, grossier, à deux micas et peu porphyroïde, a été lui aussi localement recherché (fig. 6). Plusieurs points doivent être soulignés : le grand nombre de sites d'extraction, la densité des exploitations en bordure de mer, mais aussi les dimensions et les morphologies très variées des chantiers, depuis les simples débitages de boules isolées, souvent énormes (un peu partout), jusqu'aux véritables carrières en profondeur (près du château de Kergornadéac'h...), en passant par les pointements rocheux partiellement débités (Kervaliou...) [Chauris, 1993a, 1993d, 2013d].

Le granite de Cléder offre des nuances de teinte très délicates, allant du blanc bleuté au gris clair selon les sites. C'est une roche dure, très résistante à l'altération, ne rouillant pas et présentant une excellente aptitude à la taille. Le volume des boules affleurantes témoigne de la possibilité d'obtenir des blocs de très grande dimension. À Mendohoren, dans la zone de passage au "Brignogan ", une boule de $8 \mathrm{~m}$ de hauteur a été fendue verticalement, sans le moindre défaut. Jusque vers les années 1950, ces boules ont été encore exploitées sporadiquement dans les champs. Aujourd'hui, seule la carrière ouverte au lieu-dit Kerliviry, à l'extrémité ouest de la commune, est encore exploitée par l'entreprise Crenn, dans un faciès intermédiaire entre le «Cléder » et le " Moguériec ».

Malgré les destructions, plusieurs menhirs de haute stature se dressent encore aux environs de Plouescat : Cam Louis, Pors ar Streat, Prat Meur, tous façonnés dans le faciès intermédiaire entre "Brignogan » et "Cléder » et érigés sur la zone de transition entre les deux roches. Celui de Kergallec est également en faciès intermédiaire, tandis que le menhir d'Irvit, en plein affleurement du granite "Brignogan ", se rapporte à ce dernier. Ces observations indiquent que la pierre de ces monuments mégalithiques a été extraite à proximité; la même constatation peut être faite pour l'allée couverte du Kernic, sur la grève à l'ouest de Plouescat, également en faciès "Brignogan ". Ainsi, aucun transport de quelque importance n'a pu être mis en évidence (fig. 7).

Le granite de Cléder a été abondamment extrait pour la construction (fig. 8). Dans les églises, il est attesté au moins depuis le $\mathrm{XvI}^{\mathrm{e}}$ s. : Tréflaouénan représente l'une de ces utilisations anciennes parvenues jusqu'à nos jours. À Saint-Vougay, ce même matériau apparaît en association avec le granite tout proche de Sainte-Catherine. L'église de Plounévez-Lochrist, reconstruite en 1871-1872, avec conservation du clocher (1767) et du porche (17681769) de l'édifice précédent, montre l'utilisation partielle du granite de Cléder, en association avec la diorite locale. À Sibiril (1767), le granite de Moguériec est associé à celui de Cléder. À part sa tour (fin XviI ${ }^{\mathrm{e}}$ s.), l'église de Cléder 


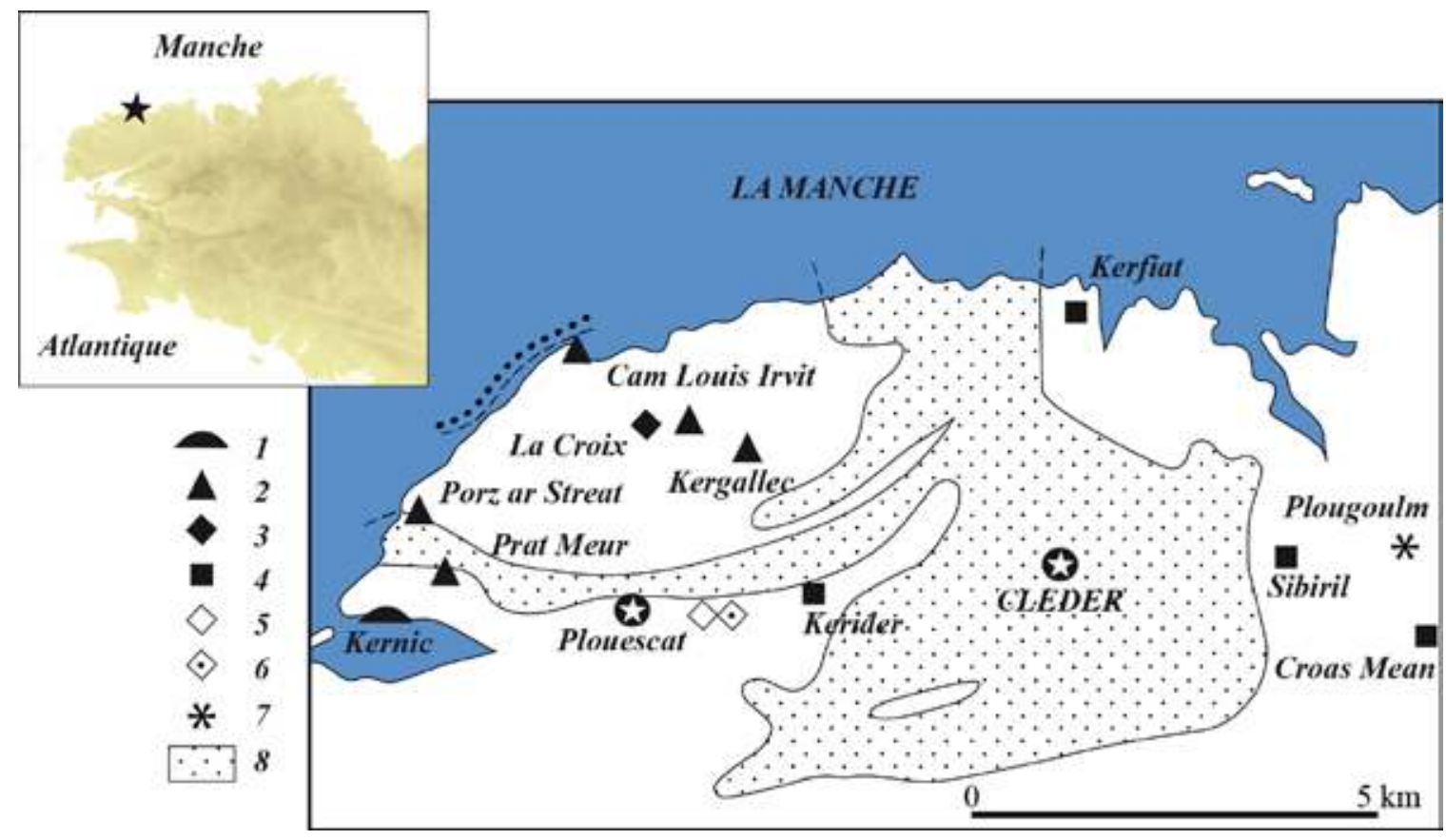

Figure 7 : Mégalithes et stèles de l'âge du Fer dans la région de Cléder.

Figure 7: Megaliths and Iron Age stelae from the Cléder area.

1 à 3 : en granite de Brignogan ou en faciès intermédiaire Brignogan-Cléder. 1 : Allée couverte; 2 : Menhir ; $3:$ Stèle ; $4:$ stèle en granite de Cléder ou en faciès intermédiaire Cléder-Moguériec; 5 et 6 : en granite fin de Plouescat ( $5:$ Menhir ; 6 : Dolmen) ; 7 : stèle en granite fin à nids de tourmaline ; $8: z$ zones d'affleurement du granite de Cléder.

1-3: of Brignogan granite (or intermediate Brignogan-Cléder facies). 1: Gallery grave; 2: Menhir; 3: Stela; 4: Stela of Cléder or intermediate Cléguer-Moguériec facies; 5 \& 6: fine-grained Plouescat granite (5-Menhir, 6-Dolmen). 7: Stela of fine-grained granite with nests of Tourmaline. 8: outcrop area of Cléder granite.

date de 1830; elle présente, comme il était prévisible, un emploi généralisé de la pierre du pays. L'église de Plouescat (1863-1870) offre également une très large utilisation de cette même roche.

Tous ces édifices sont situés sur les zones d'affleurement du granite de Cléder ou à leur proximité. D'autres églises, plus lointaines, ont aussi recherché ce granite : on remarque alors qu'il s'agit de constructions récentes, remontant seulement à la seconde partie du XIX ${ }^{e}$ s. ou au tout début du xx $x^{e}$. Ainsi à Santec (1851-1855), où toutefois, le granite de l'île de Sieck, toute proche, a été utilisé pour le clocher (1893). L'église de Carantec (1866-1867) a fait appel pour partie au granite de Cléder, associé à ceux de l'île Callot, de Guerlesquin et de l'île Grande; le granite de Cléder était embarqué à Pempoul, port de Saint-Pol-de-Léon, sur des gabares qui atteignaient, à marée haute, la grève de Carantec; les pierres, jetées à la mer, étaient chargées à marée basse dans des voitures qui les charroyaient jusqu'au bourg. Les églises de Plouénan (1884-1887) et de Mespaul (1899-1900) ont employé le granite de Cléder en pierres de taille, alors que le granite de Sainte-Catherine, moins éloigné, fournissait les moellons. À plus forte distance des sites d'extraction, le granite de Cléder a été utilisé pour les églises d'Henvic (consacrée en 1902) et de Taulé (consacrée en 1904). En résumé, la répartition spatio-temporelle du granite de Cléder dans les édifices religieux obéit à des règles précises : jusqu'à la seconde moitié du XIX ${ }^{e}$ s., localisation étroitement liée au massif granitique et à sa proximité; dès la deuxième partie du XIX ${ }^{e}$ s., par suite des progrès dans les moyens de transport, acheminement jusqu'à des églises plus lointaines.

Plusieurs châteaux ont fait appel, au moins partiellement, au granite de Cléder. L'un des exemples les plus remarquables est celui de Kergornadéac'h, en Cléder (fin du XVI ${ }^{e}$ s.), dont les ruines soulignent la qualité de la pierre en grand appareil. La même roche se retrouve à Tronjoly et dans le colombier voisin. Le même granite a été également utilisé dans les châteaux récents de Keromnès en Carantec (extrême fin du XIx ${ }^{e}$ s.) et de Lannigou en Taulé (vers la même époque?). Toutefois, mieux que nulle part ailleurs, la roche de Cléder n'expose son aptitude à la taille et sa résistance aux intempéries dans le château de Kernévez en Saint-Pol-de-Léon, édifié entièrement en grand appareil vers 1850 : malgré la proximité immédiate de la mer, aucune altération n'a pu y être décelée.

Pour l'habitat, le granite de Cléder a été recherché dans plusieurs agglomérations, en particulier semble-t-il dans la seconde partie du XIX ${ }^{e}$ s. et au début du Xx'e ce qui cor- 


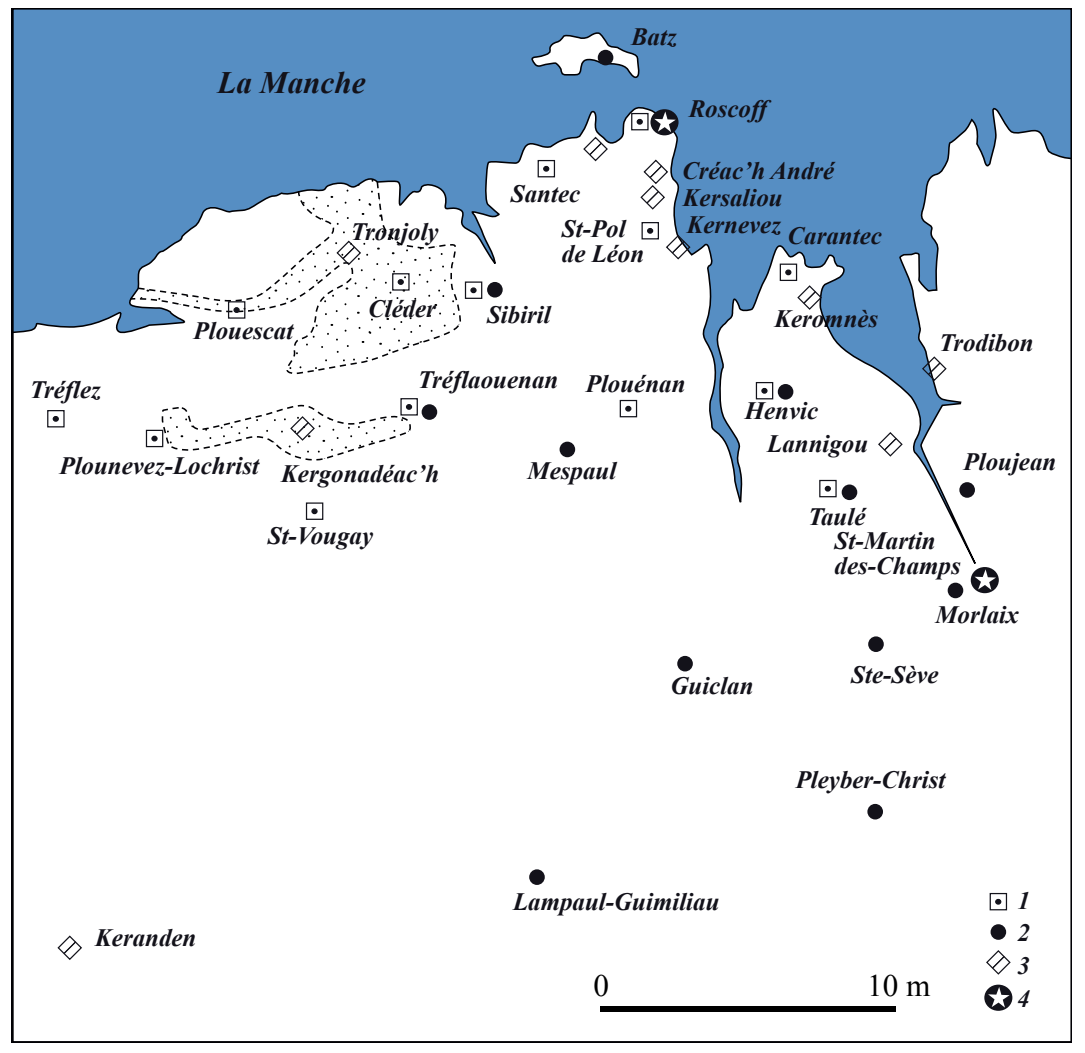

Figure 8: Quelques emplois remarquables du granite de Cléder.

Figure 8: Some notable uses of Cléder granite.

1 : édifice religieux ; 2 : monument aux morts ; 3 : châteaux et manoirs ; 4 : Divers.

1: Religious building; 2: War memorial; 3: Castles and Manors; 4: Miscellaneous. respond à la période majeure des extractions. On observe cette belle pierre à Cléder, mais aussi à Roscoff - où elle avait succédé à l'emprise antérieure des granites de l'île de Batz - Roscoff, à Saint-Pol-de-Léon et à Carantec (où elle avait pris la suite du granite de Callot) mais aussi à Landivisiau, parfois même à Landerneau et dans bien d'autres localités de la région... À Morlaix, le granite de Cléder a été recherché pour la construction du théâtre, inauguré en 1888. À Roscoff, la Société Générale et la Caisse d'Épargne l'ont également employé; c'est aussi le cas de la mairie de Guimiliau...

Pour les travaux maritimes, ce granite a été recherché du fait de sa grande résistance à la corrosion, par exemple, en partie, pour les jetées centrale et septentrionale du vieux port de Roscoff. Dans cette dernière, les pierres de taille du parement ont été façonnées - en allant d'ouest en est - dans le granite rose de l'Aber Ildut, puis dans le granite de Cléder et, enfin, dans le kersanton gris : trilogie réunissant de belles roches du Finistère! Toujours à Roscoff, on remarquera des bornes taillées dans le granite de Cléder, ainsi que le phare du port, dont la base est façonnée en superbes éléments. Les infrastructures ferroviaires de la ligne Morlaix-Roscoff ont aussi mis en œuvre le granite de Cléder : pierres de taille des deux ponts près de TraonErc'h en Roscoff; chaînages d'angle et encadrements des ouvertures des gares de Saint-Pol-de-Léon et de Taulé... L'ancien chemin de fer à voie étroite Saint-Pol - Plouescat a également fait appel au granite de Cléder (pont près de Sibiril)... Par ailleurs, du fait de sa ténacité, la même pierre a naguère été recherchée pour la confection de rouleaux agricoles.

De nombreux monuments aux morts ont été érigés, après la Grande Guerre, en granite de Cléder dans la région morlaisienne. On a ici un bon exemple de l'utilisation d'un granite local de qualité pour l'édification de ce type un peu particulier de construction, malgré la concurrence d'autres matériaux : en plus du kersanton, prédominant dans le Finistère, le granite du Huelgoat (en provenance du sud), le granite porphyroïde dit du Ponthou (en provenance de l'est) et, dans une moindre mesure, la diorite de Plounévez-Lochrist; employée dans cette localité - ce qui paraît normal - cette roche l'a aussi été, ce qui est plus étonnant, à Cléder!

\section{Île de Batz}

L'ossature de Batz et des nombreux récifs qui frangent l'île jusqu'à Roscoff, est essentiellement constituée par un granite à grain fin, de teinte gris clair, légèrement porphyrique, souvent recoupé par de minces veinules de pegmatites à tourmaline qui lui confèrent un aspect très caractéristique. Localement, comme au nord-ouest de Gwalès et à la pointe occidentale de l'île, le granite est en contact avec des masses gris-noirâtres de diorite affleurant sous forme de boules très dures. Seul le granite 
a fait l'objet d'une exploitation intense; les diorites, de façonnement difficile, ont été peu recherchées.

Les rivages de Batz présentent une impressionnante succession de perrières abandonnées (fig. 9a). Les vestiges de ces anciennes extractions (une cinquantaine au moins) s'échelonnent presque tout au long de la côte, sauf évidemment sur la plage dunaire d'Aod Wenn; leur grand nombre compense en quelque sorte les faibles dimensions individuelles des chantiers. Des sites d'extractions apparaissent également sur les îlots et récifs voisins (Porz Kernoc'h, Porz an Ilis...), parfois jusqu'à $500 \mathrm{~m}$ de la côte. En plusieurs points, la présence de lest, constitué de roches totalement étrangères à l'île, témoigne de gabares venues charger le granite (Chauris, 1993b, 1993c, 1993d, 2002b).

Pour ce qui est de l'utilisation du granite de l'île de Batz (fig. 9b), la plus ancienne utilisation dans les édifices religieux conservés remonte à l'édification au début du $\mathrm{XI}^{\mathrm{e}}$ s., peut-être même à la fin du $\mathrm{X}^{\mathrm{e}}$, de la chapelle Sainte-
Anne dont les ruines sont partiellement dégagées des sables dunaires qui l'avaient envahie. Toujours sur Batz, la dernière construction religieuse importante ayant utilisé le granite insulaire est l'église paroissiale (1873-1874). Le phare de Batz, allumé en 1836, est sans conteste le plus prestigieux édifice de l'île. Sa construction en pierres de grand appareil, soigneusement façonnées et dépassant souvent $1 \mathrm{~m}$ de long, a fait essentiellement appel au granite local dont on mesure ici pleinement les qualités architectoniques (Chauris, 1996a). Plus encore que pour le phare, la construction du long môle, achevé en 1854 et qui abrite Porz Kernoc'h des terribles houles d'ouest, a nécessité un impressionnant cubage de pierres de taille en granite proximal, localement très riche en filonnets de pegmatites qui conferrent aux parements un aspect balafré (Chauris, 1996b).

La défense de Batz était assurée dans le passé par plusieurs forts à présent plus ou moins ruinés. Le principal
Figure 9 : Île de Batz.

\section{Figure 9: Batz Island.}

A : sites d'extraction ; $B$ : pierres de construction : I : matériaux insulaires (1 à 6 : granite. 1 : édifice religieux ; 2 : phare ou sémaphore; 3 : calvaire; 4 : fort ou corps de garde ; 5 : môle ou cale; 6 : enrochement); 7 : construction avec un peu de diorite. II : matériaux continentaux : (8-10: granites. 8 : Huelgoat; 9 : Aber-Ildut; 10 : Cléder) ; 11 : Kersanton.

A: quarrying sites; $B$ : building stones: I: insular (1-6: granite. 1: Religious building; 2 : Lighthouse or Signal station; 3: Calvary; 4: Fort or Coastguard station; 5: Jetty or Slipway; 6: Blocking); 7: Building with some Diorite. II: Continental materials (for details, see above).
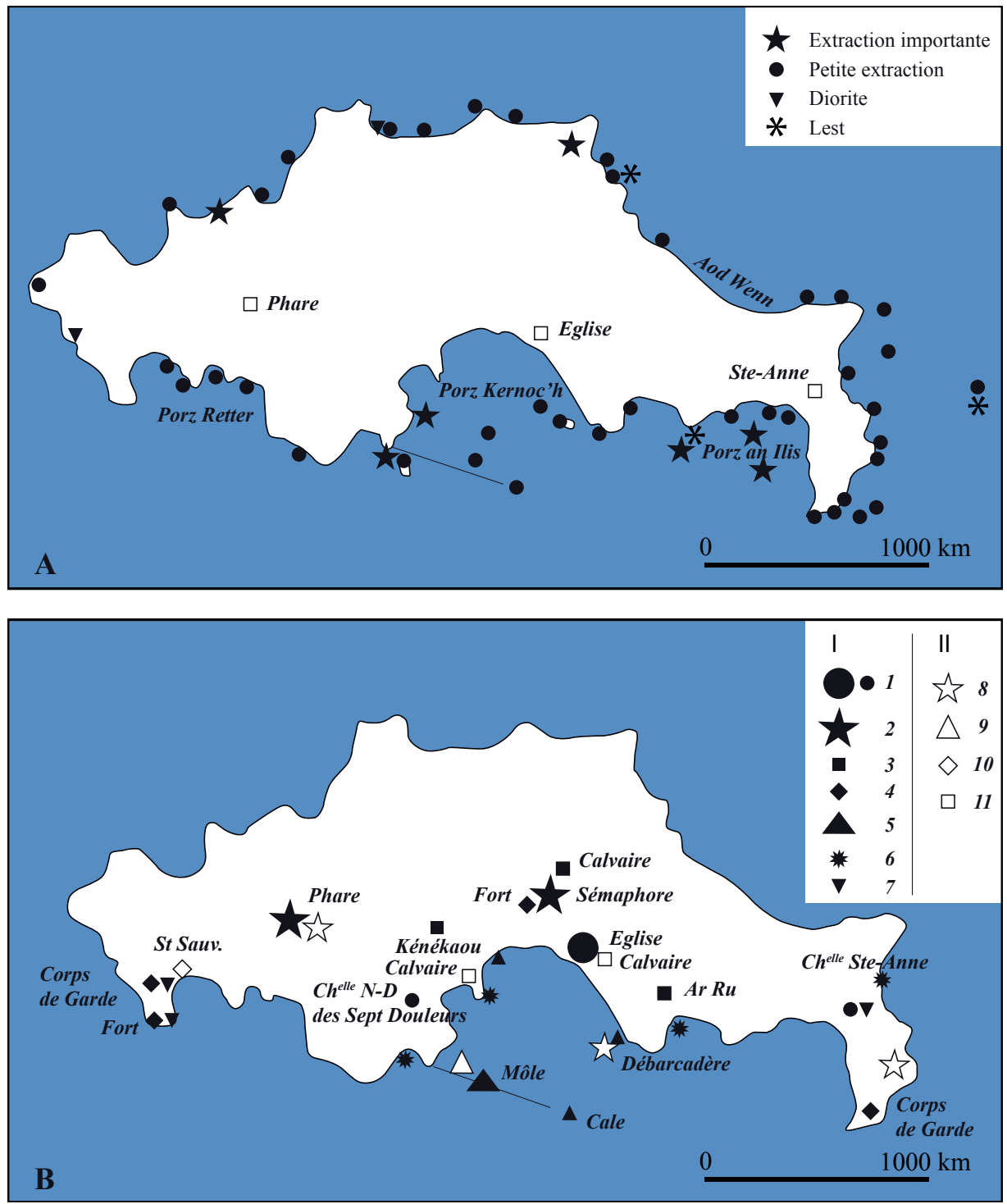
ensemble fortifié est situé dans la partie médiane de l'île, à l'emplacement de l'actuel sémaphore; la large muraille permet d'observer une maçonnerie en pierres sèches où le granite de Batz est associé à la diorite qui affleure en ce point. Un autre fort, qui défendait la partie occidentale de l'île près de Porz Retter, a été construit en granite local associé à un peu de diorite. De même, dans le corps de garde occidental, le granite est mélangé à quelques éléments de diorite; le corps de garde oriental est aussi en granite insulaire (fig. 9b; Chauris, 2002b).

La qualité du granite de Batz, les facilités de son extraction sur les estrans et de son acheminement au moyen de gabares remontant les rias du Dossen et de la Penzé expliquent l'intérêt porté à cette pierre dans la région morlaisienne (fig. 10). À la fin $\mathrm{du} \mathrm{Xv}$ s. et au début du $\mathrm{XVI}^{\mathrm{e}}$, il a été largement recherché pour la reconstruction de l'église Saint-Melaine où il est facile à reconnaître dans la façade occidentale, la partie inférieure de la tour et celle de la tourelle qui la flanque, mais aussi pour partie dans l'élévation méridionale ainsi qu'au chevet. Les observations lithologiques in situ sont confirmées par des données d'archives; ainsi " Le 18 janvier 1490, deux batelées de grosses pierres de Batz... remontent la rivière du Dossen " jusqu'au pied du chantier. Ce même granite a été aussi noté dans plusieurs parties de l'ancienne église des Jacobins avec une utilisation maximale au $\mathrm{Xv}^{\mathrm{e}} \mathrm{s}$. On observe la même roche (en association avec d'autres granites) dans la tour de l'église Saint-Mathieu (seconde moitié du XVI ${ }^{\mathrm{e}}$ s.). La même pierre a été aussi employée pour la chapelle du couvent de Cuburien en bordure du Dossen dans la première moitié $\mathrm{du} \mathrm{XVI}^{\mathrm{e}} \mathrm{s}$. Le transport par voie d'eau depuis Batz est attesté par la présence sur les estrans de l'île, de lest formé de schistes zébrés très caractéristiques du sous-sol morlaisien (Chauris, 1991b).

Édifiée dans la première moitié du XvI ${ }^{\mathrm{e}} \mathrm{s}$., la belle église de Roscoff a utilisé, selon toute probabilité, le granite extrait des zones rocheuses s'échelonnant de Batz à la cité roscovite; le plus souvent, il s'agit d'un granite à grain fin, recoupé par de nombreux filonnets de pegmatites parfois entrecroisés, ou plus rarement par des tourmalinites qui confèrent aux élévations en grand appareil un curieux aspect balafré qui rappelle vivement celui présenté par le parement du grand môle de l'île; plus sporadiquement, a été utilisé aussi un granite riche en petits nids de tourmaline dont un faciès comparable a été observé en plusieurs points de la côte méridionale de Batz.

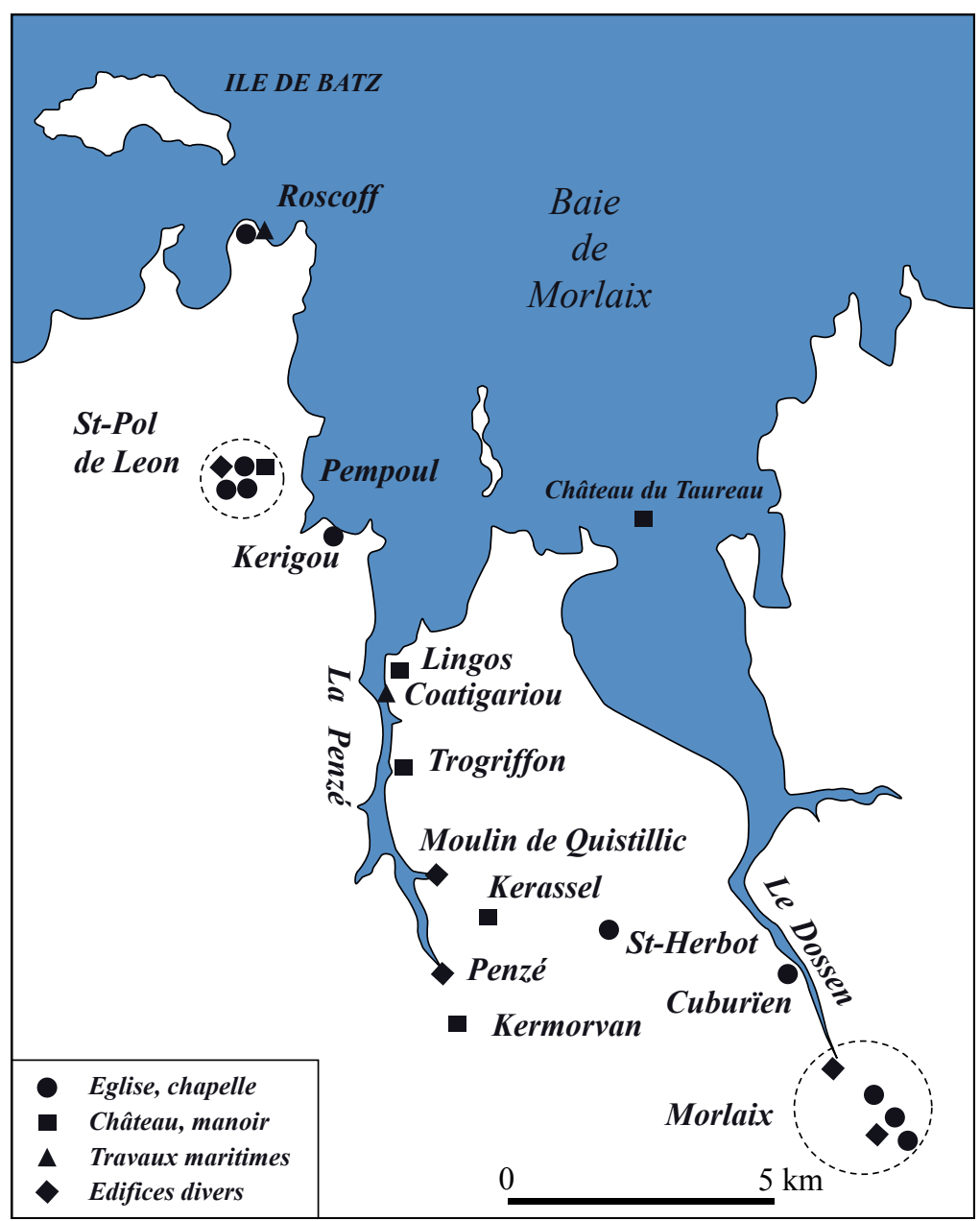

Figure 10: Emploi du granite de l'île de Batz sur le continent, de Roscoff à Morlaix.

Figure 10: Use of Batz granite on the Continent, between Roscoff and Morlaix. 
Le château du Taureau, forteresse édifiée aux XVII et $\mathrm{XVIII}^{\mathrm{e}}$ s. pour défendre l'entrée de la rade de Morlaix, a surtout employé le beau granite rose de l'île Callot; toutefois, le granite gris de Batz a été aussi localement utilisé. À Saint-Pol-de-Léon, la belle maison prébendale, de la première moitié du Xvi ${ }^{\mathrm{e}}$ s., a très largement mis en œuvre le granite de Batz pour les façades en grand appareil ainsi que pour les aménagements intérieurs (portes, cheminées...). Le rôle de la Penzé comme voie de pénétration du granite de Batz se manifeste par la présence de cette roche dans les manoirs de Lingoz et de Trogriffon en Henvic, de Kerassel en Taulé, de Kermorvan en Guiclan... (Chauris, 1993d).

En résumé, le granite de Batz a été exploité - au moins de façon intermittente - pendant une dizaine de siècles. Si son utilisation dans l'île est considérable, la mer a permis aussi son acheminement à des distances de l'ordre de $25 \mathrm{~km}$ jusqu'à Morlaix, certainement dès la fin $\mathrm{du} \mathrm{Xv}^{\mathrm{e}} \mathrm{s}$. Batz fournit ainsi un bon exemple de granite insulaire importé.

\section{MICROGRANITES}

D'origine magmatique comme les granites, les microgranites s'en distinguent immédiatement par leur cristallisation en deux temps : dans un fond à grain très fin, dit "aphanitique ", se détachent des minéraux (feldspath, quartz...) bien discernables à l'œil nu, les "phénocristaux ». Par ailleurs, à l'inverse des granites qui constituent souvent d'immenses plutons, les microgranites affleurent sous forme de petits pointements appelés "stocks ", ou plus souvent de filons rassemblés en champs filoniens (fig. 11). Les nuances sont fort diverses : assez fréquemment rougeâtres, souvent grisâtres ou roses, parfois jau- nâtres, plus rarement blanchâtres... Dans le passé, ces roches microgrenues ont reçu des appellations variées qui seront rappelées au fur et à mesure. En fait, l'éventail lithologique est étendu, comprenant les microgranites sensu stricto (sodiques ou potassiques), les microsyénites, les microdiorites quartziques... Ici, tous seront regroupés sous la dénomination générale de microgranites sensu lato. Ces roches sont assez fréquentes en Bretagne; les unes sont célèbres, comme la "pierre de Logonna ", ou encore celle de "l'île Longue "... mais bien d'autres sont aujourd'hui méconnues. Leur utilisation est restée toute locale ou au contraire a atteint une diffusion régionale, voire nationale. Ces quelques pages vont tenter de les faire sortir d'un oubli injustifié.

\section{L'île Longue et ses voisines}

En rade de Brest, l'île Longue, Trébéron et l'île des Morts forment des pointements microgranitiques intrusifs dans des schistes dévoniens (fig. 12); leur existence même est le reflet de l'érosion dégageant ces roches dures de leurs encaissants sédimentaires plus tendres. À l'île Longue et ses abords affleurent deux variétés différentes: le type « île Longue » sensu stricto offre une dissémination de feldspaths blanchâtres visibles à l'œil nu dans un fond à grain très fin, de nuance gris-bleuté à beige; il est connu sous l'appellation aujourd'hui obsolète de "porphyre »; le type « Rostellec », caractérisé par les dimensions microscopiques de tous ses minéraux, de teinte gris très clair, était naguère qualifié d'" eurite " (Bigot de Morogues, 1809; Bonnemaison, 1822; de Fourcy, 1844; Frapolli, 1845; Barrois, 1886a, 1902; Babin et al., 1968).
Figure 11 : Localisation des microgranites examinés

Figure 11: Location of the microgranites.

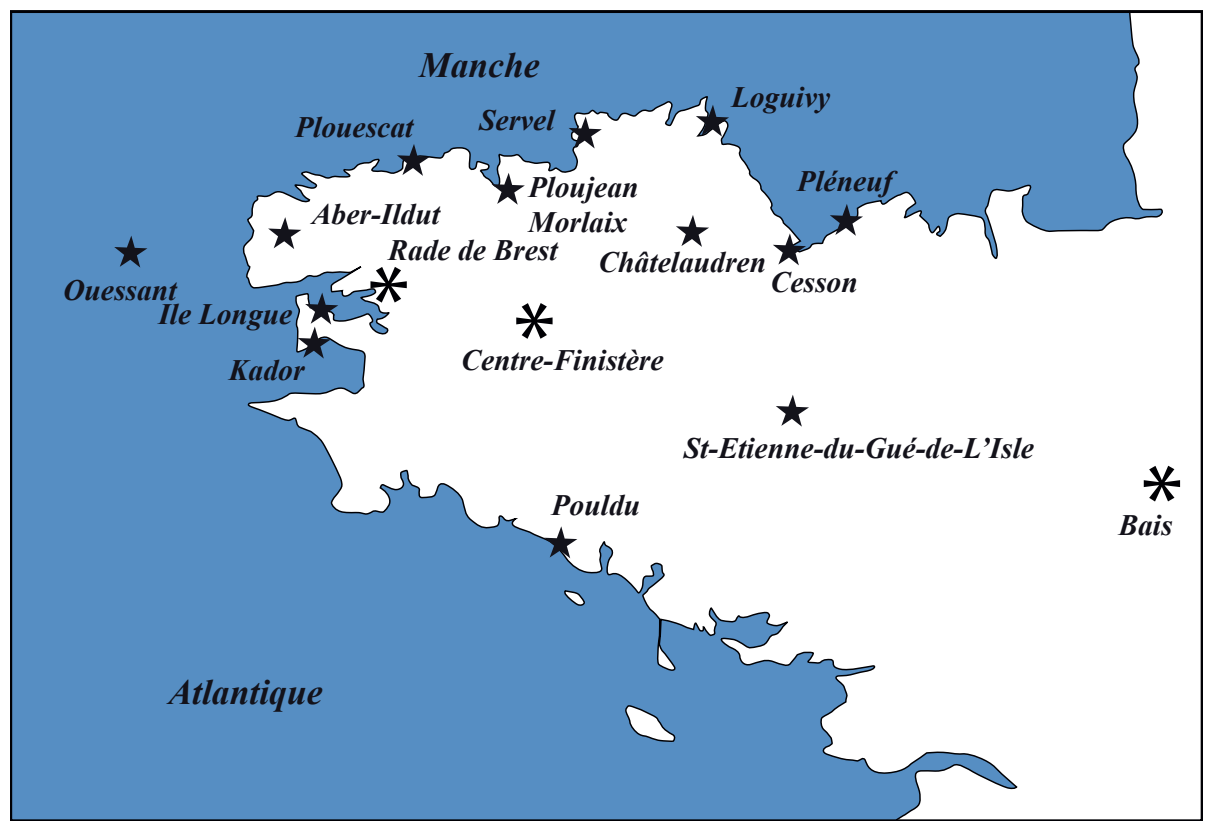


Avec la presqu'île de Rostellec, l'île Longue a été longtemps un centre important de taille des pavés, matériaux qui exigent une résistance exceptionnelle à l'usure. En 1855, l'ingénieur des Ponts et Chaussées Garet souligne cette qualité mais relève que " les pavés de l'île Longue [...] finissent, en raison même de leur dureté, par acquérir sous l'action du roulage, un poli qui les rend [...] dangereux même pour les piétons, et qui augmente considérablement les difficultés de traction pour les chevaux. "Le grand nombre des sites d'extraction (fig. 12) traduit la célébrité du district. Déjà, en 1822, Bonnemaison évoque l'île Longue « aux flancs dénudés par des exploitations multipliées "; selon L. Collin (1926), le nombre des carrières est alors d'au moins une douzaine. La multiplicité des sites entraine de fortes différences dans leur importance relative; la plus grande carrière, ouverte à l'ouest de Kermeur, était appelée « ar Vengleuz Braz ». Le regroupement des exploitants aurait permis la mise en œuvre de moyens plus performants. La position littorale des carrières permettait de déverser les éléments rebutés sur l'estran et, tout en édifiant des terre-pleins, de désencombrer les fronts de taille, créant ainsi de la place pour le façonnement des pavés. Avant sa métamorphose récente en base sous-marine, l'île Longue offrait un double visage : des formes d'érosion liées aux excavations échancrant les falaises et des formes de sédimentation sur les rivages dues aux déblais.

Selon les marchés, les pavés, taillés sur place, étaient livrés sous différentes dimensions. L'espèce dite " gros blocage " offrait en moyenne 18 à $22 \mathrm{~cm}$ de longueur et 18 à $20 \mathrm{~cm}$ de "queue "; dans d'autres cas, la longueur de la face de tête était comprise entre 14 et $22 \mathrm{~cm}$ et sa largeur entre 10 et $16 \mathrm{~cm}$, avec une queue de 16 à $18 \mathrm{~cm}$; on a aussi des largeurs de tête de 8 à $12 \mathrm{~cm}$. Vers les années 1875, la production annuelle de l'île Longue - Rostellec était de l'ordre de 500000 pavés (Chauris, 2010b, p. 26-31).

La situation littorale des gisements a joué un rôle essentiel dans la diffusion de ces pavés. Le "porphyre " de l'île Longue - souvent associé à l' " eurite » de Rostellec - a été longuement et largement recherché pour le pavage des villes, non seulement dans le Finistère (Brest, Landerneau, Châteaulin, Quimper, Concarneau...) mais aussi beaucoup plus loin : Boulogne, Bordeaux... Le même " porphyre " était également utilisé dans les infrastructures portuaires : bien sûr à Brest, tant au port de guerre qu'au port de commerce, mais aussi dans les petits ports de la rade (Le Caro, Lanvéoc, L'Auberlac'h, Le Fret, Le Faou, Port-Launay), dans plusieurs autres ports finistériens (l'Aber Wrac'h, Saint-Pol-de-Léon) et beaucoup plus loin (La Rochelle, Rochefort, Bordeaux, Boulogne), ainsi que pour le pavage des forts de la région brestoise (Chauris, 1996c, 2010a). À présent que les carrières de l'île Longue sont définitivement perdues pour l'extraction, leurs célèbres pavés, du fait de leur résistance remarquable, sont assez fréquemment remployés après récupération, soit encore pour le pavage, soit pour la décoration (murettes de jardins, bacs à fleurs...).

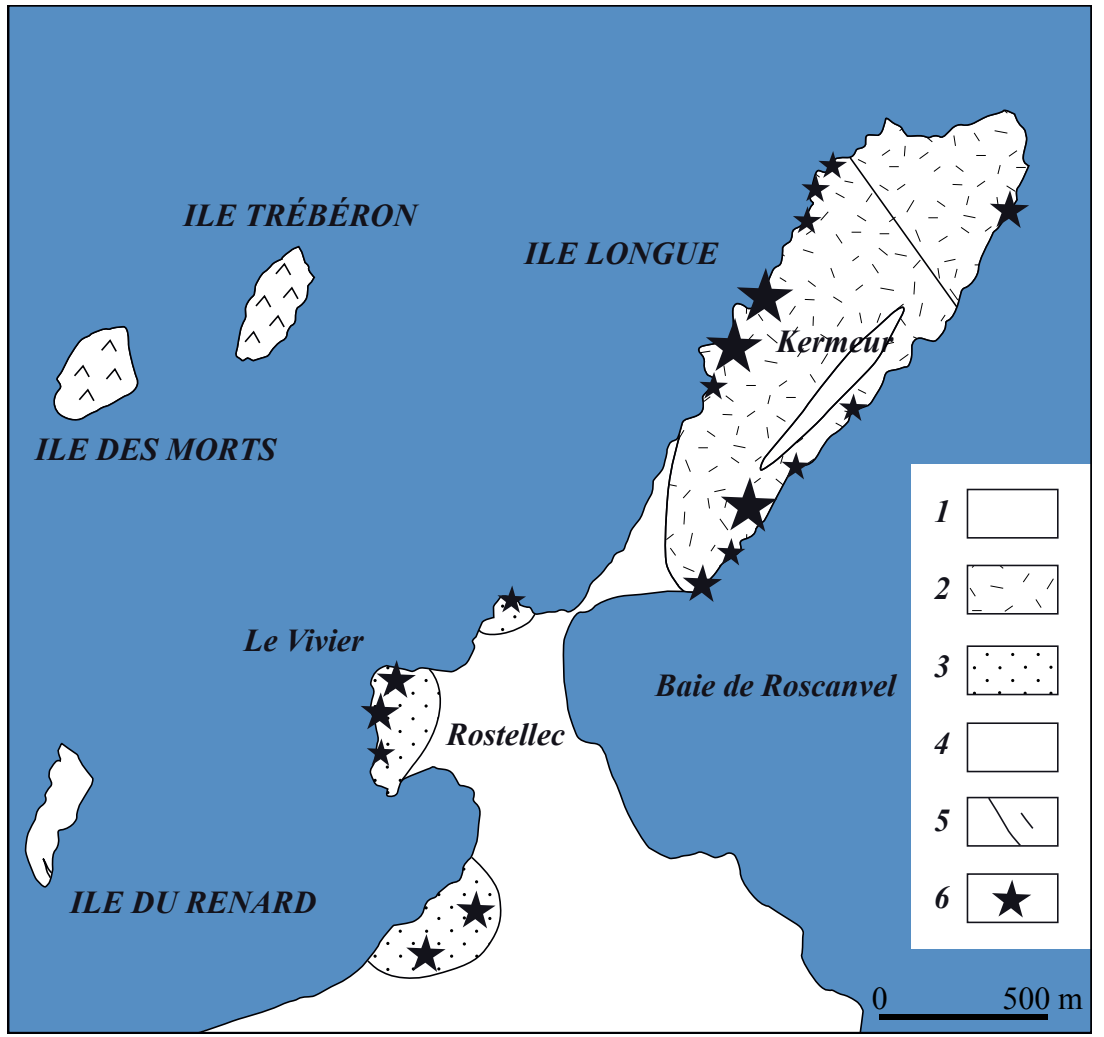

Figure 12 : Le district de l'île Longue en rade de Brest.

Figure 12: The Île Longue district in Brest harbour.

1 : formations dévoniennes; $2:$ " porphyre » de l'île Longue ; 3 : « eurite » de Rostellec; 4 : microgranite de Trébéron et de l'île des Morts; 5 : filons de Kersanton; 6 : carrières abandonnées ou en activité vers 1930. La dimension des symboles indique l'importance des carrières non reportées sur Trébéron et l'île des Morts.

1: Devonian formations; 2: Ile Longue " porphyry »; 3: Rostellec " eurite »; 4: Trébéron and île des Morts microgranite; 5: Kersanton vein; 6 : quarries (abandoned or still in use in the 1930's). Size of marks indicates the quarry's importance (not reported on Trébéron and île des Morts). 
En sus des pavés, ce microgranite fournissait des moellons largement utilisés dans les fortifications de l'île Longue (Chauris et Duigou, 2010). Celui de l'île des Morts a été mis en œuvre, généralement sous forme de moellons et plus rarement de pierres de taille, pour les infrastructures militaires du site : poudrière, caserne, quais... (Chauris et Duigou, 2006). À l'île Trébéron, le microgranite local est omniprésent dans les différentes constructions insulaires, le plus souvent en moellons hétérométriques : tablette de la cale de débarquement, bâtiment de garde, latrines nordouest et sud-est, élévation du bâtiment principal (en dehors de l'encadrement des ouvertures et des chainnages d'angle), mur de clôture du cimetière (Chauris et Duigou, 2007). La même pierre a été utilisée pour l'exécution des quais à Landerneau (Bazin, 1973).

\section{Le champ filonien de la rade de Brest}

Cet essaim de filons s'étend en fait vers l'est jusqu'aux environs de Sizun. Le type le plus fréquent est représenté par une microdiorite quartzique à tonalité plus blanchâtre que jaunâtre. En l'absence de données archivistiques, il n'est pas toujours facile d'en préciser la provenance dans les édifices anciens. Toutefois, dans la majorité des cas, la pierre extraite dans la célèbre carrière du Roz en LogonnaDaoulas a joué un rôle prépondérant par rapport aux autres microgranites, moins résistants (celui de l'île Longue mis à part, voir supra), moins colorés et surtout moins décoratifs. C'est ce matériau exceptionnel qui retiendra principalement notre attention (fig. 13; Chauris, 1994a).

La microdiorite quartzique de Logonna - dite " pierre de Logonna "-a été exploitée pendant des siècles dans le promontoire du Roz. Ces perrières étaient déjà en activité au début du XVI ${ }^{\mathrm{e}}$ s. ainsi que nous l'apprend un acte du 3 octobre 1514. Dans un aveu du 30 septembre 1738, les détenteurs de la carrière du Roz déclarent la tenir sous la seigneurie de Rosmorduc (Pérennes, 1928). Au moment de la Révolution, la carrière était exploitée aux mêmes conditions... et l'extraction était encore active jusqu'à une date toute récente (entreprise Kerbiriou). On comprend facilement que dans ces conditions, le site primitif ait été complètement transformé. En breton, le terme " roz » signifie "tertre" (le pointement est intrusif dans des schistes noirs très tendres). À présent, l'ancien relief est fortement éventré; les excavations antérieures sont plus ou moins réunies en une seule grande carrière d'environ

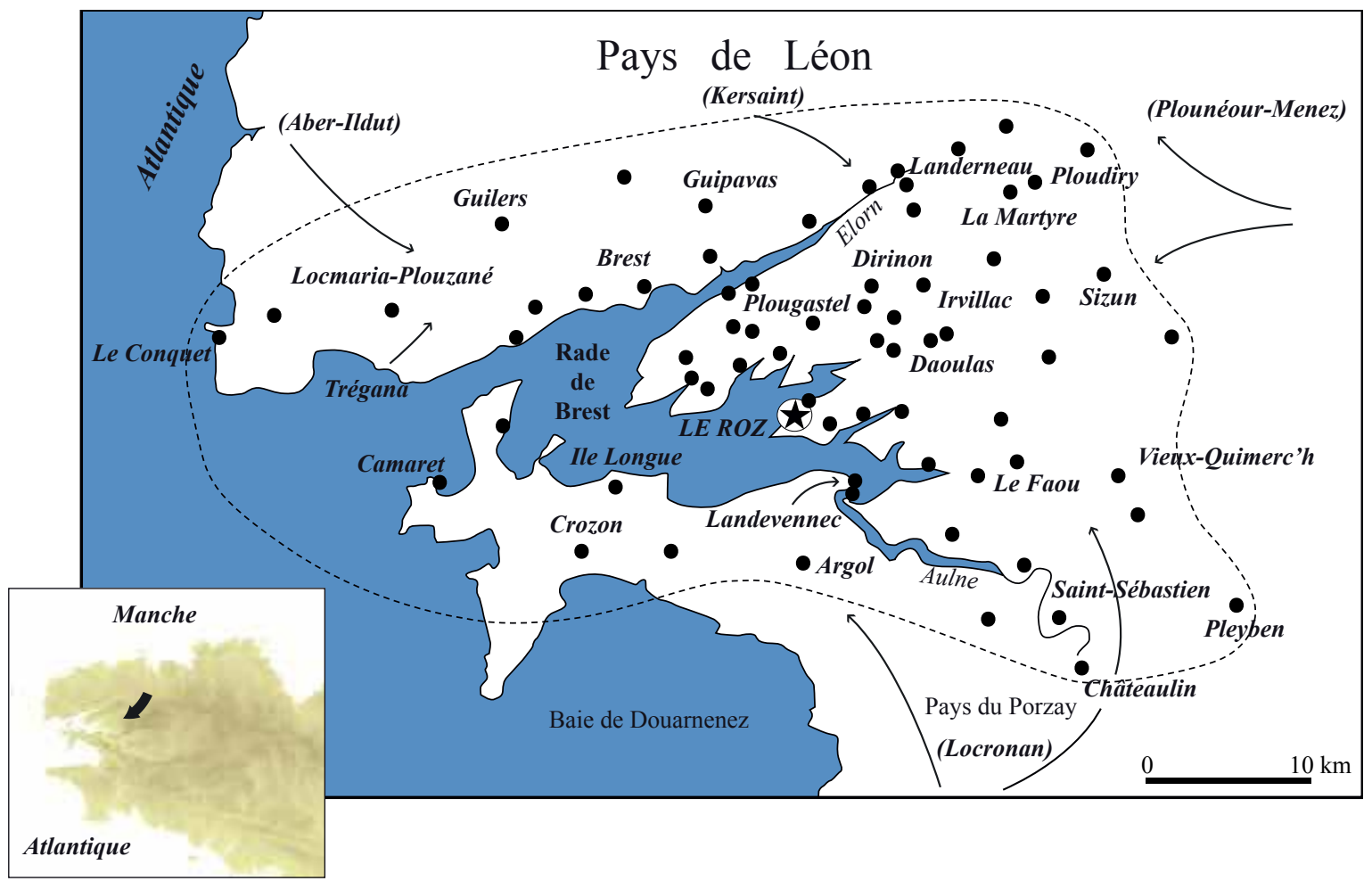

Figure 13 : Emploi des « microgranites » du bassin de la rade de Brest dans les édifices religieux (églises, chapelles, ossuaires).

Figure 13: Use of "microgranites" from the Brest harbour area in religious buildings (churches, chapels, ossuary; dotted line marks the approximate limit of utilization).

En pointillé, limite approximative d'utilisation ; la carrière du Roz est figurée par une étoile ; les flèches indiquent la concurrence des granites environnants.

The star marks Le Roz quarry and arrows indicate concurrence from neighbouring granites. 
$275 \mathrm{~m}$ de long sur $125 \mathrm{~m}$ de large, avec une profondeur qui dépasse localement une trentaine de mètres. La carrière est ouverte à proximité immédiate d'un diverticule de la rade de Brest le long duquel les déblais déversés ont formé un terre-plein. Le fond de l'excavation est nettement au-dessous du niveau de la mer. Le front de taille présente de grandes diaclases subverticales qui, débitant la roche en bancs, en facilitent l'extraction.

La pierre du Roz se distingue au premier coup d'œil par la présence, dans un fond jaune beige à grain fin, de multiples cernes subconcentriques, brunâtres, d'hydroxyde de fer. La genèse de ces cernes est due à la lente percolation et aux dépôts successifs des solutions ferrugineuses circulant à partir des diaclases. Parfois, mais en fait assez rarement, le cœur des bancs est dépourvu d'auréoles. Ces cernes aux formes capricieuses, mimant à s'y méprendre les zones d'accroissement du bois, conferrent au matériau une originalité certaine et une qualité décorative assez remarquable. Soumise à l'érosion après son extraction, la pierre du Roz subit la disparition superficielle des phénocristaux feldspathiques, ce qui provoque l'apparition de microcavités qui ne diminuent en rien la résistance du matériau comme en témoigne l'examen d'innombrables constructions.

Plusieurs dizaines d'édifices religieux (églises paroissiales, chapelles, ossuaires) ont recherché la pierre de Logonna (ou, dans quelques cas, d'autres roches microgrenues apparentées, extraites dans le bassin de la rade de Brest). Leur première utilisation paraît remonter à l'époque romane. C'est en effet au XII ${ }^{\mathrm{e}} s$. (ou peut-être au début $\mathrm{du} \mathrm{XIII}^{\mathrm{e}}$ ) que se rapporte la façade occidentale - aujourd'hui encore intacte - de l'église abbatiale de Daoulas. C'est sans doute à la même époque qu'il convient aussi d'attribuer les contreforts internes de l'élévation ouest de l'église abbatiale de la pointe de SaintMathieu. Un " microgranite " a été aussi observé dans les ruines de l'abbaye de Landévennec. La provenance précise de ces roches - qui diffèrent légèrement de celle du Roz reste encore indéterminée. En fait, la pierre de Logonna va surtout être largement employée aux XVI ${ }^{e}$ et XVII ${ }^{\mathrm{e}}$ s. Les exemples sont trop nombreux pour pouvoir être présentés en détail. Parmi d'autres, citons, un peu au hasard de nos pérégrinations : la chapelle de Rocamadour à Camaret (1527, avec réparations au XvII ${ }^{\mathrm{e}}$ s.); l'église d'Argol (XVI ${ }^{\mathrm{e}-}$ $\mathrm{XVII}^{\mathrm{e}}$ s.) avec, à l'entrée de l'enclos, un arc de triomphe monumental (1659); le porche de l'église de Guilers (1601); l'église de Dirinon (surtout XVI $I^{\mathrm{e}}$-XVII ${ }^{\mathrm{e}}$ ); les clochers de Logonna-Daoulas $\left(\mathrm{xvII}^{\mathrm{e}}\right)$, de Saint-Conogan près de Landerneau (1591); l'église d'Irvillac (surtout $\left.\mathrm{XVII}^{\mathrm{e}}\right)$; l'église du Vieux-Bourg de Quimerc'h $\left(\mathrm{XvI}^{\mathrm{e}}\right)$; la chapelle Saint-Sébastien en Saint-Ségal (XVI ${ }^{\mathrm{e}}$-XVII ${ }^{\mathrm{e}}$, avec un arc de triomphe du $\mathrm{XVI}^{\mathrm{e}} \mathrm{s}$.) ; les églises de LogonnaQuimerc'h $\left(\mathrm{XVII}^{\mathrm{e}}\right)$ et du Faou (surtout XVII ${ }^{\mathrm{e}}$ ); pour partie le porche de Ploudiry (1665) ; l'église de Tréflévénez; des piliers à Sizun $\left(\mathrm{XVI}^{\mathrm{e}}\right.$-XVII $\left.\mathrm{I}^{\mathrm{e}}\right)$. La roche apparaît localement dans l'élévation sud à Pleyben ( $\mathrm{XvI}^{\mathrm{e}} \mathrm{s}$.). Elle figure aussi dans plusieurs chapelles de Plougastel-Daoulas : SainteChristine $\left(\mathrm{XVI}^{\mathrm{e}}\right.$-XVII $\left.{ }^{\mathrm{e}}\right)$, Saint-Claude $\left.(\mathrm{XVII})^{\mathrm{e}}\right)$, Saint-Trémeur $\left(\mathrm{XVI}^{\mathrm{e}}-\mathrm{XVII}^{\mathrm{e}}\right)$, Saint-Guénolé... En Logonna-Daoulas (Couffon et Le Bars, 1988), ce seront les chapelles SainteMarguerite (XVII ${ }^{\mathrm{e}}$ s. avec transformation au XIx ${ }^{\mathrm{e}}$ ) et SaintJean $\left(\mathrm{XvII}^{\mathrm{e}}\right)$. Évoquons aussi la belle église Saint-Thomas $\left(\mathrm{XVI}^{\mathrm{e}}-\mathrm{XVII}^{\mathrm{e}} \mathrm{s}\right.$.) qui est, à Landerneau, l'édifice religieux où la pierre de Logonna a été le plus largement employée même si, comme dans les cas énumérés ci-dessus, d'autres matériaux y ont été également recherchés; on l'observe dans le chevet plat (où la restauration récente a fait heureusement appel à la même roche), dans la sacristie (avec clocheton portant la date de 1669); on la retrouve pour les niches (vides!) du porche, pour partie dans le dallage, dans plusieurs piliers et arcades ou encore dans la tour et dans les élévations nord et sud... La remarquable voûte de la sacristie (également en pierre de Logonna) confère à cette partie de l'édifice un étonnant aspect de casemate.

Les ossuaires ayant utilisé la pierre de Logonna méritent également une mention spéciale. Ces petits édifices, situés dans le cimetière près de l'église, sont en effet particulièrement soignés. Parmi les plus beaux, on remarquera ceux de la Roche-Maurice (1639-1640), d'Argol (1665), de Saint-Thomas à Landerneau (1655), de Pencran - pour partie seulement en pierre de Logonna (1594 avec restauration en 1716)... L'ossuaire d'Irvillac (XvII ${ }^{\mathrm{e}}$ s.) a surtout fait appel à un autre microgranite, à grain plus fin, de provenance imprécisée. La sacristie de l'église de La Martyre, construite de 1697 à 1701, a également mis en œuvre un autre microgranite dont la provenance proximale a pu être précisée par les archives.

Comme l'établit notre carte (fig. 13), le site du Roz, d'où provient la majorité des pierres " microgrenues" utilisées dans les édifices religieux, dessert approximativement une vaste zone de subelliptique dont le grand axe atteint plus de $50 \mathrm{~km}$, et le petit axe près de $40 \mathrm{~km}$. La répartition des constructions y souligne encore une fois le rôle essentiel joué par les transports maritimes. Les pierres, directement embarquées à la carrière, pouvaient atteindre aussi bien les rives septentrionales de la rade de Brest et de ses abords occidentaux dans le Pays de Léon (d'où les constructions en pierre de Logonna ne s'éloignent guère de plus de 6-7 km) que les rives méridionales de la même rade en presqu'île de Crozon (éloignement maximum de l'ordre de $5 \mathrm{~km}$ ). Mieux, par les rias de l'Élorn et de l'Aulne, les navires pouvaient s'avancer profondément dans les terres et atteindre respectivement Landerneau et Châteaulin; de là, la pierre du Roz pouvait encore rayonner un peu par charrois. En fait, il semble 
évident que sans cette double conjoncture éminemment favorable (extraction au bord de la mer et transport aisé par voie d'eau), la pierre de Logonna n'aurait pas connu un tel essor dans le passé.

Vers le début de la seconde partie du $\mathrm{Xx}^{\mathrm{e}}$ s. s'est manifesté un nouveau regain d'intérêt pour la pierre du Roz dans l'architecture religieuse avec l'érection de trois ensembles importants : l'église Saint-Louis à Brest, consacrée en 1958 (l'ancien édifice avait été partiellement détruit lors du siège de la ville en 1944); pour partie, l'église de Guipavas (détruite lors de la même bataille et consacrée en 1955); enfin, la nouvelle église abbatiale de Landévennec, bâtie entre 1962 et 1965.

En matière d'architecture civile, de nombreuses demeures - tant citadines que rurales - ont recherché la pierre de Logonna dont les limites spatiales d'utilisation coïncident approximativement - et pour les mêmes raisons - avec celles mises en évidence pour les monuments religieux. Ces habitations, bien caractérisées par la teinte jaunâtre de leurs parements, ont été notées en particulier à Logonna, Daoulas, Dirinon, Le Faou, Landévennec, Crozon, Le Conquet, Saint-Renan, Brest, Châteaulin... et surtout à Landerneau. Le large emploi de la pierre de Logonna confère à de multiples maisons anciennes de cette cité un charme indéniable. Et, fait assez exceptionnel pour être souligné, plusieurs constructions récentes y ont encore utilisé ce même matériau, témoignage d'une profonde fidélité... Sans conteste, le plus bel exemple, fort bien conservé, est représenté par la maison dite de la Sénéchaussée, datée de 1664, avec sa tourelle ronde engagée, son pavillon avancé en guérite, soutenu par des corbelets que l'on retrouve à la base de la toiture. À Landerneau, le promeneur a donc l'embarras du choix : on citera encore, à l'angle du pont de Rohan, la demeure bâtie à même le lit de la rivière, avec sa toiture à corbelets (1639); la grande maison à tourelle engagée, datée de 1667, 5 rue du Commerce; la maison dite des Treize Lunes en face de Saint-Thomas; l'actuel « Bar de l'Armorique " (1626), quai de Léon... Toujours à Landerneau, la pierre de Logonna - matériau noble - est très souvent réservée aux encadrements (portes et fenêtres), les murs eux-mêmes étant élevés en moellons de nature variée. Évoquons ici, parmi bien d'autres, le n ${ }^{\circ} 38$ de la rue J.-L.-Rolland avec les linteaux de la porte et de la fenêtre adjacente aux curieuses moulurations $\left(\mathrm{XVI}^{\mathrm{e}} \mathrm{s}\right.$.); rue Romain-Desfossés, au n ${ }^{\circ} 22$, l'oculus à agrafes, situé au-dessus de la porte, offre un bon exemple de l'aptitude au façonnement de la pierre de Logonna (XVII ${ }^{\mathrm{e}}$ s.)... (Chauris, 1993f).

Plusieurs châteaux ou manoirs ont également fait appel à la même roche, tant à proximité du site d'extraction (Rosmorduc en Logonna) qu'à des distances assez consi- dérables (Keranden à Landerneau; Halegot, Kerlembars en Plouzané; Kerscao, Goulven en Locmaria-Plouzané; Kerjanmol en Trébabu... Dans le château de Brest, le bastion Sourdéac (deuxième partie du Xvi ${ }^{\mathrm{e}} \mathrm{s}$.), qui avait mis en œuvre - pour partie - la pierre de Logonna, a été récemment restauré avec la même roche. Le moulin du Roual en Dirinon est pour partie en ce matériau (Chauris, 2013a).

Les monuments funéraires en pierre de Logonna sont très rares. Dans le cimetière Saint-Martin à Brest, une dalle tumulaire porte le millésime de 1809. Le monument aux morts de l'ancienne commune de Lambézellec a mis en œuvre la même pierre.

Plusieurs constructions publiques ou privées ont fait récemment appel à la pierre de Logonna : les aménagements du jardin Kennedy à Brest; les trois entrées nord des bâtiments de la Thomson-CSF à Brest (1962); la poste de Saint-Pol-de-Léon; la mairie et la poste de Daoulas... La même pierre, une fois sciée, a fourni le dallage de la grande salle du manoir de Kerscao en LocmariaPlouzané : par l'imitation du bois, l'effet produit est saisissant... Également en pierre du Roz sciée, un très beau dallage (environ $2000 \mathrm{~m}^{2}$ ) a été posé à Landerneau devant l'ancienne chapelle des Capucins et dans la grande cour intérieure voisine (Fonds H. et E. Leclerc); les nombreux cernes brunâtres de la roche confèrent à ce revêtement un net cachet décoratif. L'entreprise Kerbiriou a enfin livré de nombreuses cheminées.

\section{Le Kador, à Morgat}

L'un des plus originaux microgranites de Bretagne est sans doute celui dit du Kador à Morgat, en presqu'île de Crozon. Un excellent affleurement est observable dans la falaise un peu au sud du port de plaisance, sous forme d'un sill (filon parallèle aux roches encaissantes) qui attire le regard par son étonnante blancheur. Les phénocristaux sont constitués par du quartz et par des lamelles de muscovite qui lui conferent un aspect caractéristique; la mésostase est extrêmement fine. Une autre occurrence a été signalée au sud de Lespiguet en Telgruc (Thonon, 1973); la présence de filons identiques, aujourd'hui masqués par la végétation, est très probable. Plusieurs constructions anciennes de la presqu'île de Crozon ont mis en œuvre ce microgranite, sans que l'on puisse toutefois, faute de données archivistiques, préciser la localisation des sites d'extraction (fig. 14; Chauris, 2009a).

\section{Édifices religieux}

Le porche méridional ( $\mathrm{XvI}^{\mathrm{e}}$ s.) de l'église paroissiale de Crozon a été conservé lors de la reconstruction à la fin du $\mathrm{XIX}^{\mathrm{e}}$ s. Typiquement polylithique, il montre l'association 


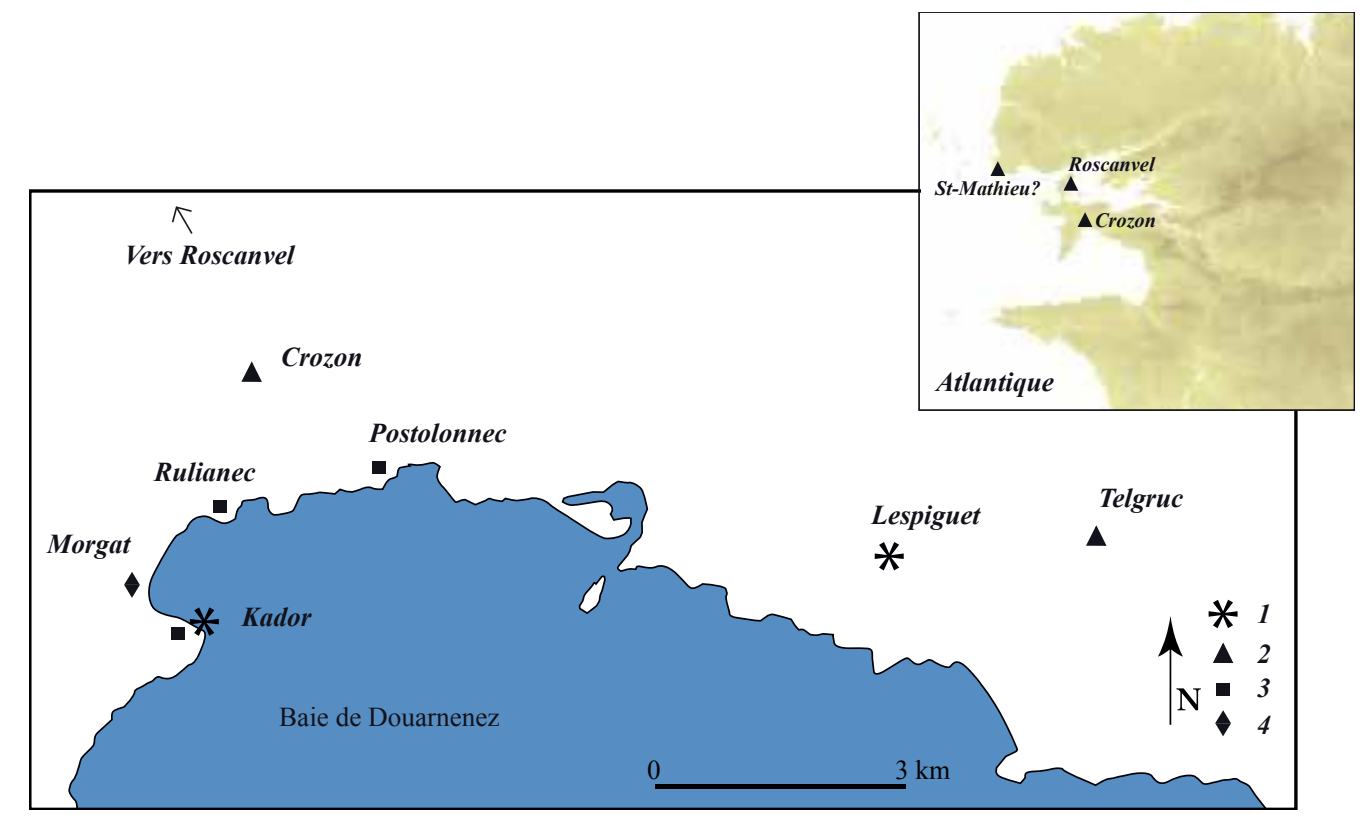

Figure 14 : Mise en œuvre du microgranite type « Kador».

Figure 14: Use of "Kadortype" microgranite.

1 : affleurement ; 2 : édifice religieux ; 3 : infrastructures militaires; 4 : habitat.

1: Outcrop; 2: religious building; 3: military infrastructures; 4: habitat. d'un leucogranite gris clair des environs de Douarnenez au microgranite jaune de Logonna et au microgranite blanc du Kador. Les élévations de cette église sont essentiellement en moellons de grès armoricain de provenance locale; s'y adjoignent, de manière aléatoire, des éléments leucogranitiques et microgranitiques (Logonna et Kador), en remploi. À Telgruc, les moellons du transept présentent quelques éléments en microgranite du Kador. Cette roche est très rare dans l'église de Roscanvel (élévation méridionale) et certainement en remploi. À titre d'hypothèse, c'est à la même roche que semble pouvoir être rapporté le microgranite blanc observé localement dans les ruines de l'abbaye de Saint-Mathieu, en Plougonvelin dans le pays de Léon.

\section{Infrastructures militaires}

L'encadrement de meurtrières des réduits (modèle 1846) de Postolonnec (1860), Rulianec (1860) et Kador (1861) a fait appel à ce matériau. Depuis sa mise en place, la pierre a subi une érosion prononcée, entraînant vis-à-vis des éléments voisins, de nature différente, un recul impressionnant (une dizaine de centimètres à Postolonnec); la même roche a été aussi localement utilisée en moellons (Rulianec).

\section{Habitat}

À Morgat, l'emploi de ce microgranite, en moellons disséminés, est peu répandu et toujours ancien. Selon toute probabilité, une prospection plus fouillée révèlerait d'autres occurrences.

En dépit de sa provenance très localisée, le microgranite du Kador montre cependant une certaine diffusion. Son utilisation est due - au moins en partie - à un façonnement nettement plus aisé que celui des granites. Il appartient à cet immense cortège de pierres à l'originalité évidente qui, tombées aujourd'hui dans l'oubli, se doivent d'être signalées à l'attention des archéologues.

\section{En Centre-Finistère}

Les cartes géologiques montrent quelques intrusions microgranitiques recoupant les formations dévoniennes dans la région de Brasparts (Barrois, 1905; Babin (dir.), 1982; Castaing (dir.), 1988). Ces roches, de teinte grisâtre passant au beige par altération, ont surtout été recherchées pour l'habitat rural, voire pour des murettes. À Goël, en Brasparts, un microgranite gris ou beige a été mis en œuvre dans une demeure, tant comme pierres de taille qu'en moellons. Une carrière, abandonnée et envahie par la végétation, était ouverte en contrebas de la maison. Le microgranite y offre un grain très fin, avec quelques phénocristaux submillimétriques de biotite altérée et des quartz de plusieurs dixièmes de millimètres (Chauris, 2010c). Également en Brasparts, dans le hameau de Langle, un bâtiment de ferme, remontant au début du XIX ${ }^{e}$ s., présente deux portes en microgranite à grain fin, grisâtre à beige, façonné en pierres de taille; dans l'élévation, se notent des moellons microgranitiques à côté de schistes et quartzites dévoniens. Le manoir de Langle a largement mis en œuvre le microgranite local, associé au granite de Brennilis. À Kerbraz, une pierre d'angle microgranitique, peut-être en remploi, porte le millésime 1631 (ou 1691?); on y note aussi de très nombreux moellons également en microgranite et un encadrement d'ouverture en granite du Huelgoat; à proximité, la fontaine a fait un large appel au microgra- 
nite. Au hameau de Benniel, une maison abandonnée a été édifiée en moellons hétérométriques de microgranite qui portent de nombreuses traces d'outils de façonnement, suggérant que la mise en œuvre de la pierre offrait quelques difficultés. Dans le bourg même de Brasparts, une maison ancienne (1805) montre l'association microgranite grisâtre et granite de Brennilis. Dans la murette de l'enclos de la célèbre chapelle de Saint-Herbot, les moellons de schiste dévonien, grès armoricain et quartzite gédinnien sont associés à quelques moellons de microgranite.

Un filon microgranitique pouvant atteindre plusieurs dizaines de mètres de puissance, d'orientation générale ouest-est, jalonne de façon pratiquement continue, sur une vingtaine de kilomètres, le contact septentrional des formations dinantiennes du bassin de Châteaulin au sud avec les complexes briovériens et dévoniens au nord. Cartographié par C. Barrois (1905), ses contours ont été ultérieurement précisés (Castaing, 1988; Babin, 1982). Son tracé est jalonné par de nombreuses carrières abandonnées, montrant une roche leucocrate, blanchâtre, avec phénocristaux, en particulier des paillettes de muscovite, dans une mésostase aphanitique. Par altération, il peut présenter des cernes brunâtres subconcentriques d'hydroxyde de fer. Nos recherches sur les constructions, encore préliminaires, établissent cependant que ce microgranite constitue une pierre de qualité. Un bon exemple d'utilisation est fourni par quelques parties de l'église de Poullaouen (première moitié $\mathrm{du} \mathrm{XVII}^{\mathrm{e}} \mathrm{s}$. avec restauration au $\mathrm{XIX}^{\mathrm{e}}$ ) : localement, pierres de taille dans le mur intérieur de l'élévation septentrionale et dans l'élévation méridionale extérieure. Toujours à Poullaouen, le même microgranite a été également observé dans la chapelle Saint-Quijeau (reconstruite vers le milieu du $\mathrm{XIX}^{\mathrm{e}} \mathrm{s}$.), en encadrement d'ouvertures (porte et baies). La même roche a été aussi utilisée dans l'habitat à Poullaouen. Dans l'ouest des Côtes-d'Armor, le porche de l'église de Plusquellec s'avère d'un intérêt particulier avec l'emploi du microgranite non seulement dans l'élévation, mais aussi dans les motifs sculptés; non loin de là, à Callac, le porche de l'église est voûté en petits moellons de microgranite blanchâtre devenant parfois jaunâtre, tandis que les moellons microgranitiques jouent un grand rôle dans les élévations latérales.

\section{Aux abords de la baie de Goulven}

Les microgranites apparaissent dans deux champs d'ampleur inégale, de part et d'autre de cette baie du nord-Finistère (fig. 15; Chauris et al., 1977; Chauris et Marcoux, 1998).

À l'est, le plus important d'entre eux a pu être suivi de manière discontinue, selon la direction d'ensemble NNE-
SSW, depuis les anses de Cam Louis et de Poulfoën au nord de Plouescat jusqu'à la petite butte de Keryun au nord de Plounévez-Lochrist, soit environ $5 \mathrm{~km}$. Sur l'estran, les affleurements sont localement excellents. À Cam Louis, le filon, orienté $\mathrm{N} 40^{\circ} \mathrm{E}$ et d'une puissance maximale de l'ordre de $10 \mathrm{~m}$, est totalement arasé. La roche, de teinte beige et extrêmement diaclasée, livre des éléments anguleux. À Poulfoën, le filon, orienté N $10^{\circ} \mathrm{E}$, avec une largeur de l'ordre de 5-6 m, apparaît en creux par rapport au granite porphyroïde encaissant. Il affleure sous forme de grosses masses extrêmement tenaces, de nuance très sombre où, dans un fond gris-noirâtre, apparaissent des phénocristaux allongés de feldspaths potassiques automorphes pouvant atteindre jusqu'à $3 \mathrm{~cm}$, et de quartz ocellaire. Par suite de leur relief en creux, de leur faible largeur et de l'épaisseur du manteau de limons quaternaires, les microgranites sont difficiles à cartographier à l'intérieur des terres où ils n'apparaissent généralement qu'en éboulis ou en "pierres volantes ", plus rarement à la faveur d'anciennes carrières (près de Poulhazec, à Keryun).

À l'ouest, les filons sont uniquement connus dans les parties occidentale et méridionale de l'anse de Brignogan. Le premier groupe, près de Moabren, est orienté SW-NE, avec une puissance maximale de $2 \mathrm{~m}$; les blocs ont été plus ou moins déplacés. Le second, de direction subméridienne, semble se poursuivre dans le bourg de Brignogan comme le suggèrent les gros blocs quasi en place dans les murs près du château d'eau. Par ailleurs, de nombreux galets de microgranite ont été observés sur la plage du Bihou (au sud-est du sémaphore), laissant présumer la présence de filons plus au large. L'existence d'autres filons microgranitiques dans la région est attestée par la découverte d'une nouvelle occurrence au sud-ouest de Tréflaouénan. Il est évident que de nombreux filons ont encore échappé à l'attention des géologues. L'âge moyen d'un filon de l'anse de Brignogan, analysé par la méthode potassium-argon, est de $244 \pm 12$ millions d'années (Bellon et al., 1985a, 1985b), ce qui suggère que ces intrusions sont à rapporter au Permien, c'est-à-dire après la fin des plissements hercyniens.

Ces microgranites sont toujours restés d'emploi très localisé. Ils n’ont guère été recherchés que pour les constructions rurales (murettes...) et pour l'empierrement des chemins, ainsi que l'attestent encore les anciens sites d'extraction sur l'estran (Poulfoën) et à l'intérieur des terres (Poulhazec, Keryun...).

\section{Dans la région de Morlaix}

\section{Champs filoniens albitiques}

À notre connaissance, Puillon Boblaye (1827) est le premier auteur à avoir signalé la présence de filons dans la 
région morlaisienne. Une vingtaine d'années plus tard, le $D^{r}$ Le Hir (1845) publiait un article sur les « eurites porphyriques » des environs de Morlaix. En 1886, C. Barrois mettait en relation les deux champs filoniens signalés au nord de cette ville avec les pointements granitiques de Kerscoff et du Menez (Barrois, 1886b). Cependant, il aura fallu attendre près d'un siècle (Chauris, 1971; 1993g; Chauris dans Chantraine [dir.], 1986) pour que la nature véritable de ces formations, puis leurs conditions de mise en place soient élucidées. Les nombreux filons qui rayonnent à partir des pointements de granite albitique sont des microgranites sodiques. Comme les massifs générateurs, ils sont très riches en soude et pauvres en potasse. Ces filons sont caractérisés par leur teinte claire, leur grain fin (à peine discerne-t-on les phénocristaux de plagioclase au sein de la pâte), leur faible puissance (souvent de l'ordre du mètre seulement) et leur boudinage plus ou moins accentué au sein des schistes bleu-noirâtre, souvent zébrés, qu'ils injectent fréquemment. Laltération météorique y a entraîné la formation de cernes concentriques d'hydroxyde de fer brunâtre. Les principaux essaims filoniens sont visibles près de Kerscoff et du Menez, autour du bourg de Ploujean (fig. 16).

\section{- Édifices religieux}

Les édifices religieux fournissent aujourd'hui les meilleurs exemples de l'emploi de ces microgranites sodiques dans le Trégorrois occidental (Chauris, 1994c).

- À Ploujean, où constructions et transformations de l'église paroissiale se sont échelonnées sur un millénaire, l'utilisation du microgranite semble bien être limitée à la partie la plus ancienne de l'édifice, la nef romane ( $\mathrm{XI}^{\mathrm{e}} \mathrm{s}$.) où il apparait en association avec le granite albitique. Le microgranite n'apparaît pas en effet dans les piliers octogonaux du chœur ( $\mathrm{xIv}^{\mathrm{e}} \mathrm{s}$.) ni dans la tourelle flanquant le clocher ( $\mathrm{XVI}^{\mathrm{e}} \mathrm{s}$.); a fortiori, il n'a pas été utilisé pour les modifications du début $\mathrm{xx}^{\mathrm{e}}$ qui ont fait appel au granite porphyroïde du Ponthou;

- Dans l'église de Locquénolé, les premiers ensembles, de style roman, datent de la fin $\mathrm{du} \mathrm{XI}^{\mathrm{e}}$ s. On note ici plusieurs éléments - associés à des schistes tuffacés - de
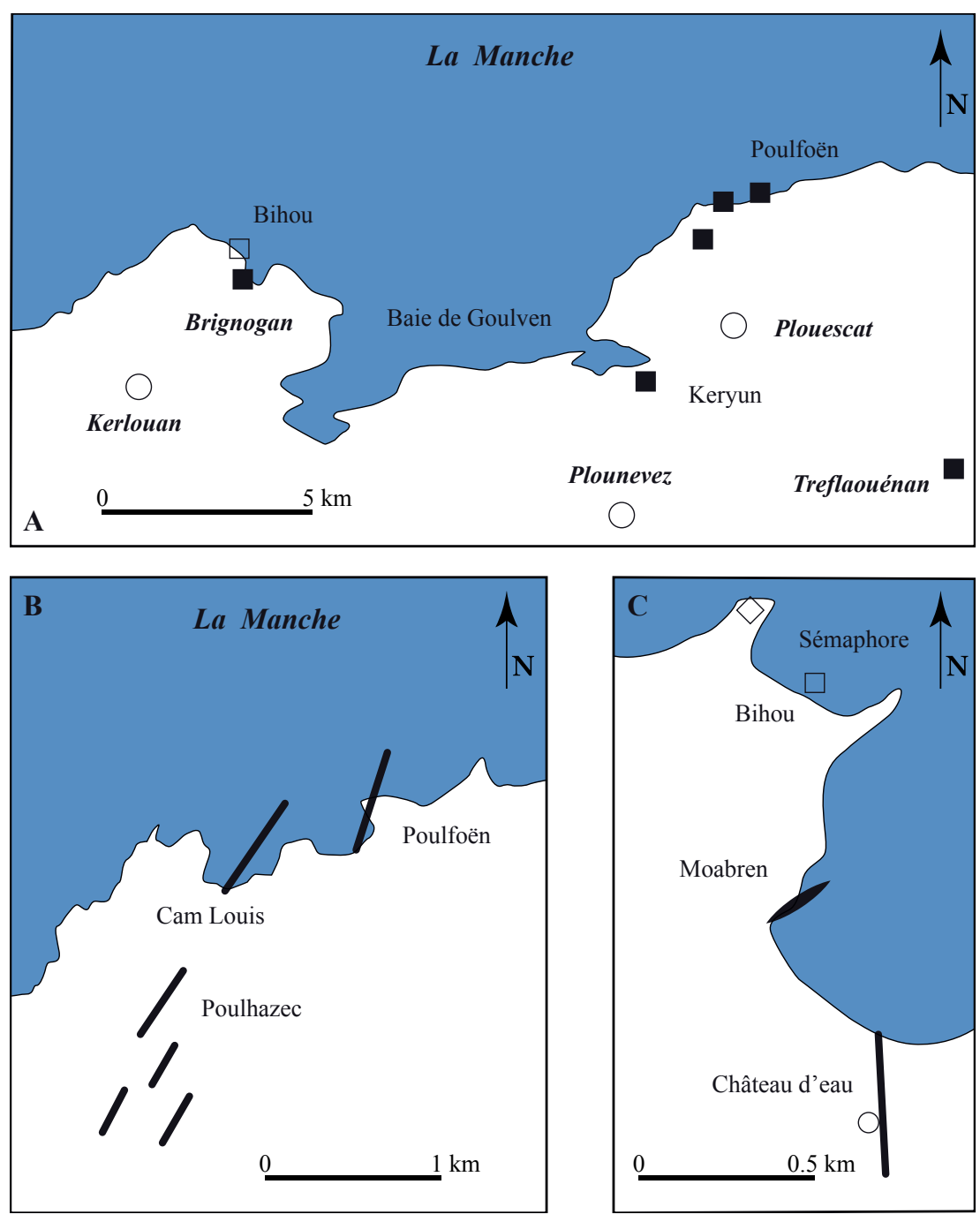

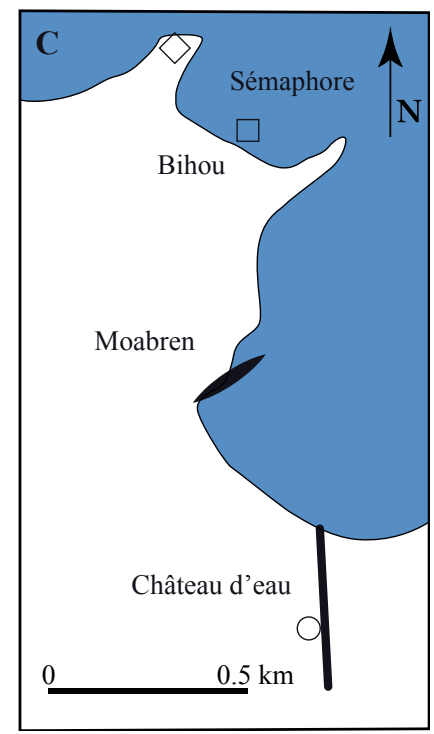

Figure 15 : Localisation schématisée (parfois à titre collectif) des filons de microgranites, de part et d'autre de la baie de Goulven et détail de deux champs filoniens.

Figure 15: Schematic location (sometimes collectively reported) of microgranite veins around Goulven bay, and detail of two fields.

A : au nord de Plouescat; B : à Brignogan (orientations approximatives; visible uniquement sous forme de galets au Bihou).

A: North of Plouescat; B: near Brignogan (orientations are approximate; visible only as pebbles at Le Bihou). 
Figure 16: Microgranites sodiques et leurs utilisations près de Morlaix.

Figure 16: Location and uses of sodic microgranites near Morlaix.

1 : granite albitique du Menez et de Kerscoff ; 2 : filons de microgranite albitique ; 3 : édifices religieux ; 4 : châteaux et manoirs ; 5 : fermes ; 6 : murs et murets ; 7 : limite approximative de la zone d'emploi des microgranites sodiques (état actuel des recherches).

1: Menez and Kerscoff albitic granite; 2 : veins of albitic microgranite; 3: religious buildings; 4: castles and manors; 5: farmhouses; 6: walls; 7: approximate limit of utilization area (present stage of survey).

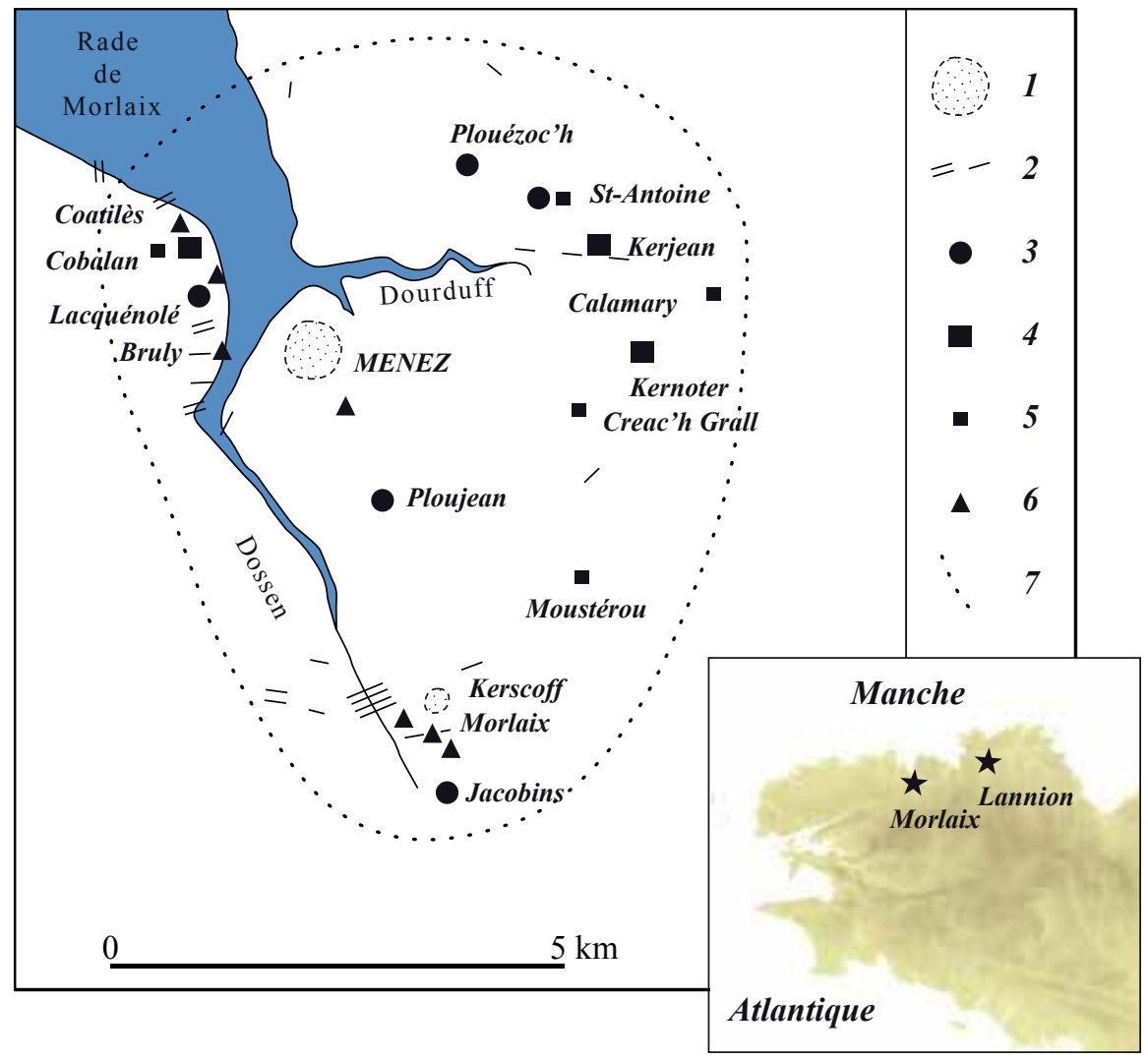

granite albitique (en provenance du Menez) et surtout de microgranite, à l'origine toute locale (les filons sont très nombreux dans les schistes de Locquénolé) ; le microgranite n'a pas été recherché lors des transformations importantes du XVII ${ }^{\mathrm{e}}$ s. Tout comme à Ploujean, cette roche toute locale reste confinée aux parties primitives (romanes) de l'édifice; elle est ensuite délaissée.

\section{- Édifices civils}

Le château de Coatilès, en Taulé (Xvir ${ }^{e}$ s.) a privilégié le clair granite à muscovite de l'île Grande, très bien façonné, et a réservé le microgranite local pour les constructions annexes (pour partie, le colombier et les murs du domaine). Le manoir restauré de Kerjean, au sud-est de Saint-Antoine en Plouézoc'h, oppose des moellons microgranitiques aux encadrements en pierres de taille façonnées au moins pour partie dans le granite albitique. Par contre, dans le manoir de Kernoter Vras en Plouézoc'h, plusieurs portes cintrées laissent voir le microgranite. Les microgranites sodiques ont aussi été fréquemment utilisés pour la construction des murs et des murettes, souvent en association avec les schistes zébrés de même provenance. Parmi d'autres, citons, à Morlaix, des vieux murs dans l'ancien couvent des Capucins, le mur de clôture du cimetière Saint-Charles (en association avec le granite de Kerscoff et les schistes zébrés, toutes roches d'origine proximale), ainsi que la rue J.-Y.-Guillard où le microgranite présente de remarquables auréoles d'altération ferrugineuses. Le même microgranite, toujours associé aux schistes zébrés, se retrouve aussi à Locquénolé (mur de soutènement de la route de corniche au droit du Bruly, mur de clôture du manoir de Keromnès...).

Ce bref survol de l'utilisation du microgranite sodique indique clairement que ce matériau - aux gisements fort nombreux en région morlaisienne $-\mathrm{y}$ reste d'usage limité; malgré une exploitation qui remonte à un millénaire, il n'est en règle générale employé que parce qu'en fait, les constructeurs ne disposaient pas, à un moment précis, d'autres pierres. Il fournit un bon exemple d'économie circulaire, utilisant au maximum les ressources locales.

\section{Microgranite de Ploujean}

Qualifiée très tôt de "porphyre " par E. de Fourcy (1844a), d' " eurite granito-porphyrique » par le docteur Le Hir (1845), d' " eurite porphyrique " par le comte de La Fruglaye (dans Onfroy-Kermoalquen, 1849-1850), puis de porphyre apparenté aux microgranulites par Barrois (1886b), cette roche fut cartographiée par le même auteur en 1905. La roche filonienne de Ploujean (commune désormais rattachée à Morlaix) est déterminée aujourd'hui comme un microgranite potassique (Chauris, 1994b). 
Les filons s'allongent d'ouest en est sur une quinzaine de kilomètres dans le Trégor occidental, entre le Dossen (ou Rivière de Morlaix) et le Douron, à la limite des Côtes-d'Armor, à proximité de la vallée du Dourduff (fig. 17). Généralement, leur épaisseur ne dépasse guère quelques mètres; cependant, à Voasven (en PlouégatGuérand), l'occurrence est plus importante : peut-être a-t-on ici un "stock" (pointement) ? La roche est peu visible aujourd'hui : les affleurements naturels sont le plus souvent médiocres, les carrières toujours de faibles dimensions et abandonnées; les pierres éparses jalonnant à travers champs le passage des filons sont généralement de mauvaise qualité.

Le microgranite de Ploujean présente une cristallisation en deux temps très accusée : au sein d'un fond à grain très fin (mésostase) grisâtre à rouge-brunâtre s'y développent des phénocristaux qui étonnent dès l'abord par leurs fortes dimensions (jusqu'à près de $8 \mathrm{~cm}$ de long!) et le bel automorphisme des feldspaths potassiques blanchâtres à jaunâtres; les phénocristaux de quartz se singularisent par leur sombre coloration gris-mauve et leur forme bipyramidée.

Dans une contrée à dominante schisteuse, les matériaux apparentés aux granites sont évidemment très appréciés. Aussi n'est-il pas surprenant de constater l'emploi du microgranite de Ploujean dans les constructions rurales anciennes, malgré un façonnement assez difficile, d'où fréquemment des surfaces irrégulières voire bosselées; parfois certains éléments taillés atteignent près d' $1 \mathrm{~m}$ de long. Nos itinéraires ont toutefois établi que sa répartition est toujours restée locale : les constructions ne s'éloignent guère des sites d'extraction (Chauris, 1995a).

Le plus souvent, ce microgranite a été utilisé comme moellons, sans façonnement particulier, dans les murs des fermes et des bâtiments annexes, en association avec d'autres roches de provenance généralement proximale. Tel est le cas à Torongan ou Coat-Grall (en Ploujean) ou, en Garlan, au sud de Coat-ar-Roc'h, à Kervoalen (avec schistes tuffacés grisâtres) et à Poullalen); de même à Kerguillarm (en Lanmeur) ou, en Plouégat-Guérand, à Kerlosquet, Kergoualc'h, Convenant Saison...

Assez fréquemment, la même roche a été recherchée comme pierre d'angle : Coat-Grall, Dourmeur (en Ploujean); au sud du château de Coat-ar-Roc'h (où les éléments peuvent atteindre $70 \times 50 \mathrm{~cm}$ ); Mesguen (également en Garlan); Kerveatous (en Plouégat-Guérand). Parfois, le microgranite a été utilisé comme dallage à l'entrée de la maison d'habitation (Coat-Lescoat en Plouigneau). Rarement (Poullalen en Garlan), il a été façonné en belles pierres de taille pour encadrement de porte; à Poullalen, un demi-cintre a même été taillé dans cette roche.

La même pierre a été également observée dans les murettes, comme à Porz Braz en Ploujean (avec moellons de quartz, de schistes et de granite albitique). Le mur du cimetière, autour de l'église de Plouégat-Guérand, en présente des éléments de grande taille, ici avec énormes

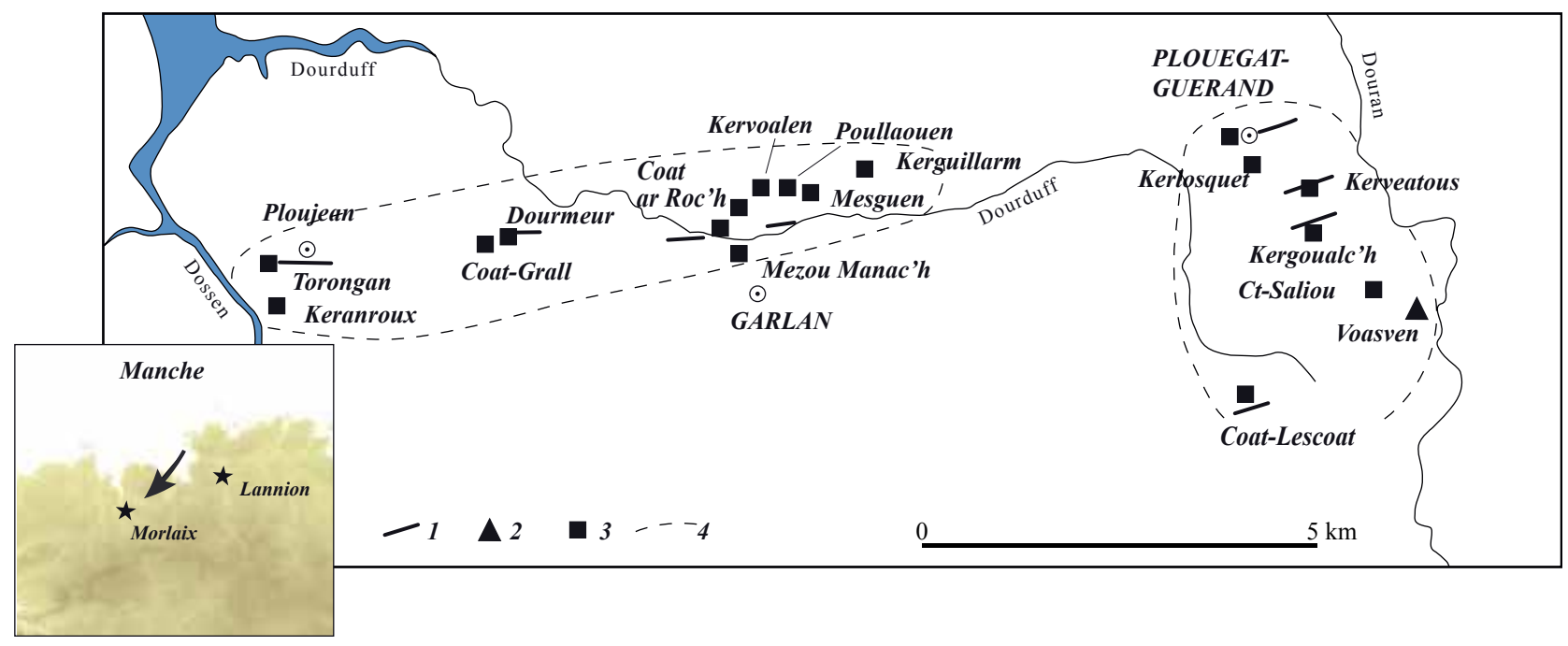

Figure 17 : Le microgranite de Ploujean et son utilisation.

Figure 17: Ploujean microgranite.

1 : filon de microgranite ; 2 : pointement de Voasven ; 3 : construction avec microgranite ; 4 : limite approximative d'emploi du microgranite. Les constructions ayant fait appel au microgranite reflètent étroitement les zones d'affleurement de la roche : dans la partie occidentale, une bande allongée d'ouest en est, parallèle à la direction de la structure filonienne ; dans la partie orientale une sorte d'ellipse, également dans la zone de dissémination des occurrences microgrenues. 
cristaux feldspathiques quelquefois plus ou moins alignés. Les puits ont pu aussi faire appel pour partie au microgranite, ainsi dans la cour du château de Coat-ar-Roc'h; il en est de même à Mezou Braz (en Garlan).

Or le microgranite de Ploujean, essentiellement utilisé comme on vient de le voir dans des constructions rurales souvent assez frustes, est susceptible de prendre un excellent poli. Et du fait de l'élégant contraste entre les clairs phénocristaux feldspathiques automorphes et le sombre fond à grain très fin, il peut alors se hisser au niveau d'une roche de qualité ornementale! C'est justement cette aptitude qui avait jadis attiré l'attention du comte de La Fruglaye lors de ses investigations sur les ressources du sous-sol trégorrois. Selon E. de Fourcy (1844a), ce zélé collectionneur des roches bretonnes l'avait employé avec succès pour pendule et cheminée. C. Barrois (1886b) croit d'ailleurs savoir que la roche de Kéranroux avait été dénommée "fruglite ".

\section{Microgranite de Loguivy}

À Loguivy en Ploubazlanec, près de l'embouchure du Trieux (Côtes-d'Armor), des microgranites recoupent la granodiorite du batholite nord-trégorrois; ils se présentent soit en filons, soit en petits massifs. Ils montrent une coloration violacée à rouge brique; à leur bordure, leur texture devient aphanitique et la teinte vire au noir.

Remontant au Néolithique final, l'allée couverte de Mélus (Ploubazlanec) a été classée Monument historique en 1951. Longue de plus de $14 \mathrm{~m}$, sa chambre à entrée latérale montre douze et dix blocs dressés en vis-à-vis (orthostates) soutenant neuf dalles de couverture (Giot, 1995; L'Helgouac'h, 1965, p. 227-232). Lithologiquement, elle est caractérisée par le large emploi du microgranite local, de teinte sombre, auquel s'adjoint la granodiorite, également proximale. Le monument apparait ainsi comme une émanation directe de son sous-sol.

Dans les constructions locales, ces microgranites ont été essentiellement utilisés en moellons par suite des difficultés de façonnement (Chauris, 2013c); en voici quelques exemples, tous en Ploubazlanec. Pour les édifices religieux, citons la chapelle de Lannevez (XviII ${ }^{e}$ s.) où il est associé avec spilite, granodiorite et granite de l'île Grande, ainsi que l'ancienne chapelle de Loguivy (1759) avec granodiorite et spilite; dans la nouvelle chapelle (1938-1939), les pierres de taille sont en granite rougeâtre de La Clarté (massif de Ploumanac'h), les moellons des élévations en microgranite gris sombre à rouge brique et en granodiorite. Dans le passé, l'habitat a fait largement appel à ce microgranite qui pouvait livrer avec surabondance des moellons très résistants; son emploi se caractérise par l'hétérométrie accusée des éléments, leur taille éclatée et leur teinte sombre, le plus souvent dans les tonalités rougeâtres. Dans le port de Loguivy, les cales (deuxième partie du $\mathrm{XIX}^{\mathrm{e}} \mathrm{s}$.) ont été exécutées en granodiorite et en microgranite.

\section{Microgranite de Châtelaudren}

Cette formation a été cartographiée pour la première fois avec précision, par C. Barrois (1896); un siècle plus tard, la même roche a été figurée sur les cartes géologiques à $1 / 50000$ (Egal, 1999). Son trait le plus apparent est la présence, dans le fond aphanitique, de grands cristaux de feldspath potassique (orthose), souvent de $1-2 \mathrm{~cm}$, parfois même de $5 \mathrm{~cm}$. Ces phénocristaux sont automorphes; de teinte claire, à tendance rosée, ils laissent parfois apparaître une texture zonée. Les phénocristaux quartzeux sont beaucoup moins développés. La matrice interstitielle présente des nuances variées : gris-bleuté quand elle est saine, beige à ocre-rouge quand elle est altérée, ce qui est de loin le cas le plus fréquent. Les diaclases qui affectent la roche ont une patine brunâtre due à la circulation des eaux ferrugineuses superficielles.

Sur le terrain, ces microgranites dessinent un impressionnant champ filonien (au total, plusieurs dizaines de filons se relayant plus ou moins régulièrement), s'étendant sur une vingtaine de kilomètres, selon une direction d'ensemble approximative nord-nord-ouest - sud-sudest; la largeur maximale du champ est d'environ 7-8 km (fig. 18). La puissance des filons va de l'ordre du mètre à une dizaine de mètres, voire plus. Par suite de leur dureté, les microgranites apparaissent parfois légèrement en relief au sein des terrains encaissants, moins résistants. Dans les terres cultivées, leur passage est jalonné de "pierres volantes " qui ont pu être utilisées telles quelles dans les murettes (Chauris, 2006). Dans les constructions, les occurrences sont multiples.

\section{Églises paroissiales}

À Châtelaudren (début du xvıII ${ }^{\mathrm{e}}$ s.), les moellons microgranitiques, souvent de fortes dimensions et de façonnement médiocre, sont associés à des pegmatitesaplites, des dolérites vert-noirâtre, ainsi qu'à des brèches ferrugineuses connues sous l'appellation de "pierre des landes" (Chauris, 2010f; 2018a). Les pierres de taille sont en granite porphyroïde - selon toute probabilité en provenance du massif de Quintin qui affleure largement plus au sud. À Goudelin apparaît un net contraste entre la partie ancienne de l'édifice, où " tuffeau vert ", pegmatite à mica palmé et granite fin gris à enclaves sont associés au microgranite, et la partie récente qui a fait appel au lointain granite de l'île Grande. À Plouagat (reconstruite au $\mathrm{XVIII}^{\mathrm{e}}$ s.), le microgranite (avec dolérite) se note dans 


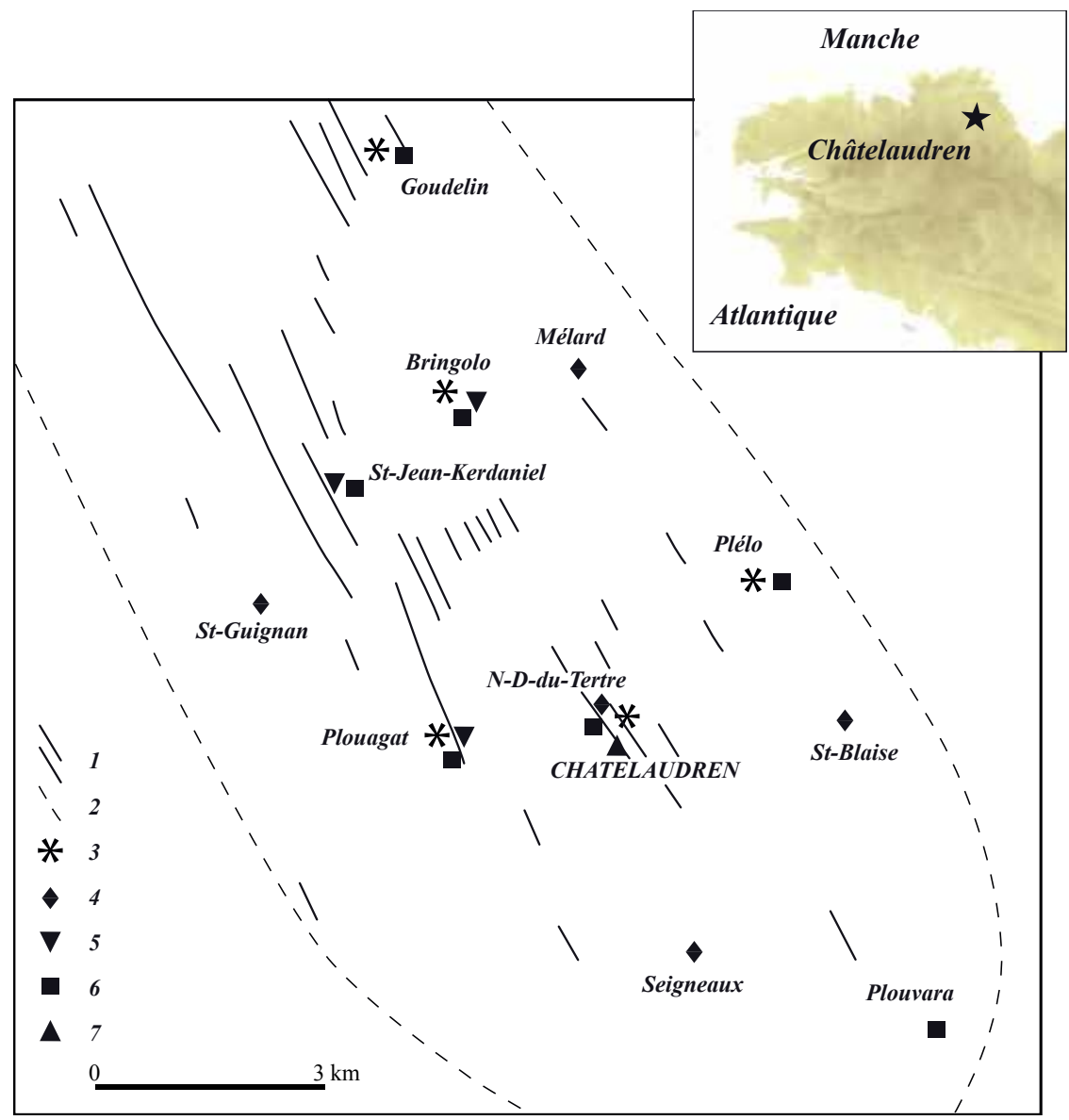

Figure 18: Esquisse du champ filonien microgranitique de Châtelaudren (d'après Barrois, 1896) et constructions ayant fait appel au microgranite.

Figure 18: Sketch map of the microgranitic Chatelaudren seamfield (after Barrois, 1896) and of buildings using microranite.

1 : filons de microgranite ; 2 : limite approximative du champ filonien ; 3 : église paroissiale ; 4 : chapelle; 5 : murette d'enclos; 6 : habitat; 7 : divers.

1: sills; 2: approximate limit of the seamfield; 3: parish church; 4: chapel; 5: enclosing wall; 6: habitat; 7: miscellaneous. l'élévation méridionale, ainsi que dans la murette de l'enclos. À Plouvara, le chevet montre aussi microgranite et dolérite; l'élévation méridionale également (mais avec en plus le granite porphyroïde de Quintin). Le portail occidental, plus récent, est en granite de Saint-Brieuc; la porte sud, également en granite de Saint-Brieuc, est surmontée d'un blason en kersanton noir de la rade de Brest. À Bringolo, le microgranite apparaît dans le transept et la sacristie, ainsi que dans le mur de l'enclos; à Saint-JeanKerdaniel, en moellons dans le mur de l'enclos. À Plélo, il constitue également des moellons dans l'église (dont les élévations sont crépies); le soubassement est en granite de Saint-Brieuc.

\section{Chapelles}

Notre-Dame-du-Tertre, aux abords de Châtelaudren, est un superbe édifice remontant pour partie au début du $\mathrm{XIV}^{\mathrm{e}} \mathrm{s}$. mais presque entièrement reconstruit au début du $\mathrm{Xv}^{\mathrm{e}}$ et modifié à la fin du $\mathrm{Xv}^{\mathrm{e}}$; il est typiquement polylithique (porche ouest) avec mise en œuvre d'un granite gris à petites enclaves; moellons des élévations en microgranite, en pegmatite-aplite...). À Saint-Blaise, en Plélo (xIv et $\mathrm{XVIII}^{\mathrm{e}} \mathrm{s}$.), le microgranite forme pierres d'angle, porte cin- trée, contrefort du pignon est - avec " pierre des landes " (Chauris, 2010f); les élévations associent des moellons de pegmatite, "pierre des landes » et microgranite. Aux Seigneaux en Plouvara, au Mélard (ENE de Bringolo), à Saint-Guignan (SSW de Saint-Jean-Kerdaniel), les moellons sont pour partie microgranitiques...

\section{Habitat}

C'est à Châtelaudren que se rencontre le plus grand nombre de maisons ayant fait appel au microgranite, employé comme moellons en association avec des gabbros vert sombre (les pierres de taille des encadrements sont en granites de Quintin et de Saint-Brieuc). Le même microgranite a été utilisé aussi pour l'habitat à Plouagat, (avec amphibolite, pegmatite, dolérite); de même à Plouvara, Goudelin, Bringolo, Saint-Jean-Kerdaniel, Plélo... Son utilisation en pierre de taille reste exceptionnelle (près de Notre-Dame du Tertre).

\section{Divers}

À Châtelaudren, on trouve le microgranite en pavés sur les trottoirs, dans les caniveaux près de Notre-Dame du Tertre, en remploi comme bordures de parterre ou 
marches d'escalier vers l'étang, dans des murs de soutènement...

Les prospections effectuées non seulement dans toute la zone occupée par le champ filonien microgranitique, mais aussi bien au-delà, permettent de formuler quelques remarques : a) L'utilisation est strictement locale : tout le bâti concerné est à l'intérieur de l'ellipse limitant le champ filonien; toutefois, à l'entrée de l'allée conduisant au château de la Roche-Jagu, un pavage récent a utilisé différentes roches en remploi, entre autres, le microgranite de Châtelaudren. b) L'emploi est essentiellement en moellons, souvent hétérogènes et de façonnement peu élaboré; dans certaines conditions, on a toutefois pu obtenir de bons pavés, exceptionnellement des pierres de taille. c) L'association avec d'autres roches, également en moellons, est fréquente; l'église de Châtelaudren en fournit un excellent exemple, mais aussi l'habitat à Plouagat. Le manoir de La Ville-Andon, près de Plélo, montre un polylithisme exacerbé; en sus du microgranite, granite de Quintin, gabbro, pegmatite, quartz, " pierre des landes "... d) La mise en œuvre de ce microgranite est relativement ancienne comme l'atteste, entre autres, son absence dans les édifices religieux récents.

\section{Microgranite de Pléneuf-Val-André}

Dans l'est de la baie de Saint-Brieuc, l'îlot du Verdelet et la pointe de Pléneuf sont constitués par une roche magmatique intrusive, naguère dénommée " microgranulite basique » et à présent " microtrondhjémite »; pour simplifier, elle sera dénommée ici " microgranite». Elle présente une texture massive, microgrenue porphyrique, avec phénocristaux de feldspath clair dans un fond gris sombre devenant brunâtre par altération météorique. Son intrusion est antérieure au début des temps paléozoïques.

Ce microgranite a été très exploité dans le passé et les anciennes carrières sont encore bien visibles (Chauris, 2013b). L'homogénéité de la pierre et surtout un débit naturel en bancs entre diaclases favorisaient son extraction; par ailleurs, sur le littoral, les affleurements étaient débarrassés de leur manteau d'altérites. Au Verdelet, l'embarquement de la production était facilité par un petit port d'échouage (Le Gal La Salle, 1994). À la pointe de Pléneuf, le percement spectaculaire d'un chemin côtier a fourni de nombreuses pierres de bonne qualité. Des exploitations étaient également ouvertes sur les hauteurs de Piégu (où une " Rue des Carrières " atteste encore leur existence passée), ainsi que sur la bordure septentrionale de l'avenue Jean-Richepin et de la rue des Pêcheurs.

La roche a été utilisée comme moellons au bourg de Pléneuf pour l'habitat auquel il confère par ses nuances brunâtres un peu tristes à l'aspect très caractéristique; il en est de même avenue Richepin, rue des Pêcheurs... Elle est parfois associée avec le grès d'Erquy. Elle a été également employée pour les travaux publics (moellons du parapet de la jetée de Piégu vers les années 1930; cale d'accès à la plage des Vallées).

\section{Aux environs de Bais (Ille-et-Vilaine)}

La carte géologique à $1 / 80000$ "Laval " $2^{\text {e édition }}$ (Milon, 1960) montre, dans son secteur sud-ouest, la présence de nombreux filons intrusifs dans les formations schistogréseuses du Briovérien, qualifiés du terme aujourd'hui obsolète de " microgranulite ", sans autres commentaires. Il s'agit le plus souvent de " microdiorite quartzique " dont les filons présentent diverses directions. Par souci de simplification, le terme plus général de microgranite sera ici conservé (fig. 19; Chauris, 2016a).

La roche est immédiatement identifiable par sa nuance jaunâtre dont la luminosité est comme renforcée par la fréquence des cernes subconcentriques brunâtres d'hydroxyde de fer. Ceux-ci, aux contours parfois capricieux, lui confèrent un effet décoratif rappelant le microgranite de Logonna (voir supra). La partie centrale, non altérée, de certaines pierres est grisâtre. Ce microgranite présente deux faciès principaux : l'un, porphyrique, où les phénocristaux feldspathiques, nettement visibles à l'œil nu, sont disséminés dans une mésostase très fine; l'autre, aphanitique, où les cristaux ne sont guère discernables.

Affleurant comme indiqué dans une région essentiellement schistogréseuse, ces microgranites ont été exploités très tôt; ils pouvaient livrer non seulement des moellons avec surabondance, mais aussi des pierres de taille voire même des éléments aptes à la sculpture (Meuret, 2011). Toutefois, à l'inverse de la roche de Logonna, ils présentaient parfois deux handicaps : leur hétérogénéité et surtout leur friabilité, se traduisant par l'érosion en creux, la desquamation et la fissuration. Dans le passé, ils étaient extraits de nombreuses petites carrières : à la Templerie (La Guerche), Carcraon (Domalain), à proximité du bourg de Moutiers, à la Mare (Moulins), la Cornouaille (Visseiche)... Aujourd'hui, à Louvigné-de-Bais, l'immense carrière exploitée par le groupe Pigeon pour l'obtention de granulats à partir des cornéennes siltogréseuses briovériennes, a atteint, en profondeur le microgranite.

\section{Églises}

L'examen de nombreuses églises situées dans la région de Bais illustre remarquablement l'engouement de naguère pour cette pierre, le plus souvent toutefois associée à d'autres roches. À Bais, les colonnettes en microgranite du porche, sous le clocher, sont localement très 


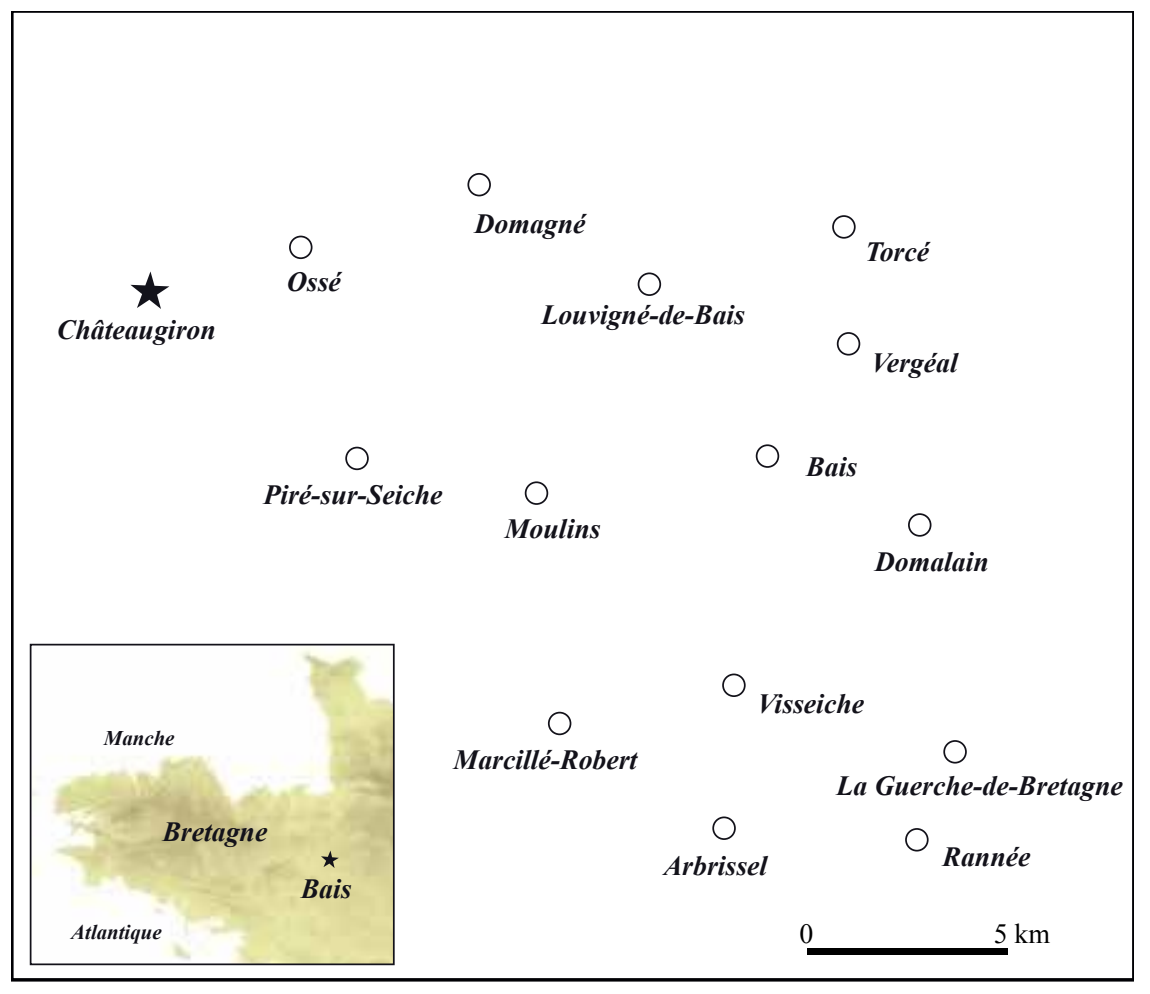

Figure 19: Mise en œuvre du microgranite du district de Bais (Ille-et-Vilaine), intrusif dans briovérien en blanc.

Figure 19: Use of microgranit in the Bais district (dept Ille-et-Vilaine), intruded in the brioverian in white. érodées; dans l'élévation, la pierre, en éléments assisés, est souvent altérée en creux sur plusieurs centimètres. À Visseiche, le portail de la façade du clocher est accosté de deux colonnes au motif basal sculpté. À Moulins, les phénocristaux, nombreux, atteignent jusqu'à $1 \mathrm{~cm}$; on les observe sur un bandeau mouluré, une baie en plein cintre, une petite porte latérale en anse de panier ou le portail méridional (dont certaines pierres présentent des cernes particulièrement bien développées). À notre connaissance, c'est à Domalain que s'élève le plus grand édifice religieux ayant mis en œuvre ce microgranite, avec élévations en pierres de taille assisées ou en moellons, contreforts, portes (dont l'une avec de nombreuses sculptures). Louvigné-de-Bais montre aussi une large utilisation du microgranite : portail, élévation méridionale (y compris le bandeau mouluré), porte latérale sud, chevet...

Plusieurs églises sont nettement polylithiques. Celle de La Guerche-de-Bretagne a été transformée dans la seconde partie du XIX ${ }^{e}$ s. par l'architecte Arthur Regnault (Andrieux, 2011); on y note du granite mancellien et du calcaire de Caen; l'altération du microgranite suggère que ces pierres remontent aux parties anciennes de l'édifice. À Ossé, se notent des schistes bleu-noir (paléozoïques?) en moellons; quelques microgranites sont employés en chaînage d'angle et en contrefort. L'église de Vergéal est en grande partie crépie mais les marches d'accès sont en granite mancellien, les contreforts associent microgranite et schiste, le soubassement est en moellons microgranitiques. À Torcé, la partie ancienne associe microgranite et "pierre des landes »; dans les parties plus récentes, le soubassement est en granite mancellien et la porte latérale en calcaire (probablement de Caen). L'église de Domagné est elle aussi nettement polylithique : microgranite pour partie dans les châ̂nages d'angle, contreforts, élévations; granite mancellien pour le soubassement; calcaire jaunâtre (de Caen?) pour le portail occidental. À Marcillé-Robert, où les chaînes d'angle sont en granite mancellien, large appel a été fait aux pierres locales, en particulier au grès vert briovérien mais aussi au microgranite et même à la " pierre des landes ". À Rannée, on note une large utilisation $\mathrm{du}$ microgranite, entre autres pour plusieurs portes; la présence locale de quelques "pierres des landes " dans les contreforts est en bon accord avec l'ancienneté de l'édifice (remontant pour partie au XII ${ }^{\mathrm{e}}$ s., avec agrandissement au XVI ${ }^{\mathrm{e}}$ ). Dans l'église d'Arbrissel, rapportée aux $\mathrm{XII}^{\mathrm{e}}$ et $\mathrm{XVI}^{\mathrm{e}}$ s., quelques éléments du portail en microgranite, assez altéré, ont été remplacés par un calcaire jaunâtre (de Caen?), laissant soupçonner, chez les restaurateurs, une méconnaissance de la belle pierre jaune du terroir... À Piré-sur-Seiche, le polylithisme s'exacerbe : grès verdâtre briovérien, schistes gréseux également briovériens (présentant parfois des cernes brunâtres subconcentriques assez comparables à ceux qui affectent le microgranite), schistes durs esquilleux (paléozoïques?), granite mancellien, "pierre des landes ", tuffeau du Val de Loire et microgranite local (par endroits superbement sculpté). 


\section{Habitat}

Dans l'habitat, le microgranite jaune a été utilisé un peu partout autour de ses sites d'extraction, généralement ici encore en association avec d'autres roches; quelques exemples, parmi bien d'autres, seront rapidement évoqués. À Piré-sur-Seiche, sur la place, près de l'église, une maison $\left(n^{\circ} 1\right)$ présente une porte au cintre surbaissé avec accolade; les moellons, hétérométriques, ont fait appel au même matériau. À Moulins, dans certaines demeures, le microgranite est associé aux schistes gréseux du Briovérien. À Bais, l'habitat a utilisé ces deux pierres proximales : ainsi, " au Vieux-Porche", nombreux petits moellons microgranitiques et rares moellons schistogréseux. À Visseiche apparaissent pierres de taille et moellons. À Louvigné-deBais, pierres de taille en granite mancellien s'associent aux moellons en microgranite. À Châteaugiron, promenade Saint-Julien, l'association est avec des moellons briovériens. Dans la forteresse médiévale de cette localité, le microgranite a été mis en œuvre avec parcimonie; par contre, dans le bâtiment du XviII ${ }^{\mathrm{e}}$ s., cette roche a été largement employée en beaux moellons équarris, associés à des pierres de taille en granite mancellien.

Ces mentions succinctes illustrent l'utilisation d'une pierre originale, naguère très recherchée et à présent bien oubliée si ce n'est auprès de quelques érudits. Sa méconnaissance est telle aujourd'hui que plusieurs auteurs la qualifient de " grès »!

\section{Deux provenances énigmatiques}

Parfois, les constructions révèlent l'utilisation d'un microgranite dont la proximité ne fait aucun doute mais dont le gisement a, jusqu'à ce jour, échappé à la sagacité des géologues. Ainsi, à Trévou-Tréguignec (Côtesd'Armor), l'église, en sus des granites distaux de l'île Grande et de la granodiorite locale, a mis en ouvre des moellons d'un microgranite assez nettement porphyrique.

Le cas de Saint-Étienne-du-Gué-de-l'Isle, également dans les Côtes-d'Armor, est encore plus curieux (Chauris et Minor, 2012). Le visiteur qui s'arrête à l'église ne peut qu'être frappé par la beauté, mieux la luminosité de la porte méridionale, dont le façonnement contraste vivement avec les frustes et sombres moellons schisteux de l'élévation voisine. Il repère la même pierre dans les murs sud et nord avec les schistes, en chaînage d'angle du transept, mais aussi en bandeau dans la façade méridionale et, au moins en partie, dans les baies du chevet, dans des ouvertures de l'élévation septentrionale... En l'occurrence, il s'agit d'un microgranite aphanitique, de teinte blanche à légère nuance beige avec développement de quelques cernes d'hydroxyde de fer, à texture équante, sans litage.
Dans un fond à grain très fin (quelques dixièmes de millimètre) apparaissent à la loupe des quartz de teinte gris gros-sel, des cristaux de feldspaths automorphes millimétriques, de minuscules muscovites et parfois de petites lamelles de biotite.

Cette belle pierre a été aussi utilisée dans le manoir du Grand Bocmé (porte cintrée...), dans une demeure au Gas du Bois, au Petit Bocmé (en récupération d'un manoir ruiné), au Linio (porte cintrée d'une longère), dans de vieux murs au bourg, très rarement, au château du Gué-de-l'Isle. Toutefois, c'est pour la construction du bâtiment qui abrite la mairie que ce microgranite a été employé avec surabondance, tant pour la façade en beaux moellons régulièrement assisés que sur le pignon en médiocres moellons hétérométriques.

La provenance de ce microgranite pose problème. N'eût-il été utilisé qu'en éléments ouvragés comme la porte de l'église ou au manoir du Grand Bocmé, il eût été possible d'envisager un site d'extraction éloigné autrefois réputé pour la qualité de ses pierres. Mais l'emploi de ce matériau également en moellons, et qui plus est avec surabondance comme pour le bâtiment de la mairie, oblige à abandonner une telle hypothèse. Au cours de nos enquêtes, plusieurs personnes, interrogées indépendamment, nous ont toutes affirmé que cette pierre - dont par ailleurs elles ignoraient la nature exacte - avait été extraite au lieu-dit le Guindard, un peu au sud du bourg. Sans doute, avons-nous mal prospecté : la carrière n'a pu être retrouvée... Toujours est-il que, sur une carte, les constructions concernées se répartissent à l'intérieur d'une sorte d'ellipse dont l'un des foyers serait approximativement situé au Guindard (fig. 20). Tout semble donc indiquer la réalité de cette provenance.

\section{LES QUARTZ FILONIENS}

Les terrains anciens de Bretagne sont recoupés par d'innombrables filons de quartz cicatrisant des failles. Certains s'étirent sur plusieurs dizaines de kilomètres telle la gigantesque structure jalonnant pour partie le linéament sud-armoricain (Chauris, 2012a) ou encore la zone silicifiée Moustéru - Saint-Julien dans les Côtes-d'Armor, élément du linéament médio-armoricain (Chauris, 1970); d'autres sont d'extension restreinte, de l'ordre de quelques dizaines de mètres seulement. Par suite de leur dureté entraînant leur résistance à l'érosion, ces filons arment fréquemment des reliefs : le mont Garreau dominant la Rance à Saint-Suliac (Ille-et-Vilaine), le Grinec hérissant le granite de Plounéour-Ménez (Finistère)... En fait, le long de leur tracé, les filons quartzeux sont décelés le plus souvent par des blocs épars à la surface du sol; il n'est pas jusqu’à la végétation : «Quenequelen »-le Tertre du 


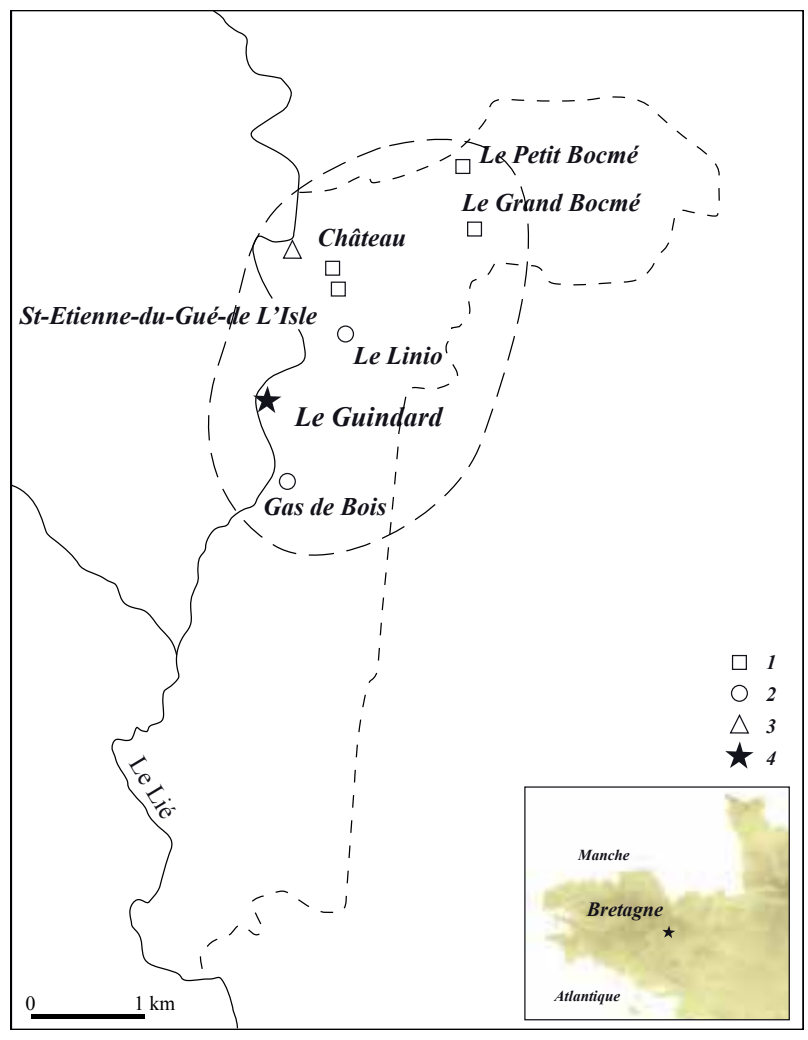

Figure 20 : Saint-Étienne-du-Gué-de-l'Isle (Côtes-d'Armor) : mise en œuvre du microgranite dit « du Guindard ».

Figure 20: Saint-Étienne-du-Gué-de-l'Isle (dept Côtes-d'Armor): utilization of the so-called "Guindard" microgranite.

1 : emploi important ; 2 : fréquent ; 3 : rare. 4 : position présumée de la carrière du Guindard.

1: important; 2: common; 3: rare; 4: presumed position of Guindard quarry.

Houx, en Plougonver - voire la toponymie (la commune de Guenroc) - pour les signaler...

Dans ces conditions, rien d'étonnant à ce que ces masses, par surcroît blanchâtres, aient été repérées par les Néolithiques pour former des alignements mégalithiques (Giot, 1995). L’un des plus célèbres était celui de Landaoudec en Crozon, qui avait naguère émerveillé Bachelot de La Pylaie (1850, p. 26-76) mais qui est aujourd'hui bien délabré, les éléments ayant été remployés lors de la construction du fort de ce nom ou remisés en bordure des parcelles par les agriculteurs; le quartz de Landaoudec est fréquemment cristallisé en rosaces qui contribuent à son esthétique (Chauris et Cadiou, 2000). Un autre alignement regroupant encore une soixantaine de pierres est situé au lieu-dit le Champ des Roches en Pleslin-Trigavou (Côtes-d'Armor); ici aussi le quartz offre parfois une texture rayonnée. Dans les alignements de Cojoux en Saint-Just (Ille-et-Vilaine), plusieurs menhirs sont en quartz, parfois intensément tectonisé (mais la confusion visuelle y reste possible avec d'autres en
À Kerprigent en Saint-Jean-du-Doigt (Finistère), un très probable alignement est à présent démantelé; un seul menhir y est encore dressé (Chauris et Sparfel, 2013). À Penvins en Sarzeau (Morbihan), tout suggère aussi qu'il y avait initialement plusieurs menhirs (Chauris, 2009c).

Plus fréquemment, ces menhirs de quartz semblent isolés. Parmi bien d'autres, citons ici, encore en presqu'île de Rhuys, Cohporh en Sarzeau (environ 3,5 m), très massif et dépourvu de tout façonnement ou, côté Locmariaquer, la Pierre Jaune, informe mais offrant de belles structures zonées. À Coisbrac en Nozay (Loire-Atlantique), l'érection d'un menhir quartzeux étonne quelque peu dans un terroir où des "schistes à barrettes » livrant des éléments très allongés et de fortes dimensions étaient susceptibles d'attirer les Néolithiques (Chauris, 2010d). À Chablé en SaintSuliac (Ille-et-Vilaine), la " Dent de Gargantua » subit, à la faveur des fissures qui l'affectent, le décollement puis la chute de gros éléments. À Kerescant en Spézet (Finistère), le menhir surprend par sa blancheur et son aspect quasimarmoréen. Par ailleurs, contrairement à ce que pensaient leurs découvreurs (Devoir et Morel, inédit), les menhirs de Kereven en Locmaria-Plouzané (Finistère) ne sont pas en quartzite, mais en quartz (Sparfel et Chauris, 2009b).

Les autres types de monuments mégalithiques ayant mis en œuvre le quartz sont beaucoup plus rares. Bien que mutilée, l'allée couverte de Bot er Mohed en Cléguérec (Morbihan) frappe par ses dimensions encore imposantes (Gouézin, 1994, p. 51-52), mais plus encore par la variété des pierres recherchées : en sus du schiste bleu foncé dominant et du grès blanchâtre subordonné, tous deux d'âge ordovicien, apparaît aussi du quartz filonien, de teinte blanche (Chauris, 2010e). Pour mémoire, indiquons aussi qu'un bloc de quartz a été noté dans le cairn du Petit-Mont en Arzon (Chauris, 2009c). En Finistère, Pen ar Run en Telgruc est un exemple assez remarquable de dolmen en quartz.

En dépit de son façonnement difficile, le quartz a été recherché pour l'habitat ancien dans toutes les zones où affleurent des filons; en voici quelques exemples :

- au voisinage du champ filonien de Plougonver Gurunhel (Côtes-d'Armor), les vieilles constructions se font immédiatement remarquer par l'abondance du quartz dans les murs. Dans plusieurs cas, en particulier pour les fondations, les blocs ont été utilisés tels quels; ils ont été aussi employés en chaînage d'angle une fois grossièrement équarris, ou en moellons. Localement, les murs jouent le rôle d'un véritable muséum en plein air car, mieux que les affleurements en place, ils permettent d'étudier les diverses modalités texturales des filons. Quant à la carte des localisations, elle montre combien les plus fortes densités des constructions "quartzeuses " coïncident avec l'ampleur maximale du champ filonien; 
l'absence de villages dans les forêts de Coat-an-Noz et de Coat-an-Hay rend compte du "vide " à l'emplacement de celles-ci (Chauris et Garreau, 1991);

- à Saint-Suliac, le quartz du puissant filon déjà évoqué a été fréquemment recherché pour l'habitat, tant en gros blocs informes dans les soubassements qu'en moellons non équarris placés de manière aléatoire dans les élévations parmi les gneiss proximaux. Assez curieusement, ce même quartz a été mis en œuvre pour l'édification d'un oratoire; - à Saint-Étienne-du-Gué-de-l'Isle (Côtes-d'Armor), le quartz jaune joue un rôle majeur dans l'habitat rural. Dans plusieurs cas, les blocs ont été employés sans façonnement, pour servir de fondations (Pont Bréhan, Petit Bocmé, Le Linio); à Guerfrac, un tel bloc a été placé à la base même du chaînage d'angle; au vu de ses dimensions (longueur : $1,0 \mathrm{~m}$; largeur : $0,85 \mathrm{~m}$; hauteur : $0,75 \mathrm{~m}$ ), avec une densité de 2,65, la pierre atteint près de 1,7 t. Dans de nombreux bâtiments, les éléments quartzeux sont associés aux schistes encaissants des filons, le plus souvent de manière aléatoire (Le Grand Bocmé, Le Rocher, Guerfrac...). Mais dans quelques cas, comme au hameau du Gas du Bois, plusieurs bâtiments anciens montrent une alternance exceptionnellement réussie de quartz et de schiste; les moellons schisteux, sombres et de faibles dimensions, sont disposés en plusieurs assises successives tandis que les moellons quartzeux, clairs et plus volumineux, forment chaque fois une seule assise. Des modalités comparables ont été observées à La Ville Hervault et à La Ville Eslan. Cette fréquente utilisation du quartz dans l'habitat rural indique à l'évidence l'absence d'autres matériaux disponibles à proximité, si ce n'est de médiocres moellons schisteux. Et c'est justement cette pénurie qui a conduit ici à l'épanouissement de constructions témoignant d'une recherche esthétique indéniable (Chauris et Minor, 2012).

Dans le passé, le quartz filonien était très recherché pour l'empierrement des routes, du fait de sa résistance à l'écrasement et de son inaltérabilité. Aussi s'explique-t-on l'engouement privilégié des Ponts et Chaussées pour cette " pierre blanche " ("Dies albo notanda lapill"). Mais sa fragmentation en éclats coupants et abrasifs a conduit à son abandon avec l'arrivée des pneumatiques (Chauris, 2002a). Le quartz a pu aussi être extrait pour livrer des granulats très appréciés du fait de leur blancheur (carrière de Calzat en Inzinzac-Lochrist, ouverte dans le linéament sud-armoricain : Chauris, 2012a).

\section{ÉPILOGUE}

En s'apprêtant à mettre le point final de cette "Géoarchéologie du Patrimoine ", l'auteur, malgré de longs développements, est pleinement conscient du caractère incomplet de son travail : c'est que, comme la mer, la matière est ici inépuisable! Et, à l'évidence, les lecteurs attentifs ne manqueront pas d'en souligner les lacunes... Qu'il nous soit permis, avant qu'il ne soit trop tard, d'en signaler quelques-unes.

L'utilisation des roches pour objets mobiliers - outils dans la préhistoire mais aussi aux périodes plus récentes (les meules de moulins...) - serait un vaste domaine, mais hors de notre sujet axé sur les constructions (et de surcroît largement traité par les archéologues); de même nous avons dû éluder les usages industriels - parfois inattendus - qui ont pu être fait de certains matériaux.

Le lecteur aura remarqué que nous n'avons consacré aucun développement au Kersanton (la kersantite des géologues). C'est que cette roche célèbre entre toutes, notamment pour son usage dans la statuaire bretonne - et à laquelle nous avons fait maintes fois référence $-\mathrm{a}$ fait l'objet d'une publication spécifique (Chauris, 2010g); nous ne pouvons qu'y renvoyer. Nous avons dû aussi négliger certains matériaux à l'usage par trop restreint : microgranites d'Ouessant, de l'Aber Ildut, du Pouldu (CloharsCarnoët), de Servel (Lannion), de Cesson (Saint-Brieuc); albitophyres de la région brestoise (retrouvés notamment dans les parties anciennes du château)... Nous regrettons par contre d'avoir passé sous silence le bâti en pisé (la " terre » est une roche!), un matériau encore si fréquent dans des constructions, le plus souvent ruinées hélas, de certains secteurs (nord de l'Ille-et-Vilaine, est des Côtesd'Armor...) où la pierre se fait rare.

Peut-être aussi aurait-il fallu faire une plus large place à la toponymie et surtout à la microtoponymie, source de précieuses informations tant sur la localisation des anciennes carrières que sur la nature lithologique de l'habitat. Certes nous avons évoqué l'onomastique bretonne la plus courante (ainsi Ti Guen peut présumer d'un bâtiment en quartz blanc) mais, par exemple, le toponyme "Chiron " a été omis; il est vrai qu'il est surtout connu en Loire-Atlantique (ainsi qu'en Anjou et Poitou, au-delà de notre propos). Tout comme notre Cairn, ce terme, qui désigne un " tas de pierres ", dériverait d'une racine préceltique (kal/kar) évoquant la pierre, suivi par le suffixe de localisation " on ".

Un fort chapitre aurait pu aussi être écrit sur les pierres abandonnées... et récupérées. Le cas du château de Suscinio, en presqu'île de Rhuys, transformé en carrière avant sa restauration, est bien connu... mais, hélas, il est loin d'être le seul! Beaucoup plus récent, et d'une toute autre ampleur, est le problème des tombes "échues" (Chauris, 1994d). Les unes trouvent parfois un remploi original : à Roscoff, de belles dalles tumulaires couronnent un muret face à la mer. D'autres sont mises de côté par des marbriers conscients de leur valeur, mais combien finissent-elles à la décharge, destin dérisoire 
d'une « concession perpétuelle »... Plus attristant encore, car faisant preuve d'une inconscience totale, le rebut de superbes pierres de taille pour des enrochements, comme il nous a été donné de le constater à Brest près du parc aux Chaînes... Exceptionnellement, de belles pierres ouvragées sont sauvées in extremis du pic des démolisseurs, tel le péristyle de la caserne Fautras, remonté en bordure du boulevard Jean Moulin à Brest... Mais combien d'autres, fort somptueuses, sont aujourd'hui enfouies dans les remblais de la cité abolie? (Chauris, 2012b). Il eut aussi fallu insister sur les métiers de la pierre, tant dans les carrières que dans les ateliers de façonnage et dans les bâtiments, avec leurs fiertés, leurs accidents (Chauris, 2000b) mais aussi leurs grèves (Chauris, 2002a, 2002b, 2002c).

Notre fil conducteur aura été fondamentalement géologique mais regrouper les pierres selon leurs différentes aptitudes (pierres de taille, moellons, pavés, ardoises, granulats...) eût été une autre approche tout aussi légitime. Rassembler les diverses roches aptes à la sculpture - et la palette bretonne s'avère particulièrement remarquable (que l'on songe à la floraison de statues colossales en cours d'exécution pour la Vallée des saints à Carnoët) ou rappeler la présence en Bretagne de roches ornementales de grande classe - ce qu'avait déjà laissé percevoir, dans la première partie du XIX ${ }^{e}$ s., le comte de La Fruglaye (Chauris, 1994e) seraient autant de facettes d'une telle démarche.

Nous avons évoqué ici et là les difficultés rencontrées aujourd'hui lors des travaux de restauration du fait de l'abandon total de nombreuses carrières induisant trop souvent l'utilisation regrettable de matériaux de substitution. Laisser entrevoir l'engouement qui se manifeste de plus en plus pour la pierre est un autre aspect dont témoigne le succès rencontré par des expositions (Collectif, 1994) et lors des excursions (Chauris, 2013d). On peut aussi s'émerveiller devant la diffusion, non seulement régionale, mais aussi nationale, voire internationale, des granites bretons. Enfin, à l'heure des matériaux de synthèse triomphants, conclure en évoquant un «nouvel âge de la pierre " (Chauris, 1994f)... 


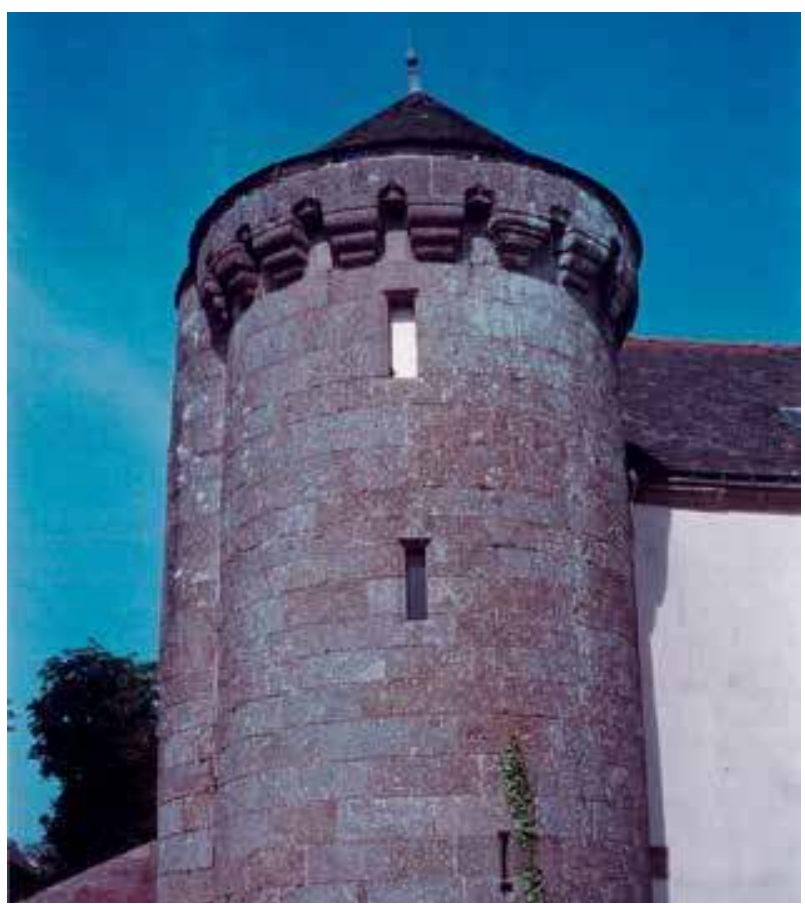

Photo I: Tour de Saint-Péran (Glomel), en granite de Rostrenen. (Cliché L. Chauris). Photo I: Saint Péran tower (Glomel); Rostrenen granite. (Photo L. Chauris).

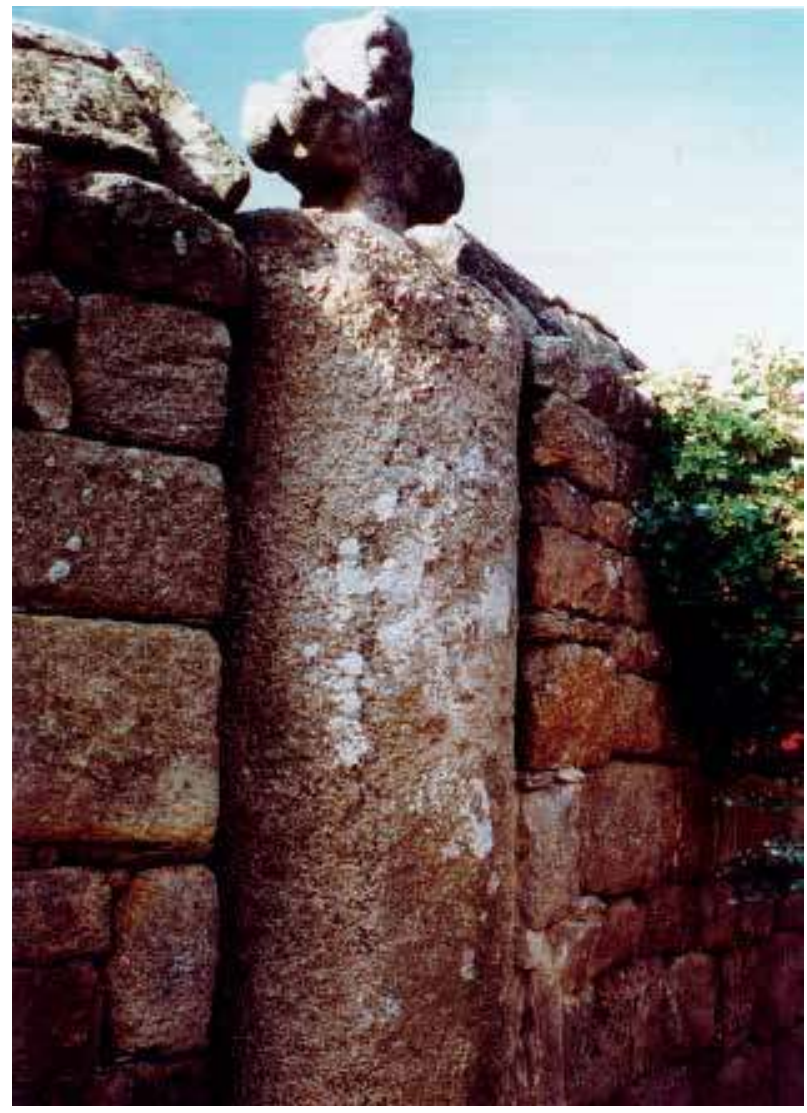

Photo II : Probable borne milliaire gallo-romaine christianisée en granite du Yaudet, à Ploulec'h. (Cliché L. Chauris).

Photo II: Probable Roman milestone at Ploulec'h; Yaudet granite. (Photo L. Chauris).

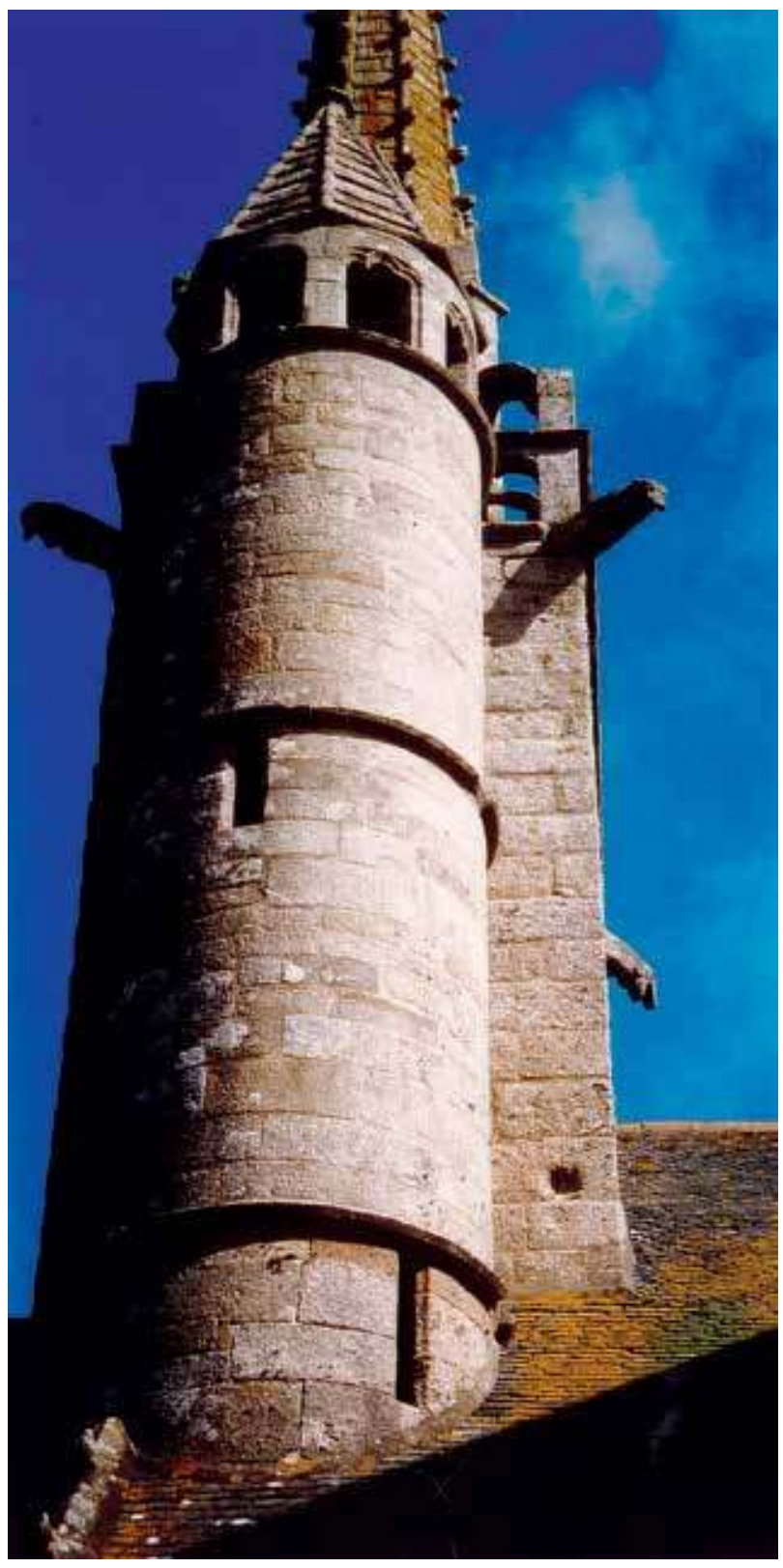

Photo III : Ploumilliau, tourelle du clocher de l'église : large appel au granite porphyroïde du Yaudet. (Cliché L. Chauris).

Photo III: Ploumilliau, turret of church bell-tower: wide-ranging use of porphyroid Yaudet granite. (Photo L. Chauris). 


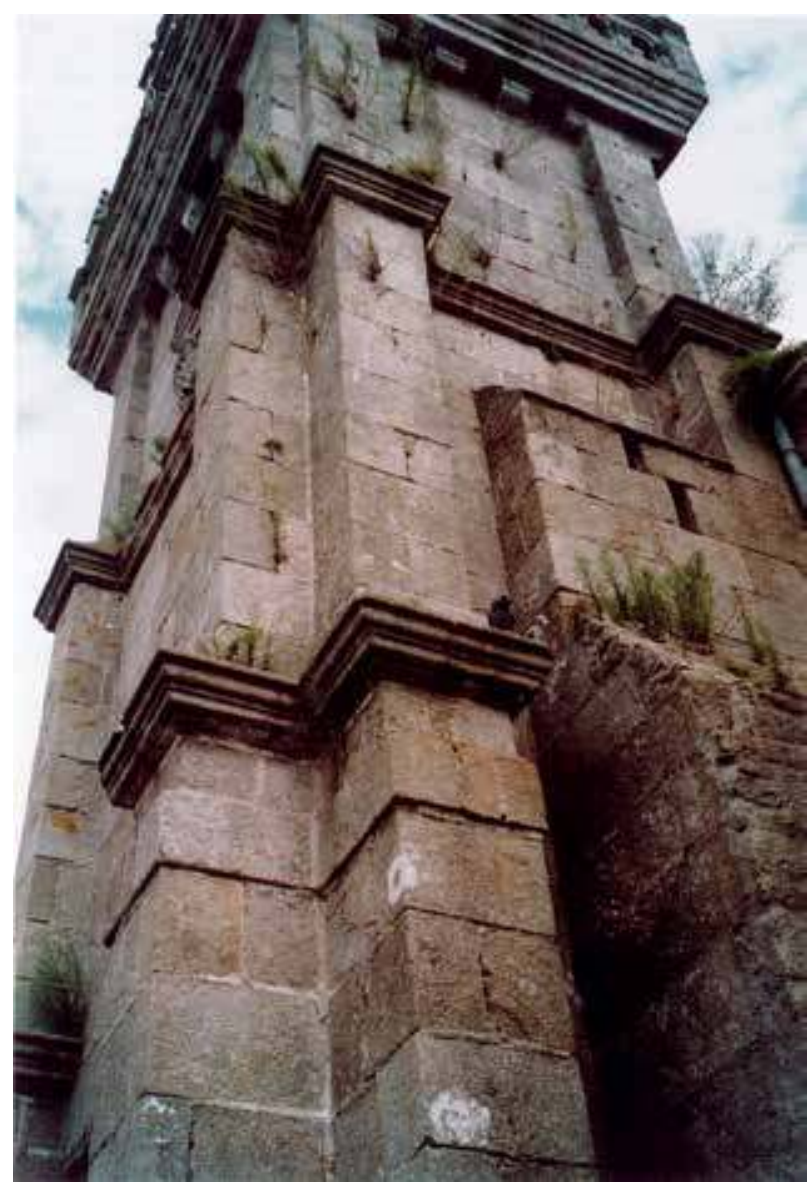

Photo IV : Église de Cléder. Contreforts de la tour en grands éléments façonnés dans le granite de Cléder. (Cliché L. Chauris).

Photo IV: Cléder church: tower buttresses, large pieces made from Cléder granite. (Photo L. Chauris).

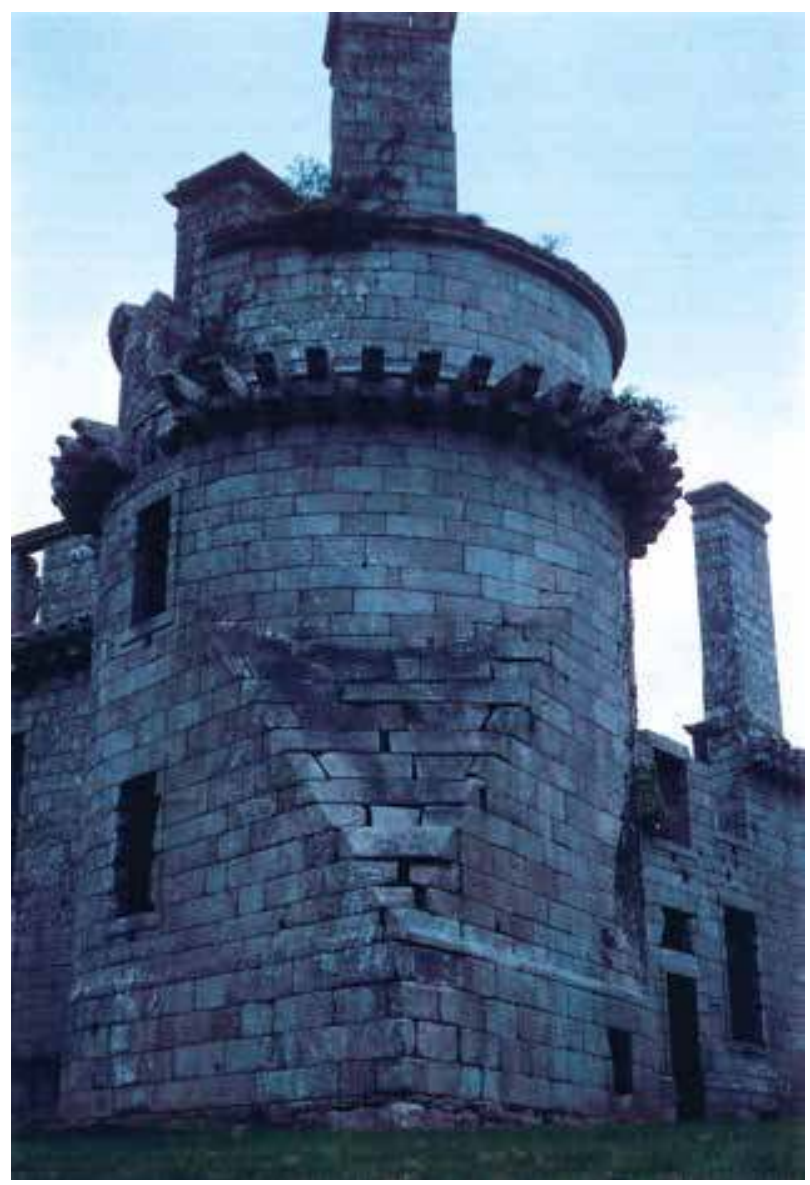

Photo V : À Cléder, le château ruiné de Kergornadéac'h ( $x V{ }^{i}{ }^{\mathrm{S}}$ s.) montre un très bel appareil en granite de Cléder. (Cliché L. Chauris).

Photo V: Ruined Kergornadéac'h castle (XVIth century) at Cléder: stone work of Cléder granite. (Photo L. Chauris).

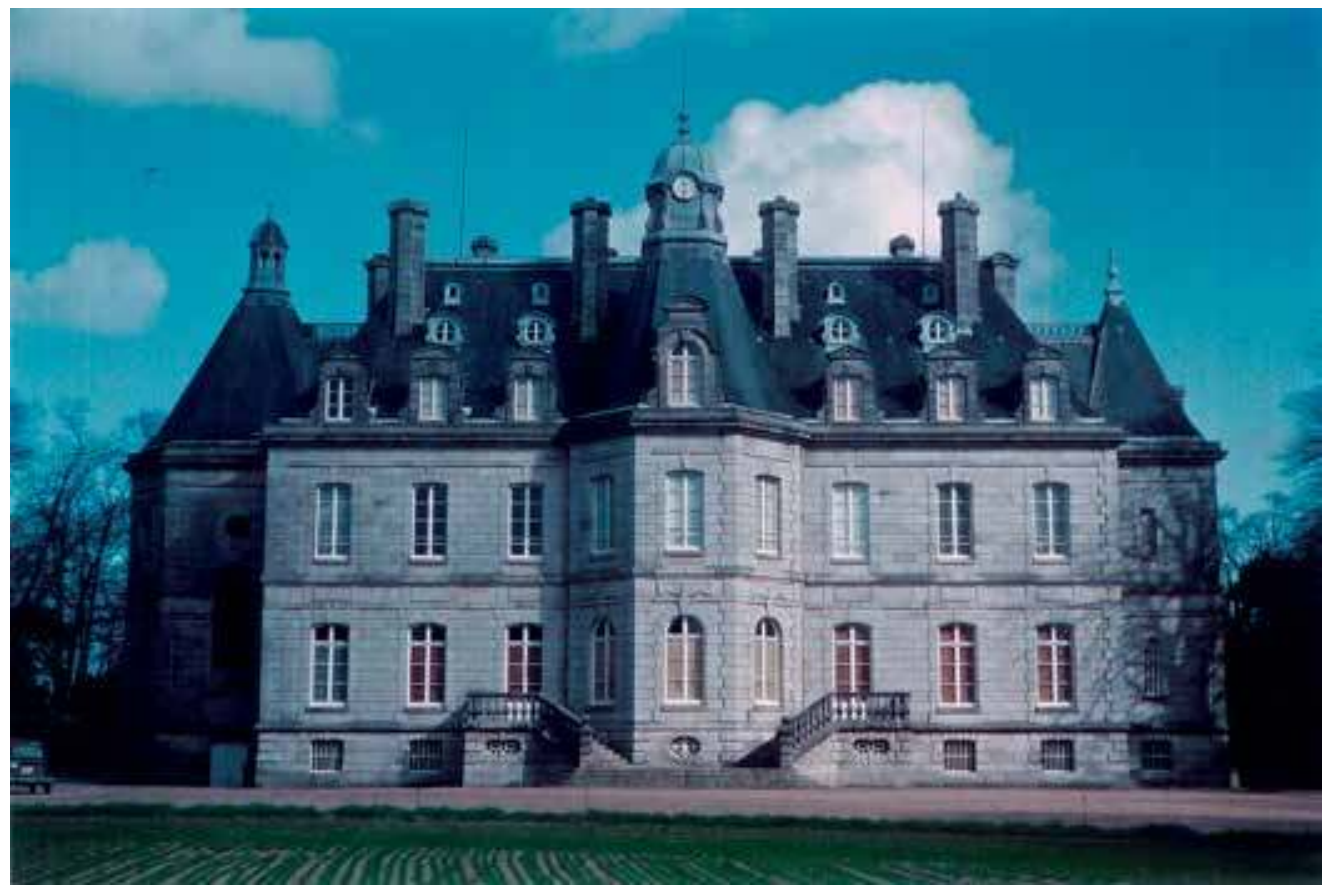

Photo VI : Château de Kernévez en Saint-Pol-deLéon : magistrale mise en œuvre du granite de Cléder au milieu du xIxe siècle. (Cliché L. Chauris).

Photo VI: Kernévez castle at Saint-Pol-de-Léon: masterly use of Cléder granite (mid-XIXth century). (Photo L. Chauris). 


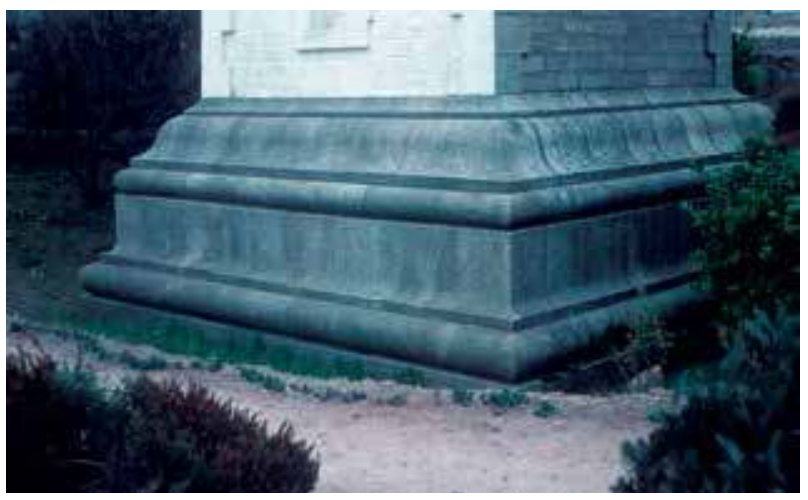

Photo VII : Soubassement du phare de Roscoff; superbes éléments moulurés en granite de Cléder. (Cliché L. Chauris).

Photo VII: Basement of Roscoff lighthouse: superbly moulded elements of Cléder granite. (Photo L. Chauris).

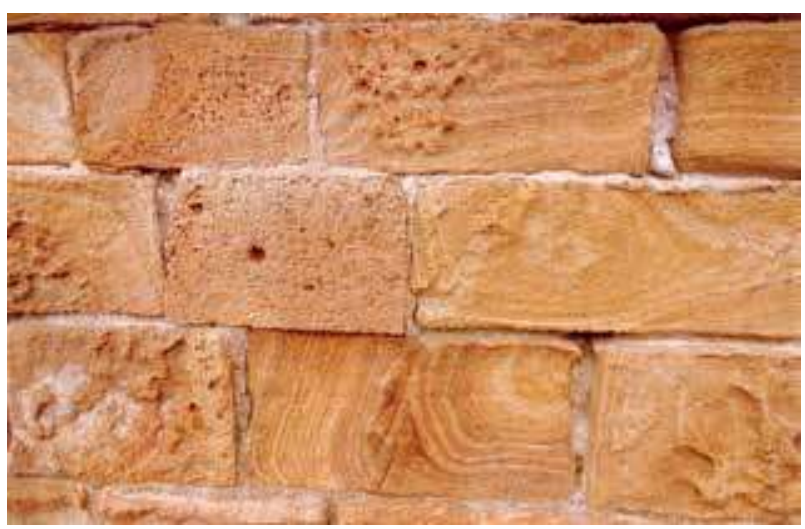

Photo VIII : Au chevet de la chapelle de Rocamadour à Camaret, la Pierre de Logonna, avec ses cernes caractéristiques, est « picorée » par l'altération. (Cliché L. Chauris).

Photo VIII: Camaret, chevet of Rocamadour chapel: « Logonna stone ", with its characteristic rings, is pecked by alteration. (Photo L. Chauris).

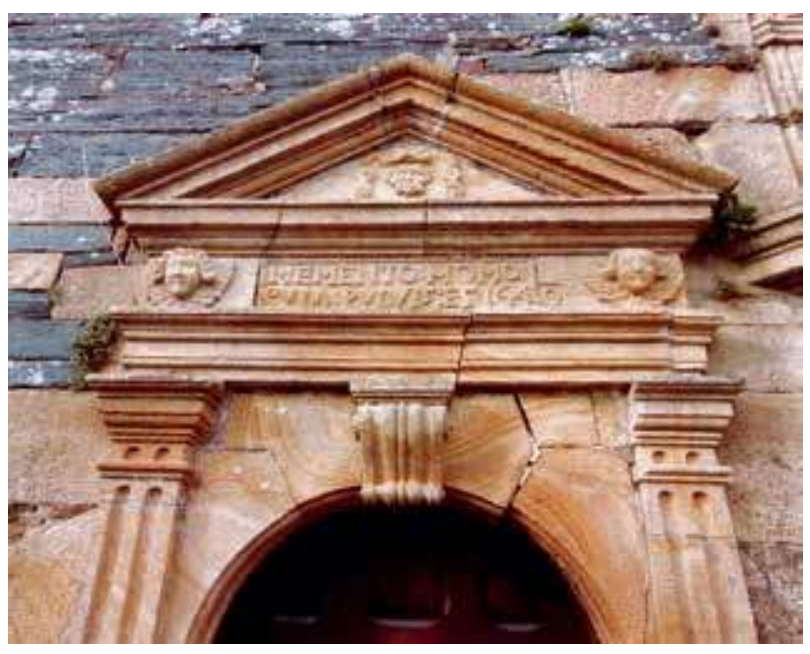

Photo IX: Ossuaire de La Roche-Maurice (1640) : fronton de l'entrée en pierre de Logonna. (Cliché L. Chauris).

Photo IX: La Roche-Maurice ossuary (1640): entrance pediment of « Logonna stone ». (Photo L. Chauris).

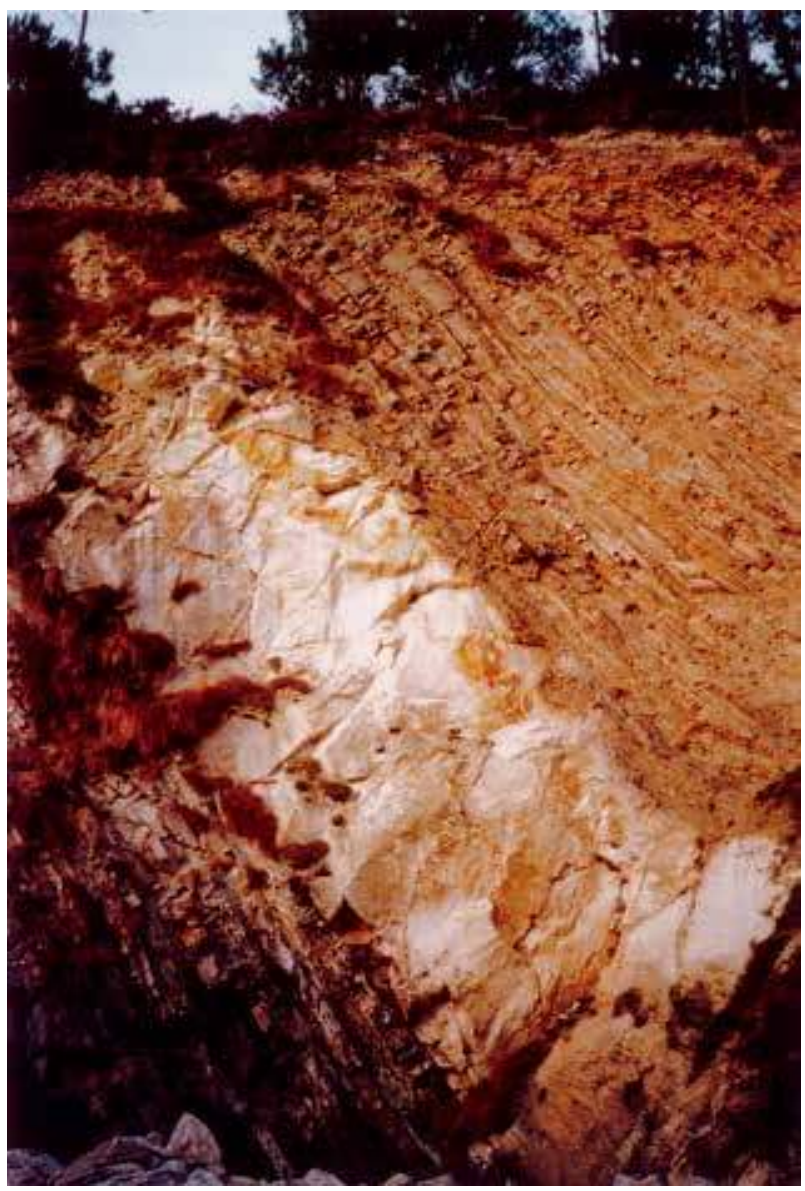

Photo X: Filon de microgranite dans les falaises schistogréseuses du Kador à Morgat en Crozon. (Cliché L. Chauris).

Photo X: Microgranite vein in the Kador schist-and-sandstone cliffs at Morgat (Crozon). (Photo L. Chauris). 


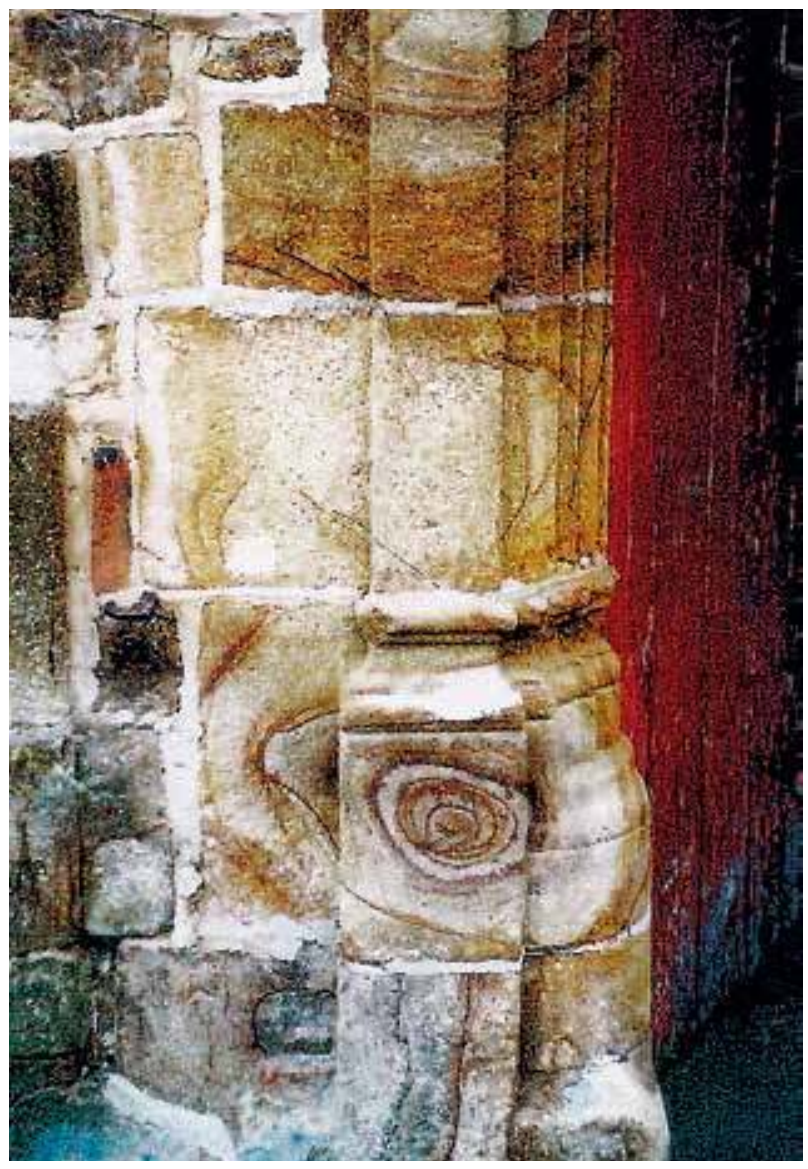

Photo XI : Détail d'un des montants de la porte dans l'église de Moulins : microgranite avec nombreux cernes d'hydroxyde de fer. (Cliché L. Chauris). Photo XI: Moulins church, detail of door frame: microgranite with numerous rings of iron hydroxide. (Photo L. Chauris).

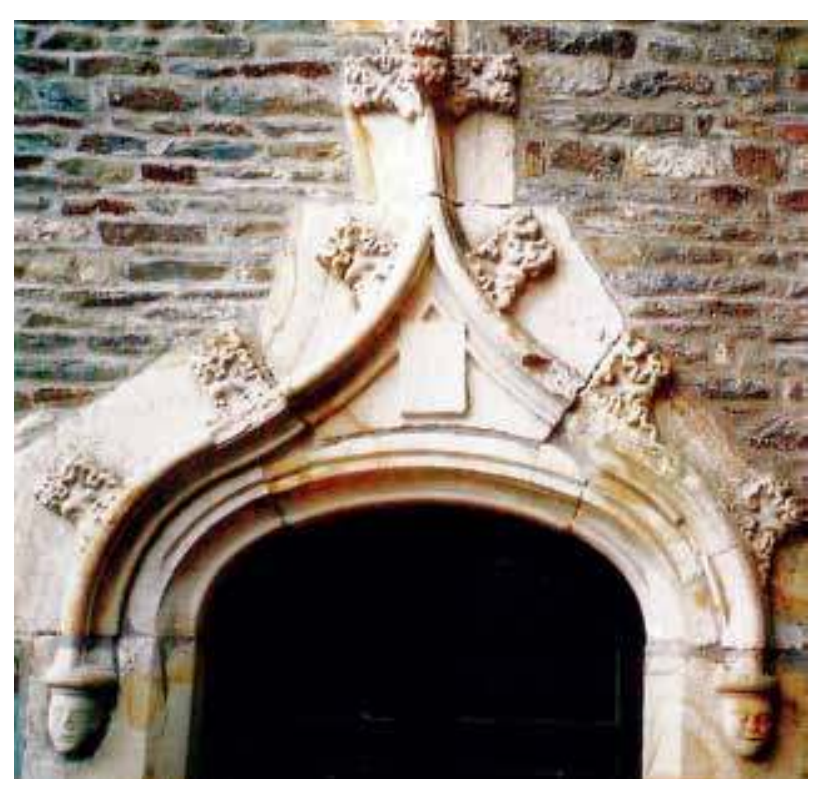

Photo XII : Saint-Étienne-du-Gué-de-l'Isle. Porte de l'église en microgranite. (Cliché L. Chauris).

Photo XII: Saint-Étienne-du-Gué-de-l'Isle. Microgranite church door. (Photo L. Chauris).

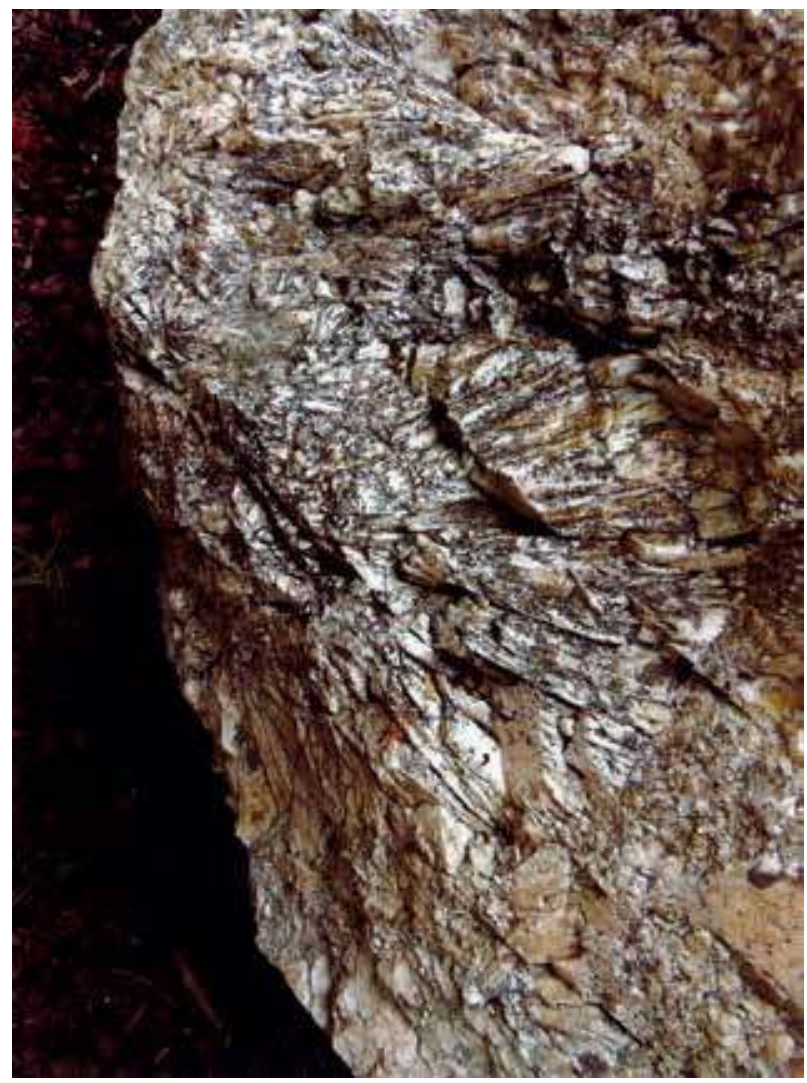

Photo XIII : Quartz en éventail dans un menhir du «Champ des Roches » en Pleslin. (Cliché L. Chauris).

Photo XIII: Pleslin: spread-out quartz on a "Champ des Roches " menhir. (Photo L. Chauris).

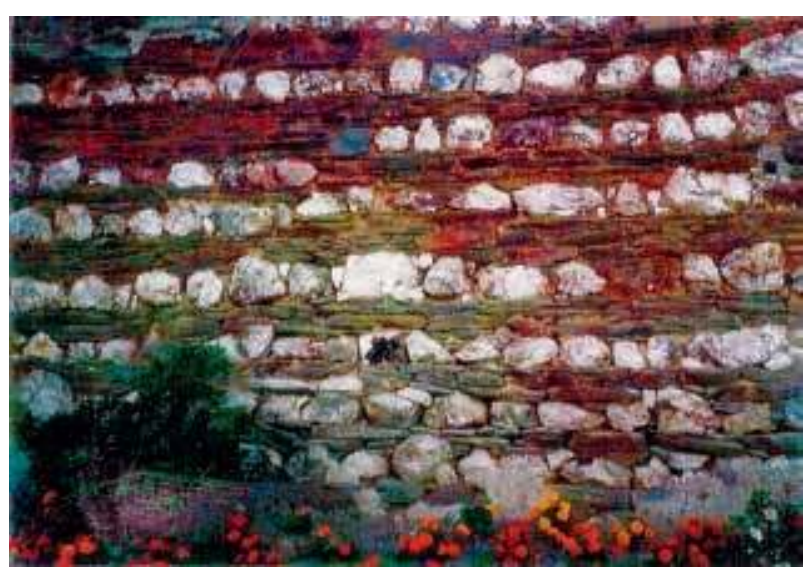

Photo XIV : Gas du Bois en Saint-Étienne-du-Gué-de-|'Isle : maçonnerie avec assises alternées de quartz et de schiste. (Cliché L. Chauris).

Photo XIV: Saint-Étienne-du-Gué-de-l'Isle: masonry of alterned layers of quartz and schist at Gas du Bois. (Photo L. Chauris). 


\section{Bibliographie}

Andrieux J.-Y. (dir.), 2011, Arthur Regnault, architecte, Rennes, Presses universitaires de Rennes, 256 p.

Babin C., Didier J. et Jonin M., 1968, "Un laccolite de microgranite en rade de Brest : l'île Longue ", Bulletin $d u$ Bureau de Recherches géologiques et minières (2), 1, 3, p. 1-9.

Barrois C., 1884, "Le granite de Rostrenen, ses apophyses et ses contacts ", Annales de la Société géologique du Nord, XII, p. 1-119.

Barrois C., 1886a, "Aperçu sur la constitution géologique de la rade de Brest ", Bulletin de la Société géologique de France, 3, 14, p. 678-708.

Barrois C., 1886b, "Compte rendu de l'excursion du 28 août 1886 aux environs de Morlaix ", Bulletin de la Société géologique de France, 3, 14, p. 888-900.

Barrois C., 1896, Carte géologique détaillée de la France à 1/80000, feuille "Saint-Brieuc ", Paris.

Barrois C., 1902, Carte géologique détaillée de la France à 1/80000, feuille "Brest ", Paris.

Barrois C., 1905, Carte géologique détaillée de la France à 1/80000, feuille "Morlaix ", Paris.

Barrois C., 1909, Carte géologique détaillée de la France à 1/80000, feuille "Lannion", Paris.

BAZIN J., 1973, Landerneau, ancienne capitale de la principauté de Léon (2e édit.), Rennes, SEPER, 288 p.

Bellon H., Chauris L., Fabre A., Hallegouët B. et ThoNON P., 1985a, "Âge du magmatisme fissural tardi-hercynien à l'extrémité occidentale du Massif armoricain (France) ", Comptes rendus de l'Académie des Sciences, 301, II, p. 297-302.

Bellon H., Chauris L., Hallegouët B. et Thonon P., 1985b, "Magmatisme fissural permien et triasique dans le pays de Léon (Massif armoricain, France) ", Comptes rendus de l'Académie des Sciences, 301, II, p. 2049-2054.

Bigot de Morogues, 1809, "Suite des observations minéralogiques sur les principales substances des départements du Morbihan, du Finistère et des Côtes-du-Nord », Journal des Mines, XXVI-XXVII-XXVIII, p. 355-384.

Bonnemaison, 1822, "Notice géologique sur une partie du département du Finistère ", Journal de Physique et de Chimie, p. 260-280.

Castaing C. (dir.), 1988, Carte géologique de la France à 1/50000, feuille "Huelgoat ", Orléans, BRGM Éditions.

Chantraine J. (dir.), 1986, Carte géologique de la France à 1/50000, feuille "Plestin-les-Grèves », Orléans, BRGM Éditions.

Chauris L., 1966, "Vue d'ensemble sur la géologie de l'île d'Ouessant (Finistère) ", Bulletin de la Société géologique et minéralogique de Bretagne, nouv. série, p. 87-119.

Chauris L., 1970, "Silification et kaolinisation hydrothermale entre Moustéru et Saint-Julien (Côtes-du-Nord) », Comptes rendus sommaires des séances, Société géologique de France, p. 292-293.

Chauris L., 1971, "Albitites quartziques et microalbitites quartziques des environs de Morlaix (Massif armoricain) ", Comptes rendus sommaires des séances, Société géologique France, p. 354-356.

Chauris L., 1987, « Mise en évidence d'une minéralisation en tungstène, molybdène et cuivre dans le massif granitique du Yaudet en Bretagne (France) ", Comptes rendus de l'Académie des Sciences, 305, II, p. 387-390.

Chauris L., 1991a, "Intrustions sodiques à affinité trondhjémitique à l'île d'Ouessant (Finistère) ", Bulletin de la Société des Sciences naturelles de l'Ouest de la France, 13, p. 119-122.

Chauris L., 1991b, "Origine des pierres de construction d'une ville d'estuaire : Morlaix en Bretagne ", $115^{\circ}$ Congrès National des Sociétés savanes (Avignon), colloque "Carrières et constructions ", Paris, CTHS, p. 323-336.

Chauris L., 1992, Pierres d'Ouessant, Crozon, Maison des Minéraux, $52 \mathrm{p}$.

Chauris L., 1993a, "Le granite de Cléder dans le Finistère. Une belle pierre de taille oubliée ", Le Mausolée, 9/1993, p. $52-57$.

Chauris L., 1993b, "Quand l'île de Batz exploitait son beau granite gris ", Le Courrier du Léon/Progrès de Cornouaille, 9 janvier.

Chauris L., 1993c, "Les pierres de construction à l'île de Batz », Le Courrier du Léon/Progrès de Cornouaille, 16 janvier.

Chauris L., 1993d, "L'emploi du granite de l'île de Batz dans le pays de Morlaix ", Le Courrier du Léon/Progrès de Cornouaille, 23 janvier.

Chauris L., 1993e, "Naguère à Cléder, petite capitale du granite... ", Le Courrier du Léon/Progrès de Cornouaille, 29 mai, 12 et 26 juin.

Chauris L., 1993f, «Landerneau : musée de la Pierre en plein air ", Le Courrier du Léon/Progrès de Cornouaille, 6, 13 et 27 novembre; 18 décembre; $1^{\text {er }}$ janvier (1994).

Chauris L., 1993g, "Une belle pierre oubliée : le granite albitique de Ploujean près de Morlaix (Finistère) ", Revue archéologique de l'Ouest, 10, p. 141-155.

Chauris L., 1994a, "La pierre jaune de Logonna », Le Mausolée, $\mathrm{n}^{\circ}$ 696, p. 76-83.

Chauris L., 1994b, " Le microganite potassique du Dourduff (Finistère). Bulletin de la Société des Sciences naturelles de l'Ouest de la France, nouv. série, 16 (2), p. 55-58.

Chauris L., 1994c, "Pierres et constructions dans le Trégor. II. Quand les granites se font rares... L'emploi des microgranites sodiques dans les constructions du Trégor morlaisien ", Trégor, mémoire vivante, 7, p. 18-23.

Chauris L., 1994d, "Que deviennent les pierres tombales abandonnées? ", Le Courrier du Léon/Progrès de Cornouaille, 27 août, 3 et 10 septembre. 
Chauris L., 1994e, "Un pionnier des Sciences de la Terre en Bretagne occidentale : le comte de La Fruglaye (17661849) ", Bulletin de la Société archéologique du Finistère, CXXIII, p. 391-404.

Chauris L., 1994f, «Vers un nouvel âge de la pierre », dans DE Menou, J. (dir.), Bretagne des granites et des hommes (catalogue d'exposition), Saint-Vougay, Association pour l'animation du château de Kerjean, p. 90-93.

Chauris L., 1995a, « Pierres et constructions dans le Trégor. Histoire d'une pierre ornementale oubliée : le "prophyre" de Ploujean près Morlaix ", Trégor, mémoire vivante, 8 , p. 23-28.

Chauris L., 1995b, «Phares et balises en Basse-Bretagne : à Pontusval au XIx ${ }^{e}$ s. La construction du phare ", Le Courrier du Léon/Progrès de Cornouaille, 25 février.

Chauris L., 1996a, « Le phare de l'île de Batz ", Le Courrier du Léon/Progrès de Cornouaille, 21 septembre.

Chauris L., 1996b, "Le port et le môle de Batz ", Le Courrier du Léon/Progrès de Cornouaille, 19 et 26 octobre; 2 et 16 novembre.

Chauris L., 1996c, "Les carrières de pavés à l'île Longue ", Avel Gornog, 4, p. 40-45.

Chauris L., 1999, « Les monuments : conservatoires des roches aujourd'hui délaissées ", Penn ar Bed, 173-174, p. 85-90.

Chauris L., 2000a, "Un granite à feldspaths géants : Rostrenen en Bretagne ", Le Mausolée, 772, p. 78-85.

Chauris L., 2000b, "Accidents de carrière à Saint-Évy en Saint-Jean-Trolimon (1903 et 1913) ", Cap Caval, 25, p. 10-12.

Chauris L., 2001b, "Kerlouan et Plounéour-Trez : deux églises paroissiales reconstruites au $\mathrm{XIX}^{\mathrm{e}} \mathrm{s}$. Propos sur les hommes et les pierres ", Environnement et Patrimoine (Kerlouan), 53, p. 11-18; 54, p. 13-21.

Chauris L., 2002a, «L'approvisionnement en matériaux d'empierrement dans le Finistère entre 1815 et 1939", L'Homme et la route en Bretagne (Kreiz, 16), Brest, CRBC, p. 51-87.

Chauris L., 2002b, "Lî̀le de Batz au large de Roscoff ", Le Courrier du Léon/Progrès de Cornouaille, 6 et 20 avril.

Chauris L., 2002c, "Une grève dans les carrières de Scaër en 1906 ", Le Courrier du Léon/Progrès de Cornouaille, 24 août.

Chauris L., 2004a, "Sur l'emploi du granite du Yaudet en Bretagne. Suggestion pour les travaux de restauration ", Bulletin du Musée de la Pierre de Maffle (Belgique), 19, p. 73-97.

Chauris L., 2004b, "Provenance des pierres utilisées dans le Pays Pagan et ses abords. Première partie : mégalithes et stèles ", Environnement et Patrimoine (Kerlouan), 64, p. 9-17.

Chauris L., 2004c, «Provenance des pierres utilisées dans le Pays Pagan et ses abords. Croix et calvaires ", Environnement-et Patrimoine (Kerlouan), 65, p. 13-22.

Chauris L., 2006, « Le microgranite de Châtelaudren (Côtes-
d'Armor) ", Mémoires de la Société d'Émulation des Côtesd'Armor, CXXXV, p. 59-65.

CHAuris L., 2007, « La pierre dans les constructions à Lannion ", Mémoires de la Société d'Histoire et d'Archéologie de Bretagne, LXXXVI, p. 5-25.

Chauris L., 2009a, "Crozon. Microgranite du Kador. Une pierre blanche naguère mise en œuvre ", Bulletin de la Société archéologique du Finistère, CXXXVII, p. 98-101.

Chauris L., 2009b, «Lithologie et mégalithes. Impacts de la géologie sur le mégalithisme ", dans Sparfel Y. et Pailler Y. (dir.), Les mégalithes de l'arrondissement de Brest, Rennes, Centre régional d'Archéologie d'Alet/Institut culturel de Bretagne, p. 46-51.

CHAuris L., 2009c, "Éclairage lithologique sur quelques mégalithes de la presquî̀le de Rhuys ", La Maison Forte et le Patrimoine de Rhuys, 16, p. 14-17.

Chauris L., 2009d, "Pour une géo-archéologie du Patrimoine : pierres, carrières et constructions en Bretagne; première partie : problématique générale ", Revue archéologique de l'Ouest, 26, p. 259-283.

Chauris L., 2010a, « Nouvelles observations sur le microgranite de l'île Longue ", Avel Gornog (Crozon), 18, p. 22-29.

Chauris L., 2010b, "Un site majeur dans la production de pavés renommés ", Lî̀le Longue. Histoire d'un site exceptionnel, Quimper, Palantines, $102 \mathrm{p}$.

Chauris L., 2010c, " Mise en œuvre de quelques microgranites du Centre-Finistère dans les constructions ", Bulletin de la Société géologique et minéralogique de Bretagne, (D), 7 , p. 53-67.

Chauris L., 2010d, « Un schiste exceptionnel : la pierre bleue de Nozay (Loire-Atlantique) ", Documents du musée de la Pierre de Maffle (Belgique), 11, p. 100-126.

Chauris L., 2010e, "Impacts de l'environnement géologique sur les constructions dans la région de Pontivy au cours de l'Histoire ", Mémoires de la Société d'Histoire et d'Archéologie de Bretagne, LXXXVIII, p. 5-30.

Chauris L., 2010f, « Pour une géo-archéologie du Patrimoine : pierres, carrières et constructions en Bretagne; deuxième partie : roches sédimentaires ", Revue archéologique de l'Ouest, 27, p. 171-207.

Chauris L., 2010g, Le Kersanton, une pierre bretonne, Rennes/ Quimper, Presses universitaires de Rennes/Société archéologique du Finistère, 242 p.

Chauris L., 2011, « Pour une géo-archéologie du Patrimoine : pierres, carrières et constructions en Bretagne; troisième partie : roches métamorphiques ", Revue archéologique de l'Ouest, 28, p. 219-245.

Chauris L., 2012a, "Observations minéralogiques et chimiques sur l'évolution hydrothermale ultime du linéament sud-armoricain ", Bulletin de la Société des Sciences naturelles de l'Ouest de la France, nouv. série, 34 (1), p. 52-58.

Chauris L., 2012b, «Brest : vieilles pierres et pierres neuves 
dans une cité reconstruite ", Mémoires de la Société d'Histoire et d'Archéologie de Bretagne, XC, p. 5-36.

Chauris L., 2012c, "Pour une géo-archéologie du Patrimoine: pierres, carrières et constructions en Bretagne; quatrième partie : roches magmatiques intrusives non granitiques ", Revue archéologique de l'Ouest, 29, p. 287-316.

Chauris L., 2013a, " Le moulin du Roual en Dirinon. Eclairage lithologique ", Les Cahiers de Dourdon (Landerneau), 8, p. 32-37.

Chauris L., 2013b, "L'histoire de Pléneuf-Val-André en Penthièvre perçue en ses pierres ", Bulletin des Amis de Lamballe et du Penthièvre, 41, p. 291-309.

Chauris L., 2013c, "Construire dans une presqu'île : Ploubazlanec en Goëlo ", Mémoires de la Société d'Émulation des Côtes-d'Armor, CXLII, p. 481-508.

Chauris L., 2013d, "Randonnée-découverte sur le granite de Cléder ", Pierre Actual, 921, p. 28-30.

Chauris L., 2013e, « Pour une géo-archéologie du Patrimoine : pierres, carrières et constructions en Bretagne; cinquième partie : les granites cadomiens (batholitee mancellien excepté) ", Revue archéologique de l'Ouest, 30, p. 261-288.

Chauris L., 2014, " Pour une géo-archéologie du Patrimoine : pierres, carrières et constructions en Bretagne; sixième partie : les granites cadomiens du batholite mancellien ", Revue archéologique de l'Ouest, 31, p. 409-430.

Chauris L., 2015, « Pour une géo-archéologie du Patrimoine : pierres, carrières et constructions en Bretagne; septième partie : une guirlande granitique sur les rives atlantiques ", Revue archéologique de l'Ouest, 32, p. 415-447.

Chauris L., 2016a, «Une pierre jaune en Bretagne : le microgranite des environs de Bais (Ille-et-Vilaine) ", Mélanges offerts à J.-P. Ducostelle, Cercle royal d'Histoire et d'Archéologie d'Ath (Belgique), p. 567-586.

Chauris L., 2016b, "Pour une géo-archéologie du Patrimoine : pierres, carrières et constructions en Bretagne; huitième partie : le batholite leucogranitique hercynien de Bretagne méridionale ", Revue archéologique de l'Ouest, 33, p. 329-366.

Chauris L., 2018a, " Les roches rouges, marqueurs de l'histoire géologique en Bretagne; impact sur l'environnement naturel et bâti ", Penn ar Bed, 230, p. 15-33.

Chauris L., 2018b, « Pour une géo-archéologie du Patrimoine : pierres, carrières et constructions en Bretagne; neuvième partie : le batholite hercynien médio-armoricain ", Revue archéologique de l'Ouest, 35, p. 241-276.

Chauris L., 2019, « Pour une géo-archéologie du Patrimoine : pierres, carrières et constructions en Bretagne; dixième partie : les granites rouges de Bretagne septentrionale ", Revue archéologique de l'Ouest, 36, p. 203-228.

Chauris L. et Cadiou D., 2000, "Mégalithisme et Géologie. Les alignements de Landaoudec en Crozon ", Avel Gornog, 8, p. 48-49.
Chauris L. et Duigou L., 2006, «Éclairage lithologique sur la poudrière de l'île des Morts et de ses annexes (1808-1814) en rade de Brest ", Bulletin de la Société archéologique du Finistère, CXXXV, p. 149-158.

Chauris L. et Duigou L., 2007, « Des carrières ... un lazaret ... L'île Trébéron en rade de Brest ", Bulletin de la Société archéologique du Finistère, CXXXVI, p. 109-114.

Chauris L. et Duigou L., 2010, "Trilogie lithologique du "Mur" de l'île Longue en rade de Brest ", Avel Gornog, 18, p. $18-21$.

Chauris L. et Garreau J., 1991, « Les champs filoniens quartzeux de Plougonver et de Gurunhuel (Côtes-d'Armor) ou les multiples implications d'une structure géologique méconnue ", Mémoires de la Société d'Émulation des Côtesd'Armor, CXX, p. 129-138.

Chauris L. et Garreau J., 1999, coll. à la Carte géologique de la France à 1/50000, feuille "Lannion ", Orléans, BRGM Éditions.

Chauris L. et Hallegouët B., 1994, Carte géologique de la France à 1/50000, feuille "Plouarzel-île d'Ouessant ", Orléans, BRGM Éditions.

Chauris L., Hallegouët B., Thonon P. et Vidal P., 1977, " Le champ filonien microgranitique du Bas-Léon (Massif armoricain) ", Bulletin de la Société géologique et minéralogique de Bretagne, C, IX, 1, p. 5-17.

Chauris L. et Marcoux E., 1998, Carte géologique de la France à 1/50000, feuille "Saint-Pol-de-Léon », Orléans, BRGM Éditions.

Chauris L. et Minor M., 2011, « Le château de Coat-Trédez en Trégor. Une remarquable émanation lithologique du terroir ", Mémoires de la Société d'Émulation des Côtes-d'Armor, CXXXIX, p. 275-284.

Chauris L. et Minor M., 2012, "Auscultation lithologique d'une petite commune des Côtes-d'Armor : Saint-Étiennedu-Gué-de-l'Isle ", Mémoires de la Société d'Émulation des Côtes-d'Armor, CXLI, p. 527-545.

Chauris L. et Sparfel Y., 2013, "Saint-Jean-du-Doigt. Kerprigent. Menhirs en quartz ", Bulletin de la Société archéologique du Finistère, CXLI, p. 189-191.

Collectif, 1994, Bretagne des granites et des hommes (catalogue d'exposition), Saint-Vougay, Association pour l'animation du château de Kerjean, 96 p.

Collin L., 1926, "Étude géologique de l'île Longue (en rade de Brest) ", Bulletin de la Société géologique et minéralogique de Bretagne, 7, $\mathrm{n}^{\text {os } 3-4, ~ p . ~ 216-223 . ~}$

CotTen J., 1975, Etude des mégacristaux du granite de Rostrenen (Massif armoricain), thèse $3^{\mathrm{e}}$ cycle, Brest, Université de Bretagne occidentale, $78 \mathrm{p}$.

Couffon R. et Le Bars A, 1988, Diocèse de Quimper et de Léon. Nouveau répertoire des églises et chapelles, Quimper, $552 \mathrm{p}$.

Cunliffe B. et Galliou P., 2004, Les fouilles du Yaudet en Ploulec'h, Côtes-d'Armor, vol. 1, 302 p. 
Devoir A. et Morel E., s. d., Notes inédites, archives du CReAAH, UMR 6566, Université de Rennes I.

EGAL (coord.), 1999, Carte géologique de la France à 1/50000, feuille "Guingamp ", Orléans, BRGM Éditions.

Fourcy E. de., 1844a, Carte géologique du Finistère, Paris, Impr. Fain et Thunot, 196 p.

Frapolli, 1845, "Mémoire sur la disposition du terrain silurien dans le Finistère, et spécialement dans la rade de Brest ", Bulletin de la Société géologique de France, $2^{\mathrm{e}}$ série, II, p. 517-573.

Giot P.-R., 1995, Bretagne des mégalithes, Rennes, éditions Ouest-France, $128 \mathrm{p}$.

GouÉzIN P., 1994, Les mégalithes du Morbihan intérieur, Rennes, ICB - Laboratoire d'Anthropologie-Préhistoire, université de Rennes 1 (coll. « Patrimoine archéologique de Bretagne »), $127 \mathrm{p}$.

Guyomard E., 1994, Construction du canal de Nantes à Brest dans le département des Côtes-du-Nord, Rostrenen, 58 p.

JÉrÉmine E. et SANDrÉA A., 1957, “Contribution à l'étude géologique de l'île d'Ouessant (microgranites et tourmalinites) ", Bulletin du Service de la Carte géologique de la France, LV (n $\left.{ }^{\circ} 252\right), 7$ p.

Jérémine E. et Pruvost P., 1955, “Observations géologiques et pétrographiques sur la région de Rostrenen ", Bulletin du Service de la Carte géologique de la France, LIII ( ${ }^{\circ} 243$ ), 32 p., 5 pl.

LANGOUËT L. (et coll.), 2006, Les mégalithes de l'arrondissement de Guingamp, Rennes, ICB - CeRAA (coll. "Patrimoine archéologique de Bretagne »), $92 \mathrm{p}$.

La Pylaie B. de, 1850, Études archéologiques et géographiques... Bruxelles, Parent (\& rééd. 1970, Quimper, Société archéo- logique du Finistère), 568 p., 15 pl.

Le Gal La Salle S. P., 1994, "Regards historiques sur le Verdelet ", Mémoires de la Société d'Emulation des Côtes-d'Armor, CXXIII, p. 138-160.

LE Hir (Dr), 1845, «Sur les eurites porphyriques de l'arrondissement de Morlaix ", Écho de Morlaix, $1^{\mathrm{er}}$ mars.

L'Helgouac' H J., 1965, Les sépultures mégalithiques en Armorique, Rennes, Laboratoire d'Anthropologie, 330 p.

Meuret J.-C., 2011, "Archives de pierre. Catherine et François Martin, seigneurs de Montlije vers 1550 ", dans Gallicé A. G. et Rey de Het (dir.), Talabardoneries ou échos d'archives offerts à Catherine Laurent, Rennes, Société d'Histoire et d'Archéologie de Bretagne, p. 129-146.

Milon Y. (coord.), 1960, Carte géologique détaillée de la France à 1/80000, feuille "Laval ", $2^{\mathrm{e}}$ éditions, Paris, ministère de l'Industrie.

Onfroy-KermoalcQuen, 1849-1850, La Foi bretonne, 20 décembre $1849 ; 8,17$ et 24 janvier 1850 .

PÉRENnES, 1928, "Logonna-Daoulas ", Bulletin diocésain d'Histoire et d'Archéologie, p. 134-136.

Puillon-Boblaye, 1827, "Essai sur la configuration et la situation géologique de la Bretagne ", Mémoires du Muséum, XV, p. 49-116.

Sparfel Y. et Chauris L., 2009a, " Le menhir du Théven à Kerlouan ", Environnement et Patrimoine (Kerlouan), 84, p. 22-23.

Sparfel Y. et Chauris L., 2009b, "Quand l'archéologie conforte la géologie. Le cas des menhirs de Kereven en Locmaria-Plouzané ", Les Cahiers de l'Iroise, 209, p. 69-70.

Thonon P., 1973, "Quelques roches filoniennes de la rade de Brest ", Penn ar Bed, 72, p. 17-24. 
Für eine Geoarchäologie des kulturellen Erbes: Gesteine, Steinbrüche und Gebäude in der Bretagne. Elfter und letzter Teil: Andere Granite, Mikrogranite, Quarz; Epilog

Dieser elfte Teil komplettiert unsere zusammenfassende Darstellung zur Geoarchäologie der Bretagne. Er umfasst:

- die Darstellung einiger granitischer hercynischer Massive, die keinen Platz in den vorherigen Kapiteln gefunden haben (Abb. 1).

- eine zusammenfassende Betrachtung der Mikrogranite, die in der Bretagne zahlreich sind, die jedoch bisher in unserer Darstellung nicht ausreichend berücksichtigt wurden.

- ein Überblick zu den der Quarzvorkommen der Halbinsel, für die bisher keine zusammenfassende Darstellung vorliegt.

Wir beschließen unsere Darstellung in dem wir die beeindruckende lithologischen Reichtum der Bretagne herausstellen, der hier zum ersten Mal in dreifacher Hinsicht behandelt wurde : aus geologischer Sicht, die hier sehr häufg Hunderte von Millionen Jahren umfasst, aus der Sicht des Bergbaus und der Steinmetzarbeit, die die kurze Zeitspanne zwischen dem Abbau aus den Eingeweiden der Erde und ihrer Verarbeitung repräsentieren und schließlich die aus der Sicht der Bauwerke, die im Laufe der Zeit ein Eigenleben gewinnen und deren Formen immer wieder erneuert werden, von den Megalithanlagen zu den Kathedralen und bis hin zur modernen Stadtgestaltung...

Schlagwortindex: granite, Mikrogranite, Quartz, Bretagne.

Por una geoarqueología del patrimonio: piedras, canteras y construcciones en Bretaña. Undécima y última parte: otros granitos, microgranitos, cuarzo; epílogo

Con esta undécima parte se termina la "saga"; ésta reúne:

- La presentación de algunos macizos graníticos hercinianos que no se realizó en capitulos anteriores (fig. 1).

- Una perspectiva general sobre los microgranitos, frecuentes en Bretaña pero aún poco conocidos desde el punto de vista adoptado.

- Un panorama sobre el cuarzo de la península armoricana, un material sobre el que no se ha publicado ninguna sintesis.

Terminaremos mencionando el impresionante abanico litológico bretón, considerado por primera vez desde tres puntos de vista: las piedras de los geólogos - aqui se cuenta frecuentemente en centenares de millones de años... ; las piedras de los canteros y los talladores, de efimera vida desde que las arrancan de las entrañas de la tierras hasta que las trabajan...; las piedras de construcción, al fin, que atraviesan tiempos históricos, cuya vida y cuyas formas no cesan de renovarse, desde los megalitos hasta las catedrales y el urbanismo moderno...

Palabras clave: granitos, microgranitos, cuarzo, Bretaña. 
